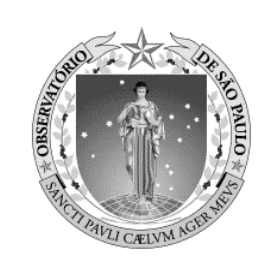

UNIVERSIDADE DE SÃO PAULO

INSTITUTO DE ASTRONOMIA GEOFÍSICA E CIÊNCIAS ATMOSFÉRICAS

DEPARTAMENTO DE GEOFÍSICA

\title{
ESTUDO PALEOMAGNÉTICO DA SUÍTE PALEOPROTEROZÓICA COLÍDER E MÁFICAS ASSOCIADAS, SUDOESTE DO CRÁTON AMAZÔNICO
}

\section{Franklin Bispo dos Santos}

Orientador: Prof. Dr. Manoel Souza D’Agrella Filho

São Paulo

Março de 2007 


\title{
Franklin Bispo dos Santos
}

\author{
ESTUDO PALEOMAGNÉTICO DA SUÍTE \\ PALEOPROTEROZÓICA COLÍDER E MÁFICAS \\ ASSOCIADAS, SUDOESTE DO CRÁTON AMAZÔNICO
}

Dissertação de Mestrado apresentada ao Instituto de Astronomia Geofísica e Ciências Atmosféricas da Universidade de São Paulo (IAG-USP), para a obtenção do título de Mestre em Geofísica.

Orientador: Prof. Dr. Manoel Souza D’Agrella Filho 
Dedico a Deus, aos meus pais Florisvaldo e Zânia e aos meus irmãos Joseane e Lyvan que tanto me incentivaram e confiaram em mim. 


\section{Agradecimentos}

A Deus por tudo na minha vida, pois Tua presença e força foram o meu suporte para a conclusão deste trabalho.

Ao meu orientador Manoel Souza D'Agrella Filho pela orientação, paciência, dedicação, incentivo e confiança.

Ao Conselho Nacional de Pesquisa (CNPq) pela bolsa de mestrado e ao Instituto de Astronomia, Geofísica e Ciências Atmosféricas da Universidade de São Paulo (IAG-USP) pelo suporte técnico.

A Fundação de Amparo à Pesquisa do Estado de São Paulo (FAPESP) pelo financiamento do Projeto de Pesquisa (projeto 03/12802-2).

Aos meus amigos de sala, Marcos Vasconcelos, Sergio Bezerra, Gileide e Guarido por este dois anos de excelente convívio regrado de muita brincadeira e diversão. Neste período, cultivamos uma grande amizade e por isso, todos vocês serão sempre lembrados na minha memória com muito carinho. A amizade de vocês foi e é muito importante para suportar a saudade e a distância da família.

Ao Marcos Vasconcelos (o Marquito) que demonstrou ser um ser humano de coração enorme, sempre disposto a ajudar a pessoas sem pedir nada em troca. Essa figura se tornou o meu grande amigo, um irmão no qual deposito muita confiança e respeito. Sempre me ajudou com seu conhecimento em geologia nas disciplinas e 
na minha dissertação. Grande companheiro nas madrugadas em que passamos estudando no IAG, “Cara, vamos parar com isso!!!”. E o mais importante, teve paciência de suportar as minhas inúmeras brincadeiras e piadinhas e ainda continuar sendo meu amigo. Infelizmente, vai deixar saudade quando retornar para Brasília. Mas isso não impedirá a continuidade de nossa amizade. Por fim, muito obrigado por tudo.

Ao Thiago Nobre (o Muchiba), mais um grande amigo que ganhei nestes dois anos, esse também me ajudou muito. Uma pessoa muito tranqüila. Tranqüila até demais, mas de bom coração, infelizmente, nos deixou e agora é "Petroleiro". Passamos muitos momentos divertidos, que estarão sempre guardados na minha memória.

Aos colegas de laboratório, Dani e Elder pela paciência que tiveram comigo nas inúmeras dúvidas que foram geradas durante este dois anos e principalmente pela amizade construída.

Aos técnicos Jéferson e Cacilda pelo suporte e ajuda com as minhas amostras, além da amizade e brincadeiras que deixam o ambiente de trabalho mais divertido para trabalhar.

A Liliane Janikian pelo auxilio e colaboração imprescindíveis na descrição petrográfica e na revisão do texto geológico.

Ao Prof. Ricardo Trindade por me auxiliar nas dúvidas sobre o paleomagnetismo. 
A Professora Irene da IGc-USP por disponibilizar o Laboratório de Anisotropia para que a realização de medidas em minhas amotras.

Aos Professores Márcia Pinho e Francisco Pinho ambos da UFMT, que também foram importantes na realização deste trabalho.

Ao Josué Antonio da Silva (o Poconé) e a Companhia Matogrossense de Mineração (METAMAT) pela colaboração nas pesquisas de campo realizadas no Estado do Mato Grosso.

A minha namorada Alexandra que nestes oito meses teve a compreensão e a paciência de suportar e de me apoiar nas inúmeras madrugradas e finais de semanas dedicados a este trabalho. Demonstrando ser uma pessoa maravilhosa e muito especial na minha vida. Muito obrigado, pela confiança depositada em mim, a sua paz, o seu carinho e a sua dedicação foram muito importantes.

Um agradecimento muito especial a minha maravilhosa família, meu pai Florisvaldo, a minha mãe Zânia, a minha irmã Joseane e o meu irmão Lyvan que sempre me apoiaram, incentivaram e confiaram que eu seria capaz de concluir esta dissertação de Mestrado. Família, muito obrigado, pelas orações e por tudo, sem ajuda de vocês, eu não conseguiria. Lembrem-se, vocês são muito importantes na minha vida.

A equipe dos baianos do IAG: Manu, Alana, Eduardo, Everton, Danilo e Igor pela amizade e confiança. A todos os colegas e funcionários do IAG-USP que de maneira direta ou indireta participaram desse trabalho. 


\section{Resumo}

Este trabalho apresenta um estudo paleomagnético realizado em rochas ácidas da Suíte Colíder e rochas máficas associadas, situadas no Norte do Mato Grosso, parte sudoeste do Cráton Amazônico. Foram coletados 5 cilindros e 42 blocos orientados de rochas ácidas e intermediárias (12 sítios) da Suíte Colider e 75 cilindros e 3 blocos orientados de rochas máficas (11 sítios) pertencentes à Intrusiva Guadalupe e à Suíte Intrusiva Flor da Serra localizados nas proximidades de Alta Floresta, Colider, Terra Nova e Matupá. A Suíte Colíder foi datada pelo método U$\mathrm{Pb}$ em zircões e apresenta idades entre 1,80 e 1,78 Ga. Para a Intrusiva Guadalupe ainda não existem determinações radiométricas que estabeleçam a sua idade.

A investigação da mineralogia magnética feita através de curvas termomagnéticas, de indução magnética e de histerese, além do tratamento térmico e por campos magnéticos alternados, indica a hematita como sendo o principal portador magnético da maioria das rochas ácidas. Por outro lado, as rochas máficas apresentam grãos de titanomagnetita pobre em $\mathrm{Ti}$, a maioria com estrutura de pseudo-domínio simples (PSD).

Espécimes destas rochas após as desmagnetizações térmicas e por campos magnéticos alternados apresentaram duas direções de magnetização característica. Uma delas (componente B) é representada por direções norte (sul) com inclinações negativas (positivas) $\left(\mathrm{Dm}=187.4^{\circ}, \mathrm{Im}=50.9^{\circ}, \mathrm{N}=16 \alpha_{95}=11.3^{\circ}, \mathrm{K}=11.7\right)$ que foram isoladas para a maioria das rochas da Suíte Colíder e máficas associadas. A outra (componente A) é representada por direções norte com inclinações positivas $\left(\left(\mathrm{Dm}=356.5^{\circ}, \mathrm{Im}=47.6^{\circ}, \mathrm{N}=3, \alpha_{95}=15.8^{\circ}, \mathrm{K}=61.9\right)\right.$ e foi encontrada para o gabro Guadalupe e outros dois diques máficos.

vi 
Dois pólos paleomagnéticos foram determinados para estas componentes, os quais estão localizados em $289.4^{\circ} \mathrm{E},-65.4^{\circ} \mathrm{N}\left(\alpha_{95}=12.9^{\circ}\right)$ (pólo SC, Suíte Colíder) e $298.8^{\circ} \mathrm{E}, 50.4^{\circ} \mathrm{N}\left(\alpha_{95}=15.1^{\circ}\right)$ (pólo IG, Intrusiva Guadalupe). O pólo SC (fator de confiabilidade $\mathrm{Q}=5$ ) de idade $1789 \pm 7$ Ma é considerado um pólo de referência para o Cráton Amazônico. Reconstruções paleogeográficas obtidas através de pólos de referência do Paleoproterozóico sugerem que a Laurentia, a Báltica, o Norte da China e o Cráton Amazônico formavam uma grande massa continental (Supercontinente Columbia) entre 1830-1770 Ma. Esta hipótese é reforçada por dados geológicos que evidenciam a existência de cinturões paleoproterozóicos bem alinhados nestas quatro massas continentais, sendo estes formados por cinturões magmáticos relacionados a subducções com a mesma polaridade. 


\section{Abstract}

This work presents a paleomagnetic study perfomed on felsic volcanic rocks of the Colider Suite (5 oriented cores and 42 oriented hand samples, 12 sites), Flor da Serra and Guadalupe mafic rocks (75 oriented cores and 3 oriented hand samples, 11 sites). These units are situated in the northern Mato Grosso State (southwestern Amazonian Craton), close to the Alta Floresta, Colider, Terra Nova, and Matupá cities. The Colider Suite rocks have been dated by the U-Pb (zircon) method, and ages vary between 1.80 and $1.78 \mathrm{Ga}$. Radiometric determinations are not yet available for the Guadalupe Intrusive.

Two very stable magnetization components were isolated after AF and thermal demagnetization: northern (southern) directions with moderate to steep downward (upward) inclinations (component $\mathrm{B}-\mathrm{Dm}=187.4^{\circ}, \mathrm{Im}=50.9^{\circ}, \mathrm{N}=16$ $\left.\alpha_{95}=11.3^{\circ}, \mathrm{K}=11.7\right)$ were isolated for most Colider Suite rocks and associated mafic rocks. Northern upward direction with moderate inclination (component A$\left.\mathrm{Dm}=356.5^{\circ}, \mathrm{Im}=47.6^{\circ}, \mathrm{N}=3, \alpha_{95}=15.8^{\circ}, \mathrm{K}=61.9\right)$ was found for the Guadalupe gabbro and other two mafic dikes. Rock magnetism experiments show that the magnetization is carried by hematite, which is probably primary in origin, in the felsic rocks. In the mafic rocks the main magnetic carrier is Ti-poor titanomagnetite in the PSD magnetic structure.

Two paleomagnetic poles were determined for these components, which are located at $289.4^{\circ} \mathrm{E},-65.4^{\circ} \mathrm{N}\left(\alpha_{95}=12.9^{\circ}\right)\left(\mathrm{SC}\right.$ pole, Colider Suite) and $298.8^{\circ} \mathrm{E}, 50.4^{\circ} \mathrm{N}$ $\left(\alpha_{95}=15.1^{\circ}\right)($ IG pole, Guadalupe Intrusive). An age of $1.780 \pm 7 \mathrm{Ma}$ is attributted to pole SC (quality factor $Q=5$ ), which is considered a key pole for the Amazon Craton. Paleogeographic reconstructions using Paleoproterozoic key poles suggest 
that Laurentia, Baltica, North China and the Amazon Craton were located in laterally contiguous positions forming a huge continental mass (Columbia Supercontinent) at 1830-1770 Ma ago. This hypothesis is reinforced by the geological evidence that paleoproterozoic mobile belts of these four continental masses fit well in the reconstruction, being formed by contemporaneous subduction-related magmatic arc belts with the same tectonic polarity. 


\section{Lista de Figuras}

Figura 2.1 Representação do Cráton Amazônico e de outros crátons 8. existentes na América do Sul. Modificado de Cordani \& Teixeira (2006).

Figura 2.2 Províncias Geogronológicas do Cráton Amazônico, extraída de Tassinari \& Macambira (1999).

Figura 2.3 Localização da área de estudo.

Figura 2.4 Mapa geológico da área de estudo indicando os pontos dos sítios amostrados. Modificada de Lacerda-Filho et al. (2004).

Figura 3.1 a) Representação do vetor na esfera e sua projeção no plano equatorial, (b) projeção estereográfica (plano equatorial da esfera).

Figura 3.2 (a) Esquema mostrando a projeção da MRN em três planos ortogonais para cada estágio de desmagnetização; (b) projeção de Zijderveld para amostras de calcários (modificada de Lowrie, 1997).

Figura 3.3 (a) Espectros de desmagnetização e projeções ortogonais representando duas componentes com espectros distintos $(\mathrm{a}, \mathrm{b})$ e com espectros que se sobrepõem parcialmente (c, d), (Butler, 1992).

Figura 3.4 Representação de um ciclo de histerese típico de partículas SD: (a) Curva de histere; (b) momentos magnéticos dos grãos começam a se alinhar na direção do campo (ponto 1); (c) ponto de saturação, todos os momentos magnéticos dos grãos totalmente alinhados com o campo aplicado (ponto 2); (d) mesmo após a retirada do campo aplicado, parte da magnetização induzida é retida pela substância (ponto 3), (e) magnetização volta a ser nula, momentos magnéticos 
dos grãos orientados aleatoriamente (ponto 4). Onde $M$ (magnetização), Ms (magnetização de saturação), Mrs (magnetização remanescente de saturação, H (campo magnético aplicado), Hcr (campo de coercividade de remanescência) e Hc (campo de coercividade). Figura modificada de Butler (1992).

Figura 3.5 Curvas termomagnéticas (a) reversíveis: característica de titanomagnetita pobre em titânio e rica em ferro; (b) irreversíveis: presença de titanomagnetita pouco oxidada formando durante $o$ aquecimento titanomaghemita (Carvallo et al, 2004).

Figura 3.6 Teste de contato positivo indicando um vetor paleomagnético estável.

Figura 3.7 A hipótese do dipolo geocêntrico axial prevê a relação $\operatorname{tg} I=2 \operatorname{tg} \lambda$ entre a inclinação I de um campo dipolar e a latitude geográfica $\lambda$; p é a colatitude (Lowrie, 1997).

Figura 3.8 Localização do Pólo Paleomagnético $\mathrm{P}\left(\lambda_{P}, \Phi_{P}\right)$ com declinação média $\left(\mathrm{D}_{\mathrm{m}}\right)$ e inclinação média $\left(\mathrm{I}_{\mathrm{m}}\right)$ calculada para uma formação geológica. A localização do sítio amostrado é $S\left(\lambda_{S}, \Phi_{S}\right)$, p é a colatitude do sítio amostrado em relação ao pólo paleomagnético (Butler, 1992).

Figura 4.1 Curvas de intensidade de magnetização normalizada em 50 função do campo alternado (a), e em função da temperatura (b).Estas curvas indicam a presença de titanomagnetita pobre em titânio como sendo o principal portador magnético nestas rochas.

Figura 4.2 Gráficos de intensidade de magnetização normalizadas em função do campo alternado (a); em função da temperatura (b). Estas curvas evidenciam a presença da maghemita e da titanomagnetita pobre em titânio como os principais portadores magnéticos presentes nestas rochas.

Figura 4.3 Gráficos de intensidade de magnetização em função do campo alternado (a), evidenciando a alta coercividade dos 
minerais magnéticos; e em função da temperatura (b), demonstrando a presença de hematita e magnetita como os principais portadores magnéticos.

Figura 4.4 Gráfico de intensidade de magnetização normalizada em função do campo alternado, mostrando a baixa coercividade apresentada por espécimes de rocha ácida do sítio 3 e 12.

Figura 4.5 Curvas de histerese para as amostras de rochas ácidas analisadas.

Figura 4.6 Curvas de histerese para as amostras de rochas máficas analisadas.

Figura 4.7 Diagrama de Day (1977) indicando a estrutura de domínios magnéticos das amostras analisadas.

Figura 4.8 Curvas termomagnéticas para os espécimes de rochas ácidas analisadas. As cores vermelhas e azuis indicam aquecimento e resfriamento, respectivamente.

Figura 4.9 Curvas termomagnéticas para os espécimes de rochas máficas analisadas. As cores vermelhas e azuis indicam aquecimento e resfriamento, respectivamente.

Figura 4.10 Exemplos de curvas de aquisição de MRI obtidas para 63 rochas ácidas (a) e máficas (b).

Figura 4.11 Exemplo de desmagnetização em que não foi possível 65 isolar a magnetização característica da amostra devido a instabilidade magnética em campos alternados mais altos. A figura mostra a projeção estereográfica, as projeções ortogonais e a curva de intensidades relativas em função do campo alternado aplicado.

Figura 4.12 Projeções estereográficas e curvas de intensidades relativas 66 para amostras máficas indicando: (a) a eficiência da desmagnetização por CA em isolar a direção de magnetização, (b) ineficiência da desmagnetização térmica para as rochas máficas analisadas. 
Figura 4.13 Projeções ortogonais e curvas de intensidade relativas obtidas para amostras do sítio 10 durante o tratamento térmico (a) e por campos alternados (b), mostrando a maior eficiência do tratamento térmico para determinar a magnetização característica através da análise de componentes principais.

Figura 4.14 Exemplo de um espécime em que a componente $\mathrm{A}$ foi 69 isolada. A figura mostra projeção estereográfica, as projeções ortogonais (diagrama de Zijderveld) e o gráfico de intensidade normalizada em função do campo alternado.

Figura 4.15 Exemplo de desmagnetização por CA de um espécime em 70 que a componente $\mathrm{A}$ foi isolada. A figura mostra as projeções ortogonais (diagrama de Zijderveld), a projeção estereográfica e o gráfico de intensidade normalizada em função do campo alternado.

Figura 4.16 Exemplo de um espécime em que a componente B com inclinação negativa foi isolada. A figura mostra a projeção estereográfica, as projeções ortogonais (diagrama de Zijderveld) e o gráfico de intensidade normalizada em função do campo alternado.

Figura 4.17 Exemplo de um espécime em que a componente B com inclinação positiva foi isolada. A figura mostra a projeção estereográfica, as projeções ortogonais (diagrama de Zijderveld) e o gráfico de intensidade normalizada em função do campo alternado.

Figura 4.18 Exemplo de um espécime em que a componente B com inclinação positiva foi isolada. A figura mostra a projeção estereográfica, as projeções ortogonais (diagrama de Zijderveld) e o gráfico de intensidade normalizada em função da temperatura.

Figura 4.19 Exemplo de um espécime em que a componente B com inclinações negativas foi isolada. A figura mostra a projeção estereográfica, as projeções ortogonais (diagrama 
de Zijderveld) e o gráfico de intensidade normalizada em função do campo alternado.

Figura 4.20 Exemplo de um espécime em que a componente B com inclinações positivas foi isolada. A figura mostra as projeções ortogonais (diagrama de Zijderveld), a projeção estereográfica e o gráfico de intensidade normalizada em função da temperatura.

Figura 4.21 Direções médias por sítio para a Componente A (a) e a Componente B (b). Símbolos cheios (vazios) representam inclinações positivas (negativas). Os símbolos $\otimes \mathrm{e} \oplus$ representam o campo dipolar e o campo geomagnético atual, respectivamente. Os círculos representam as rochas máficas e os triângulos às rochas ácidas. O símbolo + e os círculos em azul representam as direções médias para cada grupo de direções, com seus respectivos círculos de confiança; componente A $\left(\alpha_{95}=15,8^{\circ}\right)$, componente B normal $\left(\alpha_{95}=28,5^{\circ}\right)$ e a componente B reverso $\left(\alpha_{95}=12,2^{\circ}\right)$.

Figura 4.22 Posição relativa das amostras coletadas na rocha 80 encaixante em relação ao dique.

Figura 4.23 Projeção estereográfica, projeção ortogonal e curva de 82 intensidade relativa em função do campo alternado para uma amostra do dique (SD34-C2) e para amostras de rochas ácidas coletadas a 0,05 $\mathrm{m}$ (SD27-A1), a $7 \mathrm{~m}$ (SD30B2) e a $25 \mathrm{~m}$ (SD32-B1) do contato.

Figura 4.24 Direções médias por amostra obtidas para o teste do 83 contato cozido efetuado para o sítio 12.

Figura 4.25 Posição relativa das amostras coletadas na rocha 84 encaixante em relação ao dique.

Figura 4.26 Projeção estereográfica, projeção ortogonal e curva de intensidade relativa em função do campo alternado para uma amostra do dique (SD74-J1) e para amostras de granitos coletadas à 1,90 m (SD74-K2), a 2,17 m (SD74-L1) e 
a 5,67 m (SD74-N2) do contato.

Figura 4.27 Direções médias por amostra obtidas para o teste do 86 contato cozido efetuado para o sítio 23.

Figura 4.28 (a) Média das direções normais (componente B), (b) média 88 das direções normais e reversas (componente B), (c) teste de reversão. Os círculos indicam o limite de confiança $\left(\alpha_{95}\right)$. O simbolo + em vermelho e em azul indicam a média das direções normais e reversas, respectivamente. Os triângulos vazios representam direções normais.

Figura 5.1 Representação dos dois pólos paleomagnéticos obtidos 93 neste trabalho em relação a posição atual do Cráton Amazônico.

Figura 5.2 Representação da curva de deriva polar aparente (CDPA) 100 para o Cráton Amazônico para o intervalo entre 2040-1790 Ma. A parte contínua é a proposta por Momade et al. (2003) e parte tracejada é proposta por este trabalho utilizando os pólos DDII e SC (a) e seus respectivos anti-pólos (b) antipólo. A parte tracejada é ainda indefinida devido a falta de pólos paleomagnéticos de referência para o intervalo de idades entre 1990 e 1820 Ma Os círculos indicam o limite de confiança $\left(\alpha_{95}\right)$ para cada paleopólo.

Figura 5.3 Reconstrução paleogeográfica proposta por Pesonen et al. 104 (2003) para $1.83 \mathrm{Ga}$.

Figura 5.4 Reconstrução paleogeográfica entre1.8- 1.7 Ga feita 107 utilizando o pólo da componente B (pólo SC) para o Cráton Amazônico e os pólos obtidos para a Laurentia (Park et al., 1973) e a Báltica (Pisarevky \& Sokolov, 2001).

Figura 5.5 Reconstrução paleogeográfica para 1.8-1.78 Ga utilizando o pólo SC para o Cráton Amazônico e pólos obtidos para a Laurentia (Park et al., 1973), a Báltica (Pisarevky \& Sokolov, 2001; Fedotova et al., 1999) e para o Norte da China (Halls et al., 2000). As faixas em cinza evidenciam uma possível 
continuidade das províncias geológicas paleoproterozóicas ao longo das quatro massas continentais 


\section{Lista de Tabelas}

Tabela 2.1 Número do sitio, localização, identificação e litologia da amostragem paleomagnética.

Tabela 4.1 Valores dos parâmetros obtidos das curvas de histerese, bem como, as razões Mrs/Ms e Hcr/Hc.

Tabela 4.2 Direções médias por sítio e pólos geomagnéticos virtuais referentes a componente $\mathrm{A}$.

Tabela 4.3 Direções médias por sítio e pólos geomagnéticos virtuais referentes a componente $\mathrm{B}$.

Tabela 4.4 Primeiro teste de contato cozido: dados das amostras coletadas, tipo de rocha e distância destas para a intrusão.

Tabela 4.5 Segundo teste de contato cozido: dados das amostras coletadas, tipo de rocha e distâncias destas para a intrusão.

Tabela 5.1 Lista de pólos paleomagnéticos para o Cráton Amazônico entre 2.1-1.6 Ga.

Tabela 5.2 Pólos paleomagnéticos selecionados para a Laurentia, a 102 Báltica, o Norte da China e o Cráton Amazônico entre 1,83$1,70 \mathrm{Ga}$. 


\section{Sumário}

Agradecimentos

iii

Resumo

vi

Abstract

viii

Lista de Figuras

$\mathrm{X}$

Lista de Tabelas

xvii

Capitulo 1: Introdução

Capitulo 2: Contexto Geológico 5

2.1. O conceito de Cráton 5

2.2. Aspecto Geológico do Cráton Amazônico 6

2.3. Contexto Geológico Regional 12

2.4. Geologia Local 14

2.4.1. Suíte Colíder $\quad 15$

2.4.2. Intrusivas Máficas Guadalupe $\quad 15$

2.4.3. Suíte Intrusiva Flor da Serra $\quad 16$

2.4.4. Dados Geocronológicos $\quad 17$

2.5. Localização da Área de Estudo 18

2.6. Análise Petrográfica $\quad 22$

Capitulo 3: Metodologia $\quad 24$

3.1. Amostragem 24

3.2. Magnetizações Remanescentes e Processos de 25

Desmagnetizações Progressivas 25

3.2.1. Desmagnetização por Campos Magnéticos 28

Alternados (CA) 28

3.2.2. Desmagnetização Térmica 29

3.3. Análise das Componentes de Magnetização 31

3.4. Estudo da Mineralogia Magnética 34

3.4.1. Identificação dos Minerais Ferromagnéticos 34

3.4.2. Curvas de Histerese $\quad 35$

3.4.3. Curvas Termomagnéticas 38

3.4.4. Curvas de Aquisição de Magnetização 39

Remanescente Induzida (MRI) 39

3.5. Análise Estatística das Direções $\quad 40$

3.6. Testes de Campo da Estabilidade da Magnetização 42 
3.6.1. Teste do Contato Cozido 43

3.6.2. Teste da Reversão $\quad 44$

3.7. Pólo Paleomagnético 44

3.8. Curva de Deriva Polar Aparente e as Reconstruções 45

Paleogeográficas

Capítulo 4: Resultados Paleomagnéticos $\quad 49$

4.1.1. Tratamentos por Campos Alternados (CA) e $\quad 49$

Térmicos

4.1.2. Histerese magnética 53

4.1.3. Curvas Termomagnéticas $\quad 58$

4.1.4. Curvas de Magnetização Remanescente Induzida 62

4.2. Análise Paleomagnética 64

4.2.1 Componentes de Magnetização 68

4.3. Determinação das Direções de Magnetização Médias e Pólos 76

Paleomagnéticos

4.4. Teste da Estabilidade da Magnetização $\quad 80$

$\begin{array}{ll}\text { 4.4.1. Teste de Contato Cozido } & 80\end{array}$

4.4.2. Teste da Reversão $\quad 87$

$\begin{array}{lr}\text { Capítulo 5: Discussão } & 89\end{array}$

5.1. Estabilidade das Direções Paleomagnéticas 92

5.2. Pólos Paleomagnéticos Obtidos 94

5.3. Confiabilidade dos Pólos Paleomagnéticos 94

$\begin{array}{ll}\text { 5.3.1. Componente B } & 94\end{array}$

5.3.2. Componente A 95

5.4. Pólos Paleomagnéticos Disponíveis para o Cráton 97

Amazônico

5.5. Reconstruções Paleogeográficas 101

5.5.1. Reconstrução em $1,83 \mathrm{Ga} \quad 103$

5.5.2. Reconstrução em $1,78 \mathrm{Ga} \quad 105$

Capítulo 6: Conclusões $\quad 112$

$\begin{array}{ll}\text { Referências Bibliográficas } & 115\end{array}$

$\begin{array}{ll}\text { Apêndice A } & 123\end{array}$ 


\section{Capítulo 1}

\section{INTRODUÇÃO}

O trabalho pioneiro de Alfred Wegener, no início do século $X X$, propunha que os atuais continentes formavam um continente chamado Pangea. Entretanto, poucas evidências existiam para provar a veracidade desse modelo.

Com o passar das décadas, pesquisas geológicas e geofísicas, principalmente do fundo oceânico, não somente comprovaram a hipótese de Wegener, como mostraram que os continentes compõem partes de placas litosféricas que se deslocam sobre a astenosfera em um processo chamado de Tectônica de Placas. Acredita-se atualmente que este processo atuou desde os primórdios da história da Terra e que a formação e fragmentação de supercontinentes ocorreram periodicamente no passado geológico.

Assim, a definição da paleogeografia de supercontinentes é um dos estudos mais importantes para se conhecer o ciclo continental, principalmente, em períodos mais antigos, como o Proterozóico, no qual a formação de supercontinentes é ainda conflitante (Condie, 2002).

Nas últimas décadas, tem aumentado o número de estudos que reforçam a hipótese de que grandes massas continentais (supercontinentes) estariam unidas no passado geológico, embora, a duração e a configuração desses supercontinentes gerem ainda muitas controvérsias (Rogers, 1996; Dalziel, 1997; Meert, 2002; Zhao et al. 2002, 2003; Pesonen et al. 2003). 
Dentre as pesquisas empregadas, o paleomagnetismo surge como uma ferramenta essencial no estudo da formação e fragmentação de supercontinentes, principalmente para épocas em que não existem mais evidências de litosfera oceânica. No paleomagnetismo considera-se como premissa básica que o campo magnético da Terra, na média, corresponde ao produzido por um dipolo geocêntrico axial "DGA" (dipolo magnético posicionado no centro da Terra e alinhado com o eixo de rotação). Assim, o paleomagnetismo permite, através do cálculo do pólo paleomagnético de uma formação geológica, definir a paleolatitude e o paleomeridiano de um bloco continental, embora sua paleolongitude seja indefinida devido à simetria do modelo.

Assim, a determinação de pólos paleomagnéticos associados a dados isotópicos precisos é de fundamental importância para a definição da paleogeografia de blocos continentais e assim, na investigação da formação de supercontinentes. Entretanto, sabe-se que a quantidade e a qualidade dos dados paleomagnéticos decresce com o tempo geológico. Algumas tentativas de reconstruções paleogeográficas têm apresentado dificuldades por causa da grande incerteza (freqüentemente de centenas de milhões de anos) nas idades e pelas grandes lacunas existentes no registro das curvas de deriva polar aparente (CDPAs) para o Proterozóico (Buchan et al., 2000; Condie, 2002).

Um dos caminhos para minimizar as incertezas nas reconstruções continentais é intensificar a obtenção de pólos paleomagnéticos de referência, que passam por critérios de confiabilidade básicos, como os definidos por Van der Voo (1990), e são datados com métodos de alta precisão, tais como U-Pb e ${ }^{40} \mathrm{Ar} /{ }^{39} \mathrm{Ar}$, os quais permitem que as incertezas nas idades de unidades de rochas intrusivas sejam reduzidas a poucos milhões de anos ou menos (Buchan et al., 2000).

Sabe-se que a maioria das informações sobre a história de continentes e supercontinentes advém de estudos dos crátons individuais em diversas partes do 
mundo (Rogers \& Santosh, 2003). Assim, as unidades cratônicas que formam a Plataforma Sul-Americana são integrantes essenciais na história dessas aglutinações e dispersões continentais.

O Cráton Amazônico, em particular, é considerado um componente importante em muitas reconstruções de supercontinentes (Geraldes et al., 2001). Além disso, este cráton representa uma das maiores áreas cratônicas do mundo e apresenta uma evolução geológica singular na América do Sul. Estudos revelam que o Cráton Amazônico foi formado pela acresção de terrenos e microcontinentes durante os eons Arqueno e Proterozóico (Pinho et al., 2003; Tassinari \& Macambira, 2004), protagonizando parte de uma história supercontinental (Schobbenhaus \& Brito-Neves, 2003). A sua evolução geológica Paleo-Mesoproterozóica é mais compatível à da Laurentia e à da Báltica e neste sentido estas unidades podem ter sido partes de um único supercontinente durante esta época (Geraldes et al., 2001; Pesonen et al., 2003).

Entretanto, dados paleomagnéticos para o Cráton Amazônico são ainda muito escassos. Pesonen et al. (2003) e Meert (2002) destacam a escassez de dados paleomagnéticos para o Cráton Amazônico durante o Proterozóico, o que impossibilita o teste de sua posição relativa com continentes como a Laurentia e a Báltica e também impede a construção de uma curva de deriva polar aparente (CDPA) para esta unidade tectônica.

Até o final da década passada, praticamente, havia somente registros de pólos paleomagnéticos Paleoproterozóicos obtidos para unidades geológicas da Venezuela (Onstott \& Hargraves, 1981; Onstott et al., 1984a; 1984b). Para o território Brasileiro, havia somente dados paleomagnéticos preliminares obtidos para rochas ácidas e sedimentares das unidades Iriri e Beneficente (Pacca \& Cordani, 1979) e alguns pólos geomagnéticos virtuais (PGVs) obtidos para rochas do embasamento do Estado de Rondônia (Bettencourt et al., 1996). Mais 
recentemente, foram publicados novos pólos paleoproterozóicos para a Guiana Francesa (Nomade et al., 2001; 2003) e pólos mesoproterozóicos foram obtidos para unidades dos Estados de Rondônia (Tohver et al., 2002) e Mato Grosso (D'AgrellaFilho et al., 2003) com implicações importantes para a formação do supercontinente Rodinia.

Apresentamos neste trabalho resultados paleomagnéticos obtidos em rochas vulcânicas félsicas da Suíte Colíder e máficas associadas, com idade U-Pb bem estabelecida entre 1.801-1.781 Ma, situadas no norte do Estado do Mato Grosso, a sudoeste do Cráton Amazônico. O objetivo é determinar um pólo paleomagnético de referência para o Paleoproterozóico que contribua para o esclarecimento da evolução geodinâmica do Cráton Amazônico e que ajude a definir uma curva de deriva polar aparente para o mesmo. Além disso, visa estabelecer a paleogeografia desta unidade nas reconstruções globais e testar configurações de possíveis supercontinentes paleoproterozóicos. 


\section{Capítulo 2}

\section{CONTEXTO GEOLÓGICO}

\subsection{O Conceito de Cráton}

O reconhecimento inicial da existência de extensas áreas continentais com notável estabilidade foi feito por Eduard Suess, cujo trabalho foi traduzido por Sollas (1904, apud Brito-Neves, 1995).

Um dos primeiros trabalhos a denominar as porções continentais estáveis como "kratogen" (do grego "Kratos", duro, rígido) foi o de Köber (1921-apud Almeida 1977), que utilizou o termo em oposição ao "Orogen" (do grego "Oros", montanha). Em seguida, Stille (1936, apud Schobbenhaus et al., 1984) simplificou o termo para "Kratos", caracterizando esses segmentos pela "imobilidade", contrapostos aos "ortogeossinclinais", marcados pela mobilidade.

No Brasil, Almeida (1977) utilizou o termo cráton para os segmentos do embasamento consolidado em tempos pré-brasiliano/Panafricano. Segundo Hartmann \& Delgado (2001), esses segmentos compõem grandes partes de crosta continental que não foram significativamente deformadas durante a maioria das orogenias do Ciclo Brasiliano Neoproterozóico.

Para Park \& Jaroszewski (1994), um cráton constitui uma porção relativamente estável do continente, ou do interior de uma placa continental. Segundo esses autores, um pedaço da crosta que forma parte de um cinturão 
móvel, em um dado período, pode tornar-se parte de um cráton, em um período subseqüente, após o fim das atividades tectono-termais.

Brito-Neves (1995) destaca que as principais características geológicas de um cráton são estabilidade relativa, antiguidade e transitoriedade, considerando-se que, ao longo do tempo, eventos tectônicos mais novos possam modificar os contornos dos crátons. Quanto às características geofísicas, o autor ressalta a espessura litosférica privilegiada $(300-400 \mathrm{~km})$ e o baixo fluxo térmico, que varia entre $20 \pm 8$ e $62 \pm 20 \mathrm{mWm}^{2}$, enquanto que em zonas de riftes esse valor pode variar entre 60 e $107 \mathrm{mWm}^{2}$.

Segundo Alkimim (2004) os crátons são entendidos como partes diferenciadas da litosfera continental, caracterizados por espessas e antigas raízes mantélicas, possuindo alta resistência mecânica e comportamento tectônico marcado por longa estabilidade.

Geralmente, os crátons do mundo (como, por exemplo, o Amazônico, Rio de La Prata, Kalarari, Oeste África, São Francisco) apresentam contornos elípticos e diâmetros variáveis entre centenas e milhares de quilômetros. Eles possuem substratos constituídos por núcleos arqueanos, contendo adições significativas de materiais juvenis proterozóicos que podem ter sofrido algum tipo de deformação e metamorfismo. A cobertura dos crátons compreende unidades cujas idades vão do final do Proterozóico até os dias de hoje (Alkmim, 2004).

\subsection{Aspectos Geológicos do Cráton Amazônico}

O Cráton Amazônico (Figura 2.1) é considerado uma das maiores áreas cratônicas do mundo, abrangendo cerca de $430.000 \mathrm{~km}^{2}$. Localiza-se na parte norte da América do Sul, sendo limitado por cinturões orogênicos neoproterozóicos, dois situados no Brasil (Araguaia-Cuiabá e Tocantins) e um na Bolívia (Tucavaca) 
(Tassinari \& Macambira, 1999; Tassinari \& Macambira, 2004; Alkimim, 2004). Ao norte, o Cráton Amazônico representa uma extensão do Cráton Oeste África, na configuração do Gondwana e, a oeste, está afetado pela orogenia Andina.

Atualmente, o Cráton Amazônico é entendido como sendo composto por dois pequenos núcleos arqueanos circundados por cinturões orogênicos paleoproteróicos e mesoproteroizóicos (Tassinari \& Macambira, 1999; Santos et al., 2000), formados pela acresção de terrenos e microcontinentes durante o Proterozóico (Pinho et al., 2003; Schobbenhaus \& Brito-Neves, 2003). Segundo Lacerda-Filho et al. (2004), o Cráton Amazônico está exposto em duas extensas áreas, uma a norte e a outra a sudoeste, tendo a Bacia Sedimentar Amazônica interpondo-se entre essas duas áreas pré-cambrianas. 


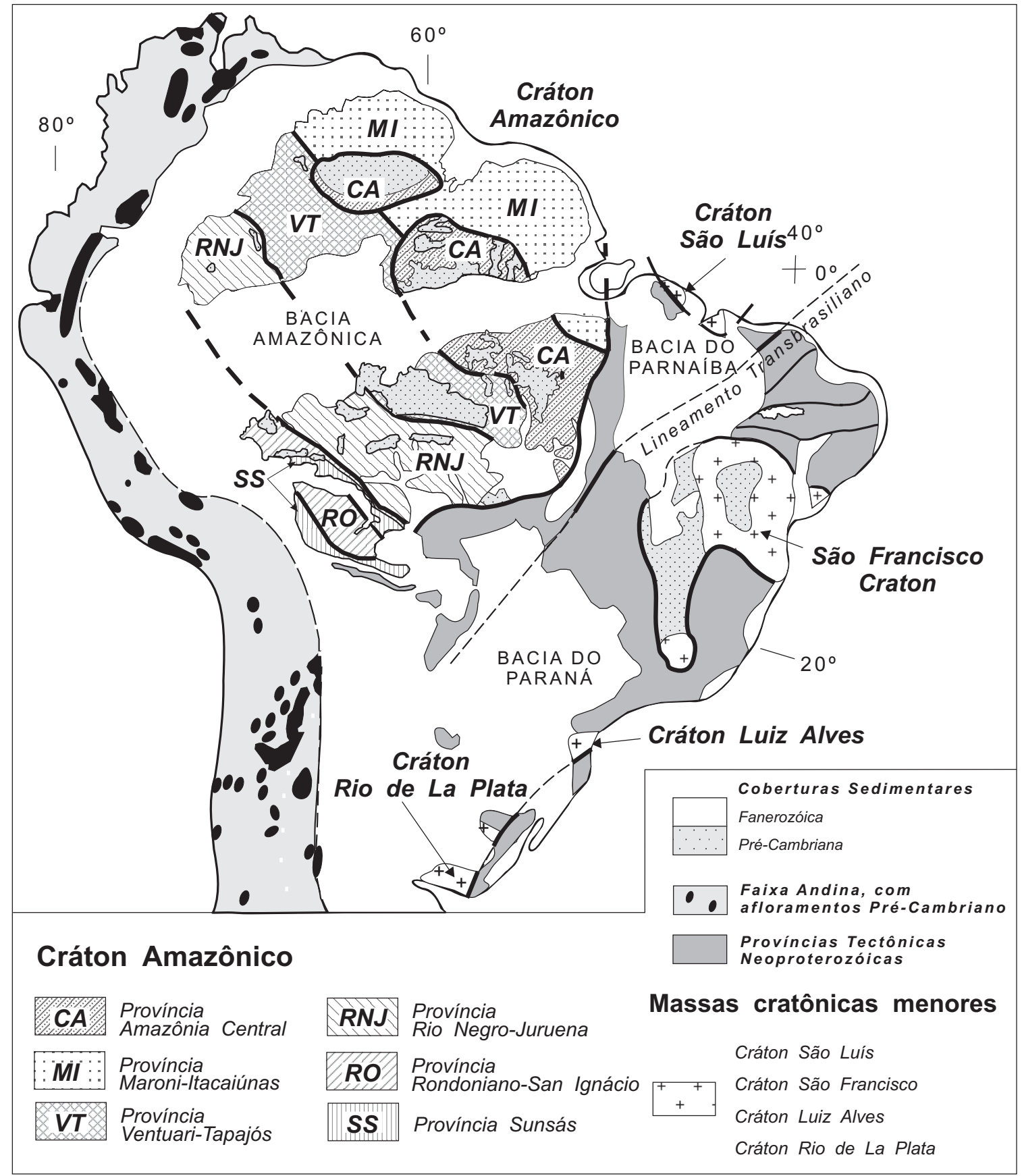

Figura 2.1: Representação do Cráton Amazônico e de outros crátons existentes na América do Sul. Modificado de Cordani \& Teixeira (2006).

Ao longo das últimas décadas várias subdivisões foram propostas para o Cráton Amazônico (Amaral, 1974; Cordani et al., 1979; Teixeira et al., 1989; Tassinari, 1996; Tassinari et al., 1996; Tassinari \& Macambira, 1999 e Santos et al., 
2000) e, diante das inúmeras contribuições apresentadas na literatura, o conhecimento sobre a sua evolução tectônica tem aumentado gradativamente.

Até a década de 1960, as partes norte e sul do Cráton Amazônico eram consideradas como tendo evoluções geológicas distintas e separadas por uma bacia intercratônica (Schobbenhaus \& Brito-Neves, 2003). Entretanto, a presença das rochas vulcano-plutônicas Uatumã a norte, a sul e sob a Bacia do Amazonas, levou Amaral (1974) a subdividir o Cráton em três províncias geocronológicas (Amazônia Oriental, Amazônia Central e Amazônia Ocidental) com base em datações K-Ar e Rb-Sr.

Almeida (1977) propôs dividir o Brasil em dez províncias estruturais, das quais o Cráton Amazônico era constituído por duas províncias: Rio Branco a norte e Tapajós ao sul, sendo ambas interpostas pela Bacia Amazônica.

Nas últimas décadas, vários trabalhos surgiram com o intuito de esclarecer a evolução geológica do Cráton Amazônico (como por exemplo, Amaral, 1974; Cordani et al., 1979; Teixeira et al., 1989; Tassinari, 1996; Tassinari et al., 1996; Tassinari \& Macambira, 1999 e Santos et al., 2000). Entretanto, enfocaremos aqui apenas os dois modelos evolutivos mais recentes, que dividem o Cráton Amazônico em províncias geológicas.

O primeiro modelo, proposto por Tassinari \& Macambira (1999), baseia-se na idéia de que durante o Arqueano, Paleo e Mesoproterozóico, teria ocorrido uma sucessão de arcos magmáticos formando grandes quantidades de materiais juvenis derivados do manto, seguidos por processos que retrabalharam a crosta. Os autores subdividem o Cráton Amazônico em seis províncias geocronológicas (Figura 2.2):

- Amazônia Central, com idades mais antigas que 2,3 Ga;

- Maroni-Itacaiúnas, com idades entre 2,2 e 1,95 Ga;

- Ventuari-Tapajós, datado entre 1,95 e 1,8 Ga; 
- Rio Negro-Juruena, entre 1,8 e 1,55 Ga;

- Rondoniano-San Ignácio, com idades entre 1,55 e 1,3 Ga;

- Sunsás, idades entre 1,3 e 1,0 Ga.

Tassinari \& Macambira (1999) sugerem que os dados geocronológicos indicam que o próton-cráton arqueano foi formado a partir da colisão de microcontinentes que foram amalgamados pela orogenia paleoproterozóica Transamazônica, entre 2,2 e 1,95 Ga. Parte das províncias Maroni-Itacaiunas e Rondoniano-San Ignácio e quase a totalidade das províncias Ventuari-Tapajós e Rio Negro-Juruena formaram-se a partir de materiais derivados do manto e evoluíram através de uma sucessão de arcos magmáticos. A evolução da Província Sunsás é associada pelos autores a processos colisionais e ao retrabalhamento das rochas pré-existentes.

O modelo de Santos et al. (2000) realizado através de estudos geocronológicos pelos métodos $\mathrm{U}-\mathrm{Pb}$ e $\mathrm{Sm}-\mathrm{Nd}$ propõe modificações nas províncias anteriormente citadas, sugerindo uma outra subdivisão para as províncias:

- Carajás e Imataca com idades entre 3,10 e 2,53 Ga;

- Transamazônica com idades entre 2,25 e 2,00 Ga;

- Tapajós-Parima com idades entre 2,21 e 1,87 Ga;

- Amazônia Central com idades entre 1,88 e 1,70 Ga;

- Rio Negro com idades entre 1,86 e 1,52 Ga;

- Rondônia-Juruena com idades entre 1,76 e 1,47 Ga;

- Sunsás com idade entres 1,33 e 1,10 Ga.

Para esta outra divisão, Santos et al. (2000) consideraram as características geológicas, estruturais, magmáticas e isotópicas de cada uma das províncias. A interpretação dos seus dados $\mathrm{U}-\mathrm{Pb}$ combinados com $\mathrm{Sm}-\mathrm{Nd}$ indicaram que algumas províncias representam crosta juvenil (Carajás e Imataca, Transamazônica, Tapajós-Parima e Rondônia-Juruena), enquanto outras estão 
relacionadas a processos colisionais (Rio Negro e Sunsás). Apenas a província Amazônia Central é produto do retrabalhamento da crosta arqueana.

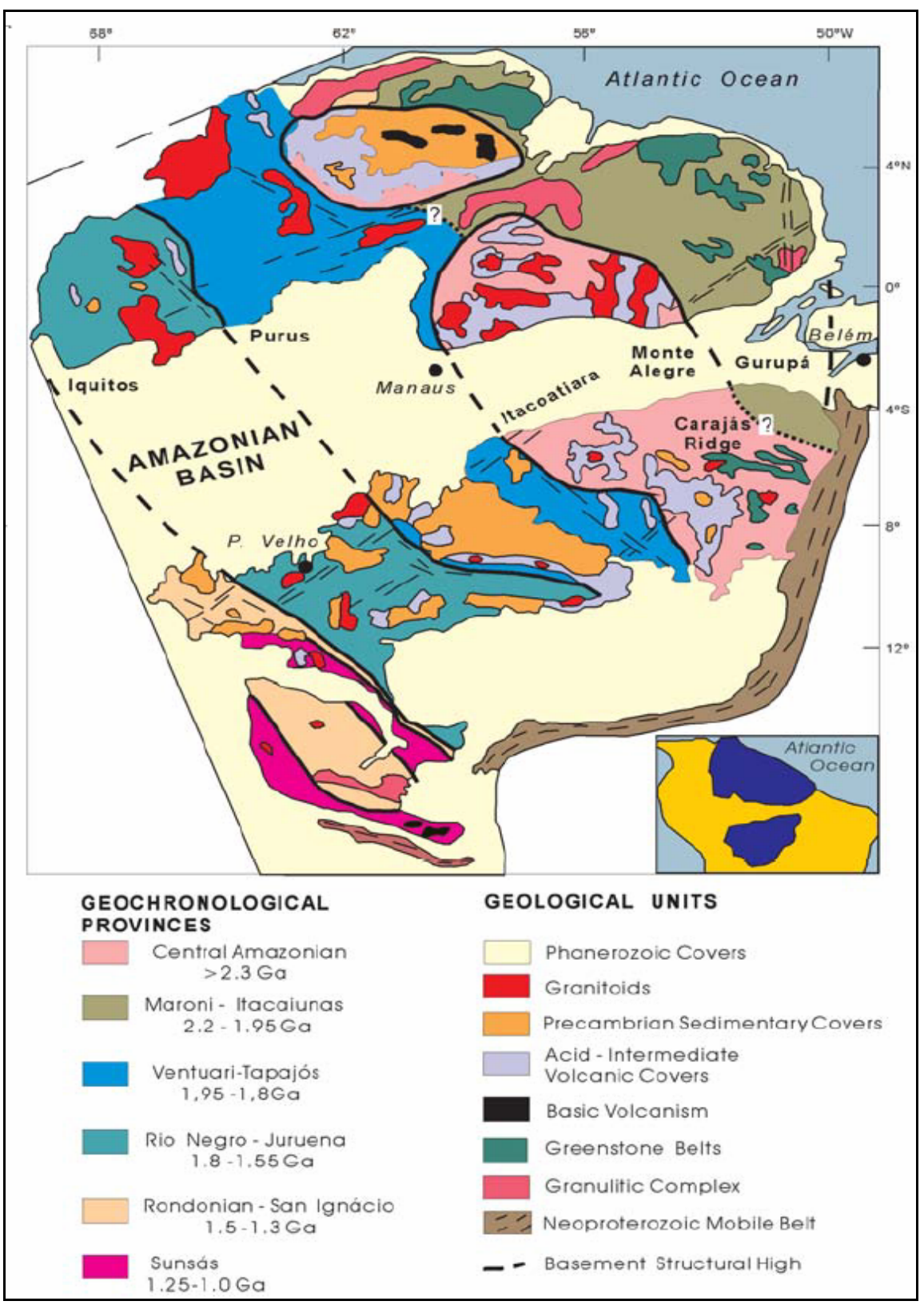

Figura 2.2: Províncias Geogronológicas do Cráton Amazônico, extraída de Tassinari \& Macambira (1999). 


\subsection{Contexto Geológico Regional}

Seguindo os principais modelos de subdivisão estabelecidos para o Cráton Amazônico, descritos anteriormente, a área de estudo deste trabalho está localizada dentro da província geocronológica Rio Negro-Juruena (Tassinari \& Macambira, 1999; Tassinari et al., 2004) ou na província Rondônia-Juruena de (Santos et al., 2000). Contudo, adotaremos o modelo geocronológico de Tassinari \& Macambira (1999) para descrever o contexto geológico da área de estudo em que este trabalho está inserido.

Para Tassinari \& Macambira $(1999,2004)$, a província geocronológica Rio Negro-Juruena, representada por um cinturão móvel juvenil que se situa na parte mais a sudoeste do Cráton Amazônico, dispõe-se paralelamente à Província Ventuari-Tapajós, sendo constituída de uma zona de intensa ocorrência de granitos e migmatitos, desenvolvida através de uma sucessão de arcos magmáticos de idades entre 1,8 e 1,55 Ga.

As unidades da Província Rio Negro-Juruena são compostas por gnaisses, granodioritos, tonalitos, migmatitos, granitos e anfibolitos. Encontra-se na parte sudoeste da província o segmento crustal "Greenstone Belt" Alto Jauru (1,79-1,75 Ga) que é constituído por seqüências metavulcano-sedimentares separadas por terrenos granito-gnaíssicos de composição toleítica, intrudidas por doleritos e cobertas parcialmente pelas rochas clásticas do Grupo Aguapeí. A parte sul da província é composta por rochas metavulcânicas félsicas de composição riolítica a riodacítica (Tassinari \& Macambira, 2004; Alkimim, 2004).

Associados aos arcos magmáticos relacionados à Província Rio NegroJuruena, ocorrem rochas vulcânicas félsicas a intermediárias e granitos com idades entre 1,65 e 1,55 Ga. Em geral, esses episódios vulcano-sedimentares estão associados a rifts continentais e constituem o Grupo Caiabis na parte sul do 
domínio. Nele ocorrem rochas metavulcânicas félsicas, de composição riolítica a riodacítica, na área entre os rios Roosevelt e Aripuanã.

De acordo com Tassinari \& Macambira (1999), os resultados de estudos geotectônicos e geocronológicos indicam que as atividades magmáticas máficas na província ocorreram em três intervalos distintos de tempo, o mais antigo entre 1,41,35 Ga e os outros variando entre 1,25-1,15 Ga e entre 0,98-0,95 Ga, evidenciando magmatismos que caracterizam a evolução tectônica da parte sudoeste do Cráton Amazônico.

É importante ressaltar que, para Santos et al. (2000) essa província, denominada de Rondônia-Juruena, é subdividida em dois domínios: o Juruena (1,85-1,72 Ga) e o Roosevelt-Aripuanã (1,76-1,47 Ga). Esses autores interpretam o Domínio Juruena como uma sucessão de arcos magmáticos constituídos de rochas plutônicas e vulcânicas félsicas e o Domínio Roosevelt-Aripuanã como seqüências metavulcanossedimentares que contêm rochas metavulcânicas ácidas a intermediárias intercaladas com rochas metassedimentares, clásticas e químicas.

A norte do Estado de Mato Grosso encontra-se um terreno plutonovulcânico deformado, composto pelas Suítes Juruena, Paranaíta, Colider, Alcalina do Rio Cristalino e o Granito Nhandu com idades entre 1850-1750 Ma e, a sul, um terreno granito-gnáissico de alto grau metamórfico com idades entre 1780-1750 Ma (Lacerda-Filho et al., 2004).

A área de estudo está inserida na Província Rio Negro-Juruena na porção norte do Estado do Mato Grosso e envolveu rochas vulcânicas félsicas e intermediárias pertencentes a Suíte Colíder, além de rochas básicas da Intrusiva Máfica Guadalupe, possivelmente contemporânea às Suítes Colíder e Paranaíta (Lacerda-Filho et al., 2004) e da Suíte Intrusiva Flor da Serra que intrudem o Granito Matupá (1848 $\pm 17 \mathrm{Ma})$. 


\subsection{Geologia Local}

Segundo Pinho (2002), rochas pirocláticas félsicas ocorrem na porção sudoeste do Cráton Amazônico no norte do Estado do Mato Grosso. Por muitos anos estas rochas foram incluídas no Supergrupo Uatumã e interpretadas como representativas de um significativo evento vulcânico intracontinental que teria ocorrido pela ruptura parcial da Plataforma Amazônica.

Esse evento, denominado de Uatumã (Oliveira \& Leonardos, 1940, apud Schobbenhaus et al., 1984), inicia-se por um vulcanismo ácido a intermediário de grandes proporções, que caracterizou uma das mais espetaculares inconformidades de que se tem conhecimento no cráton Amazônico. A cobertura vulcânica iniciou-se próximo de 1900 Ma e se estendeu até cerca de $1700 \mathrm{Ma}$ (Schobbenhaus et al., 1984).

Entretanto, a nomenclatura de Supergrupo Uatumã passou a ser modificada com o avanço dos conceitos geotectônicos suportados por dados geocronológicos. O Supergrupo Uatumã foi dividido no Estado do Mato Grosso por Silva et al., 1974, na Formação Iriri, no Granito Teles Pires e no Sienito Canamã. Neste contexto, descreveu-se a Formação Iriri como uma associação de rochas vulcânicas félsicas representadas por riolitos, riodacitos, ignimbritos e andesitos.

Dados isotópicos $\mathrm{Rb}-\mathrm{Sr}$ em rochas do vulcanismo Uatumã foram realizados por Basei (1977) e fornecem idades para a Formação Iriri de $1765 \pm 16$ Ma e para a Unidade Teles Pires de $1680 \pm 13$ Ma. Datações mais precisas em zircões (método U-Pb) revelaram para a Formação Iriri uma idade de $1870 \pm 8$ Ma e para Teles Pires uma idade de $1740 \pm 12 \mathrm{Ma}$ (Santos et al., 2000).

Recentemente, as rochas mapeadas como Formação Iriri e que bordejam as partes sul da Serra do Cachimbo e norte da Serra dos Apiacás, foram denominadas 
como Suíte Vulcânica Colíder (ver Figura 2.4) por Lacerda-Filho et al. (2001) em decorrência das idades $\mathrm{U}-\mathrm{Pb}$ mais recentes obtidas para estas rochas (Seção 2.4.4).

\subsubsection{Suíte Colíder}

A Suíte Colíder é composta pelas rochas vulcânicas, subvulcânicas, piroclásticas e epiclásticas de composição ácida a intermediária, aflorantes nas redondezas da Cidade de Colíder (Oliveira \& Albuquerque, 2004).

As rochas de composição ácida são constituídas por riolitos, riodacitos e ignimbritos. As rochas intermediárias compreendem corpos andesíticos de cor cinza-escuro a preta e estrutura maciça os quais originam solos avermelhados e ricos em magnetita. Segundo Lacerda-Filho et al. (2004), essas rochas estão relacionadas ao Arco Magmático Juruena que foi gerado entre 1.85-1.75 Ga (método U-Pb em zircão).

Esta Suíte ocorre em contato com as unidades plutônicas São Pedro, Nova Canaã, Nhandu e Matupá. A Suíte Colíder é intrudida pelos Granitos Teles Pires que apresentam idade em torno de 1750 Ma e é recoberta discordantemente por rochas sedimentares paleoproterozóicas do Grupo Beneficente e pelas rochas sedimentares mesoproterozóicas da Formação Dardanelos (Lacerda-Filho et al. 2004).

\subsubsection{Intrusivas Máficas Guadalupe}

A designação Intrusiva Máfica Guadalupe (ver Figura 2.4) foi proposta por Oliveira \& Albuquerque (2004) para caracterizar um clã de corpos básicos representados por gabro, microgabro, diabásio e diorito pórfiro, aflorantes nas 
cercanias da comunidade de Nossa Senhora de Guadalupe, sudoeste de Alta Floresta.

Lacerda-Filho et al. (2001, 2004) destacam que estes litotipos ocorrem sob a forma de diques ou stocks intrudindo os granitos da Suíte Intrusiva Paranaíta e também como megaenclaves. Por isso, os autores consideram que as Intrusivas Máficas Guadalupe e Paranaíta são contemporâneas.

Os gabros desta unidade possuem cor cinza-escuro com tonalidades esverdeadas, textura granular e estrutura maciça. Os dioritos possuem cor verde com tons acinzentados e textura inequigranular média. Observam-se também diques de diabásio porfirítico que intrudem rochas do Granito Nhandu, da Suíte Colider e da Intrusiva Paranaíta (Lacerda-Filho et al., 2004).

\subsubsection{Suíte Intrusiva Flor da Serra}

A Suíte Flor da Serra aflora nos arredores das cidades de Matupá e Peixoto de Azevedo, principalmente, na região do povoado de Flor da Serra. Segundo Lacerda-Filho et al. (2004) esta unidade é composta dominantemente por gabros, granodioritos, dioritos, monzogabros, monzodioritos e diabásios e apresenta-se geralmente na forma de corpos homogêneos e sem metamorfismo. Restritamente, ocorre sob forma de diques, com boas exposições ao longo do Rio Peixoto de Azevedo. Sua textura varia de grossa nas partes centrais, evoluindo para texturas finas e porfiríticas nas bordas.

$\mathrm{Na}$ área de exposição da Suíte Flor da Serra (ver figura 2.4) encontram-se diques com textura fina e fenocristais centimétricos de plagioclásio, que cortam freqüentemente os granitos da Suíte Intrusiva Matupá (1848 \pm 17 , U-Pb) e, mais restritamente a própria unidade numa manifestação tardia do mesmo evento (Lacerda-Filho et al., 2004). 


\subsubsection{Dados geocronológicos}

Recentemente, a Suíte Colíder foi datada por Pimentel (2001) que, através do método $\mathrm{U}-\mathrm{Pb}$ em zircão, obteve a idade de $1.781 \pm 8 \mathrm{Ma}$ e, pelo método $\mathrm{Sm} / \mathrm{Nd}$, obteve uma idade modelo $\mathrm{T}_{\mathrm{DM}}=2.344 \mathrm{Ma}$ em riolitos pórfiros, indicando contaminação de fonte crustal. Pinho et al. (2001) também obtiveram idade U-Pb (zircão) de $1.801 \pm 11$ Ma para ignimbritos e riodacitos das cercanias do Rio Moriru, que é uma continuidade oeste do vulcanismo da Suíte Colíder.

De acordo com Lacerda-Filho et al., 2001, 2004) dados isotópicos U-Pb SHRIMP fornecem idade de 1.786 \pm 17 Ma para as rochas da Suíte Colíder, a qual é concomitante à Suíte Paranaíta (1.81-1.79 Ga, U-Pb) e a Nhandu (1.8 Ga, U-Pb).

Para as Intrusivas Máficas Guadalupe ainda não existem dados geocronológicos: admite-se que tenham idade de aproximadamente de $1.8 \mathrm{Ga}$, visto que, essas rochas encontram-se associadas aos granitóides da Suíte Intrusiva Paranaíta de idade U-Pb entre 1.81-1.79 Ga. (Lacerda-Filho et al., 2004).

Dados geocronológicos para a Suíte Intrusiva Flor da Serra são ainda escassos. A datação Sm-Nd de um gabro dessa Suíte revelou idade TDM de 2.336 Ma, sugerindo contaminação com crosta mais antiga (Lacerda-Filho et al., 2001, 2004). Esses mesmos autores destacam que a Suíte Intrusiva Flor da Serra está correlacionada a Suíte Ingarana de idade $\mathrm{Pb}-\mathrm{Pb}$ em zirção de $1.887 \pm 3 \mathrm{Ma}$ (Vasquez et al., 2000) e idade U-Pb (SHRIMP) entre 1.888-1.900 Ma (Bahia \& Quadros, 2000). 


\subsection{Localização da Área de Estudo}

Grande parte da amostragem paleomagnética ocorreu na região norte do Estado do Mato Grosso, sudoeste do Cráton Amazônico (Figura 2.3), entre as Cidades de Alta Floresta e Terra Nova do Norte, nas redondezas da Cidade de Matupá e ao norte desta, ao longo da BR-163, seguindo em direção ao Estado do Pará (Figura 2.4), onde afloram rochas félsicas da Suíte Colíder, bem como máficas da Intrusiva Guadalupe e da Suíte Flor da Serra.

Para a pesquisa paleomagnética foram coletados 80 cilindros orientados e 27 blocos orientados de 17 sítios (denominados de coleção SD) constituindo-se, na maioria, de rochas máficas e ácidas. Mais 18 blocos orientados de 6 sítios de rochas ácidas (coleção CS) foram acrescentados à coleção SD, totalizando 23 sítios para o estudo paleomagnético. Do total amostrado, 18 sítios representam rochas ácidas da Suíte Colíder e máficas associadas, 4 sítios representam rochas máficas da Suíte Intrusiva Flor da Serra e 1 sítio representa rochas máficas da Intrusiva Máfica Guadalupe. Sendo que em duas localidades (sítios 12 e 23), diques máficos e a rocha encaixante apresentavam-se relativamente bem expostos e foram amostrados para o teste de contato cozido.

As amostras da coleção CS foram coletadas pelos professores Drs. Igor I. G. Pacca e Umberto G. Cordani. Essa amostragem foi realizada ao norte do Estado do Mato Grosso e ao sul do Pará (Pacca, 1981), onde eoncontra-se rochas ácidas sotopostas ao Grupo Beneficente. Resultados paleomagnéticos preliminares obtidos para a coleção CS foram apresentados por Pacca \& Cordani (1979).

A localização de todos os sítios, as litologias associadas e a identificação das amostras estão descritas na tabela 2.1. O mapa geológico da área de estudo e os pontos dos sítios coletados, incluindo os da coleção CS, estão representados na 
figura 2.4. Informações mais detalhadas sobre o processo de amostragem estão descritas na Metodologia (ver Cap. 3).

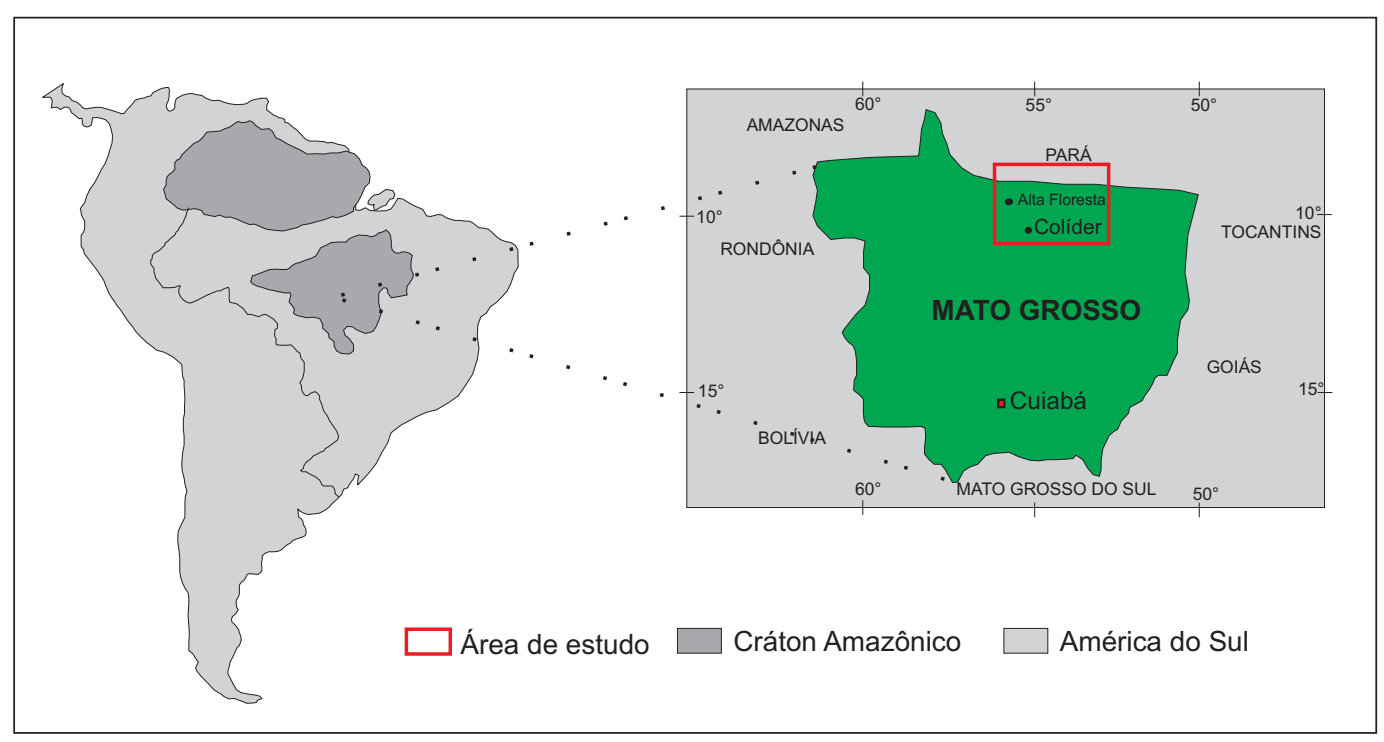

Figura 2.3: Localização da área de estudo. 


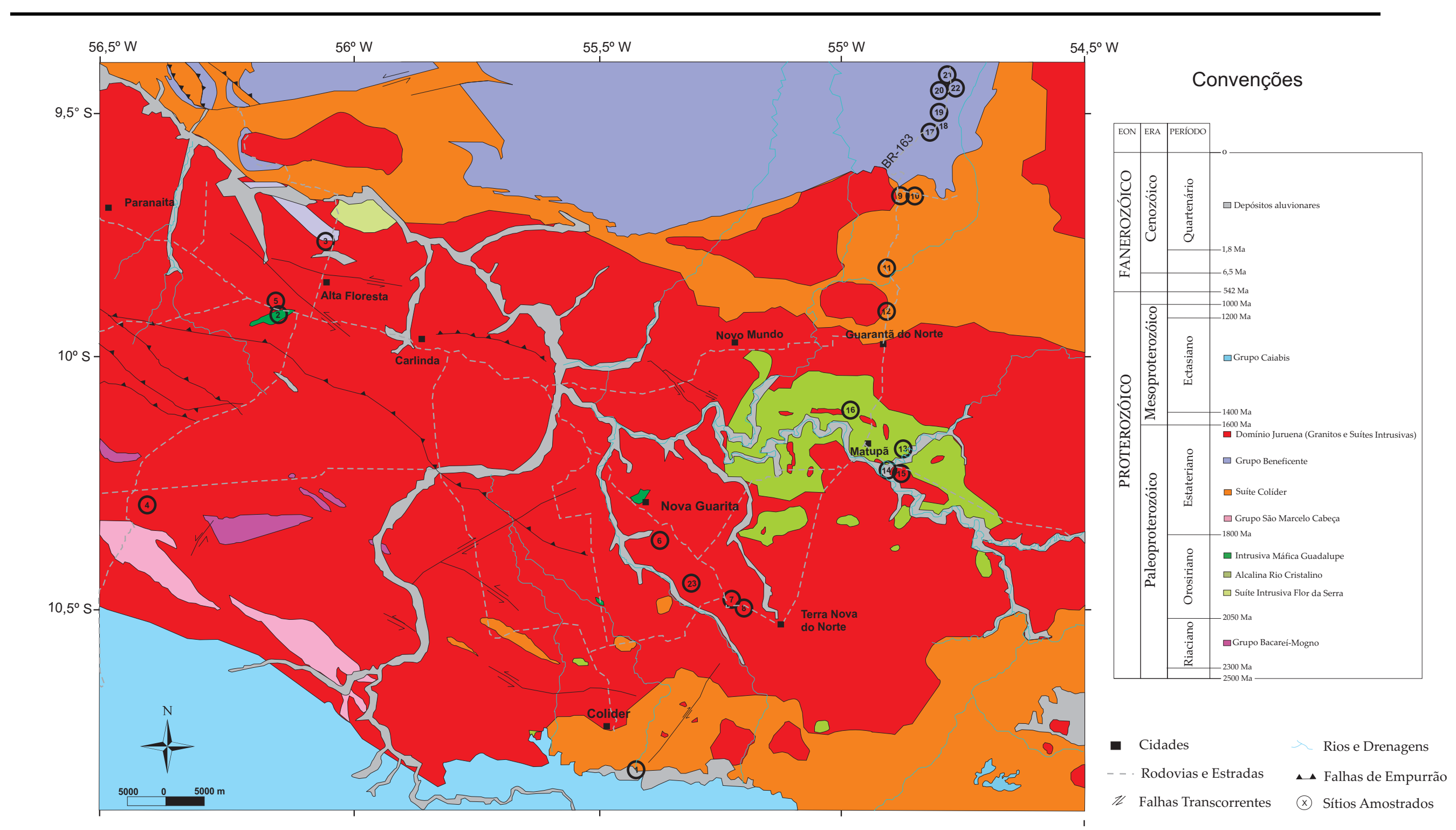

Figura 2.4: Mapa geológico da área de estudo indicando os pontos dos sítios amostrados. Modificada de Lacerda-Filho et al. (2004) 
Tabela 2.1: Número do sitio, localização, identificação e litologia da amostragem paleomagnética.

\begin{tabular}{|c|c|c|c|}
\hline SÍTIOS & LOCALIZAÇÃO & AMOSTRAS & LITOLOGIA \\
\hline 1 & $10,82^{\circ} \mathrm{S} / 55,43^{\circ} \mathrm{W}$ & SD1A a SD1E & Andesito \\
\hline 2 & $9,89^{\circ} \mathrm{S} / 56,15^{\circ} \mathrm{W}$ & SD2A a SD2E & Gabro \\
\hline 3 & $9,73^{\circ} \mathrm{S} / 56,06^{\circ} \mathrm{W}$ & SD3 a SD6 & Ignimbrito \\
\hline 4 & $10,26^{\circ} \mathrm{S} / 56,42^{\circ} \mathrm{W}$ & SD7A a SD7M & Diabasio \\
\hline 5 & $9,87^{\circ} \mathrm{S} / 56,16^{\circ} \mathrm{W}$ & SD8 a SD11 & Granodiorito \\
\hline 6 & $10,35^{\circ} \mathrm{S} / 55,36^{\circ} \mathrm{W}$ & SD12A a SD12H & Microgabro \\
\hline 7 & $10,48^{\circ} \mathrm{S} / 55,22^{\circ} \mathrm{W}$ & SD13A a SD13J & Diabasio \\
\hline 8 & $10,49^{\circ} \mathrm{S} / 55,20^{\circ} \mathrm{W}$ & SD14A a SD14D & Diabasio \\
\hline 9 & $9,63^{\circ} \mathrm{S} / 54,88^{\circ} \mathrm{W}$ & SD15 a SD17 & Riolito \\
\hline 10 & $9,63^{\circ} \mathrm{S} / 54,86^{\circ} \mathrm{W}$ & SD18 a SD21 & Riolito \\
\hline 11 & $9,80^{\circ} \mathrm{S} / 54,91^{\circ} \mathrm{W}$ & SD22 a SD25 & Arenito \\
\hline 12 & $9,91^{\circ} \mathrm{S} / 54,91^{\circ} \mathrm{W}$ & $\begin{array}{c}\text { SD26 a SD33 } \\
\text { SD34A a SD34E }\end{array}$ & $\begin{array}{l}\text { Diabasio e } \\
\text { ignimbrito }\end{array}$ \\
\hline 13 & $10,17^{\circ} \mathrm{S} / 54,87^{\circ} \mathrm{W}$ & SD35A a SD35E & Diabasio \\
\hline 14 & $10,20^{\circ} \mathrm{S} / 54,91^{\circ} \mathrm{W}$ & SD36 a SD38 & Microgabro \\
\hline 15 & $10,21^{\circ} \mathrm{S} / 54,89^{\circ} \mathrm{W}$ & SD39A a SD39E & Microgabro \\
\hline 16 & $10,10^{\circ} \mathrm{S} / 54,97^{\circ} \mathrm{W}$ & SD40A a SD40F & Microgabro \\
\hline 17 & $9,51^{\circ} \mathrm{S} / 54,81^{\circ} \mathrm{W}$ & CS22 a CS24 & Riolito \\
\hline 18 & $9,51^{\circ} \mathrm{S} / 54,79^{\circ} \mathrm{W}$ & CS25 a CS27 & Riolito \\
\hline 19 & $9,49^{\circ} \mathrm{S} / 54,80^{\circ} \mathrm{W}$ & CS28 a CS30 & Riolito \\
\hline 20 & $9,42^{\circ} \mathrm{S} / 54,81^{\circ} \mathrm{W}$ & CS31 a CS33 & Riolito \\
\hline 21 & $9,41^{\circ} \mathrm{S} / 54,79^{\circ} \mathrm{W}$ & CS42 a CS44 & Riolito \\
\hline 22 & $9,42^{\circ} \mathrm{S} / 54,78^{\circ} \mathrm{W}$ & CS45 a CS47 & Riolito \\
\hline 23 & $10,44^{\circ} \mathrm{S} / 55,31^{\circ} \mathrm{W}$ & $\begin{array}{l}\text { SD74A a SD74J } \\
\text { SD74K a SD74O }\end{array}$ & $\begin{array}{l}\text { Gabro e } \\
\text { Granito }\end{array}$ \\
\hline
\end{tabular}




\subsection{Análise Petrográfica}

Utilizando o microscópio óptico de luz polarizada realizou-se a análise petrográfica de lâminas delgadas das amostras coletadas. Abaixo descreve-se as características observadas nesta análise:

1) Espécimes SD2-C1 (sítio 2), SD7-F3 (sítio 4), SD 12-D1 (sítio 6), SD14-B1 (sítio 8), SD34-E1 (sítio 12), SD35-B1 (sítio 13), SD37-A1 (sítio 14), SD38-B1 (sítio 14), SD39E1 (sítio 15) e SD40-C1 (sítio16) constituem subvulcânicas básicas. São rochas de granulação média a grossa, composta por cristais de plagioclásio ( $55 \%)$, clinopiroxênio $(\sim 15 \%)$, opacos euedrais e intersticiais $(\sim 10 \%)$ e biotita $(\sim 5 \%)$. Petrograficamente pode ser classificada como gabro.

2) Espécimes SD8-C1 e SD11-B1 (sítio 5) apresentam-se como subvulcânicas intermediárias. São rochas de granulação média, composta de cristais de feldspato $(\sim 30 \%)$, quartzo $(\sim 10 \%)$, cristais de hornblenda $(\sim 25 \%)$, epídoto $(\sim 15 \%)$, biotita $(\sim 15 \%)$ e opacos $(\sim 5 \%)$. Petrograficamente pode ser classificada como quartzo diorito.

3) Espécimes SD27-C2, SD28-C1 e SD33-C4 (sítio 12) constituem tufos grossos ricos em cristais. São rochas que se apresentam maciças e laminadas, com cristais de quartzo e feldspato, poucos shards e raros litoclastos cognatos de rochas piroclásticas. A laminação interna do tufo se dá pela intercalação de níveis ricos em cristais (quartzo e feldspato) com níveis ricos em shards. Uma boa quantidade de minerais opacos, provavelmente magnetita ( 5\%), é observada nesses litotipos.

4) Espécime SD24-B1 (sítio 11) constitui arenito de granulação fina, com cristais de quartzo $(\sim 68 \%)$, feldspato $(\sim 17 \%)$ e litoclastos de chert $(\sim 15 \%)$, sem matriz. Classificado como arenito subfeldspático. Os clastos apresentam forte compactação e cimentação coaxial posterior à compactação. 
5) Espécime SD3-C1 (sítio 3) constitui ignimbrito, composto de megacristais de quartzo vulcânico e de feldspato, envoltos por shards, e uma matriz micropoiquilítica quartzo-feldspática. Estas texturas e feições permitiram classificar a rocha como um ignimbrito, ou seja, rocha piroclástica, gerada por fluxos piroclásticos em ambientes subaéreos. 


\section{Capítulo 3}

\section{METODOLOGIA}

Neste capítulo, descreve-se a metodologia básica empregada no paleomagnetismo, a qual envolve o procedimento de amostragem, as técnicas de desmagnetização térmica e por campos magnéticos alternados (CA) para a separação de componentes de magnetização presentes nas rochas, testes de estabilidade magnética, experimentos envolvendo a determinação de curvas de histerese, curvas de indução, curvas termomagnéticas, com o objetivo de estudar a mineralogia magnética, técnicas vetoriais empregadas para a determinação de componentes de magnetização através da aplicação de projeções ortogonais e do método de componentes principais (Kirschvink, 1980) e, finalmente, a análise estatística utilizada para a determinação de direções médias e pólos paleomagnéticos (Fisher, 1953).

\subsection{Amostragem}

Para as investigações paleomagnéticas é necessário coletar amostras orientadas das rochas em estudo que estejam “in situ” (McElhinny, 1973).

A coleta das amostras pode ser feita de duas maneiras: (1) Coleta de cilindros orientados através de uma perfuratriz portátil, movida a gasolina, que possui uma broca diamantada que retira testemunhos cilíndricos de 2,5 cm de diâmetro. (2) Coleta de blocos orientados que no laboratório são perfurados para a retirada de testemunhos cilíndricos, também de 2,5 cm de diâmetro. 
Nos dois tipos de amostragem, as amostras são devidamente orientadas através de bússolas solar e magnética. A medida do azimute magnético deve ser corrigida pela declinação magnética local, a qual é obtida pelo IGRF (Tauxe, 2002).

A utilização da bússola solar é importante para o caso de rochas com altas intensidades de magnetização, fato que ocorre com freqüência em rochas máficas. Neste caso, dá-se preferência às orientações efetuadas com bússola solar.

Depois de devidamente marcados, os testemunhos cilíndricos são cortados em espécimes de 2,2 cm de altura para as medidas paleomagnéticas.

Uma coleção paleomagnética deve conter um número de amostras por sítio suficiente para eliminar erros de amostragem e experimentais (Lowrie, 1997). Usualmente, a coleta de 6 a 10 amostras (cilindros) tem sido adequada para definir uma direção média para o sítio.

O número de sítios amostrados deve cobrir um intervalo de tempo suficiente para eliminar a variação secular do campo geomagnético e produzir um pólo paleomagnético que represente o campo de um dipolo geocêntrico axial (DGA).

\subsection{Magnetizações Remanescentes e Processos de Desmagnetizações}

\section{Progressivas}

Quando uma rocha se forma, ela adquire uma magnetização que registra o campo geomagnético da época. Essa magnetização é denominada de magnetização remanescente primária (MRP). A MRP pode se apresentar na forma de uma magnetização termo-remanescente (MTR) que é adquirida por uma rocha durante o seu resfriamento, como no caso das rochas ígneas e metamórficas de alto grau (neste caso, representa a época do metamorfismo), ou de uma magnetização 
remanescente deposicional (MRD), adquirida no processo de deposição de rochas sedimentares (Cox \& Doell, 1960).

Qualquer magnetização adquirida posteriormente a sua formação, chamamos de magnetização secundária, que pode ser representada por uma magnetização termo-remanescente parcial (MTRp), uma magnetização remanescente química (MRQ), uma magnetização remanescente isotérmica (MRI) ou uma magnetização remanescente viscosa (MRV) ou termo-viscosa (MRTV). A MRQ ocorre quando o mineral magnético presente na rocha sofre alteração química ou quando um novo mineral magnético é formado por precipitação ou pela transformação de um outro mineral não magnético. Uma MRI é adquirida se uma rocha é exposta a um forte campo magnético por um curto período de tempo em uma temperatura constante (como exemplo, pode-se citar um relâmpago atingindo a rocha).

Por outro lado, a MRV é adquirida gradualmente por uma rocha quando esta fica exposta a um campo magnético fraco, por um longo tempo (McElhinny \& McFadden, 2000). Isso acontece porque toda magnetização tende a decair com o tempo, sendo substituída por uma nova magnetização (MRV) adquirida sob a influência do campo geomagnético atuante.

A magnetização da rocha está associada aos grãos de minerais 'ferromagnéticos' que ela contém e sua estabilidade magnética depende das características destes grãos (tipo de mineral magnético, tamanho dos grãos, anisotropias magnéticas associadas).

A magnetização inicial Mo de uma rocha que contém um conjunto de grãos de domínio simples (DS), decai exponencialmente com o tempo (t), obedecendo a eq. (3.1).

$$
M r=M o \cdot \exp \left(\frac{-t}{\tau}\right)
$$


onde $\tau$ é o tempo de relaxação dos grãos magnéticos. Este parâmetro depende das propriedades dos grãos magnéticos (Eq. 3.2), tais como, a constante vibracional da rede cristalina $\left(\mathrm{C} \cong 10^{9} \mathrm{~s}^{-1}\right)$, a energia magnética anisotrópica $\mathrm{KV}$ (K representa as anisotropias magnéticas associadas aos grãos e V é o volume dos grãos) e a energia térmica kT (k é a constante de Boltzman e T é a temperatura).

$$
\tau=\frac{1}{C} \cdot \exp \left(\frac{K V}{k T}\right)
$$

Assim, quanto maior for o tempo de relaxação, maior será a estabilidade da magnetização e vice-versa.

Outra maneira de adquirir uma magnetização secundária acontece quando uma rocha sofre o processo de soerguimento seguido de erosão e resfriamento, expondo a rocha que ficou em determinada profundidade da crosta, em temperaturas elevadas $(\mathrm{T}<\mathrm{Tc})$, durante um longo intervalo de tempo. Neste processo, a rocha adquire uma magnetização termo-remanescente parcial viscosa (MTRPV) de origem secundária, a qual representa a soma de uma componente termo-remanescente parcial, adquirida durante o resfriamento da rocha, e uma viscosa adquirida durante o tempo em que a rocha permaneceu na temperatura $\mathrm{T}$.

Contudo, a magnetização remanescente natural (MRN) de uma rocha representa todas as magnetizações adquiridas durante a sua história geológica e as eventualmente adquiridas no processo de amostragem e manipulação, ou seja, é a soma vetorial da componente primária e de eventuais componentes secundárias.

No laboratório, técnicas de desmagnetização são aplicadas para separarmos essas componentes e obtermos a componente de magnetização mais estável. Esta componente mais estável é chamada de magnetização remanescente característica $(\mathrm{MRC})$ da rocha. Ela pode ou não representar a magnetização adquirida durante a formação da rocha (MRP), o que vai depender da sua história geológica. 
Para analisar a composição vetorial da MRN e isolar a componente MRC, um processo de desmagnetização é feito de maneira detalhada para possibilitar que os componentes de magnetização da rocha sejam removidos progressivamente.

Dois processos de desmagnetizações progressivas são normalmente utilizados: a desmagnetização por campos magnéticos alternados (CA) e a térmica.

\subsubsection{Desmagnetização por Campos Magnéticos Alternados (CA)}

Este processo se resume em aplicar na rocha, em ambiente de campo nulo, um campo magnético alternado com valor de pico $\mathrm{H}$, o qual diminui linearmente com o tempo até zero. Deste modo, os grãos magnéticos com coercividades (Hc, vide seção 3.4.2) menores ou iguais a $\mathrm{H}$ são sucessivamente reorientados na direção do campo magnético alternado aplicado, fazendo com que a magnetização total associada a estes grãos seja nula. Assim, os grãos magnéticos que foram desmagnetizados não contribuem mais para a medida da magnetização da amostra (Tarling, 1983).

Para a análise da remanescência magnética das rochas, dois tipos de desmagnetizadores por campos magnéticos alternados são normalmente utilizados: o de eixo fixo e o de eixo rotativo. No primeiro, a amostra é desmagnetizada ao longo de três eixos ortogonais fixos na amostra. No segundo, a amostra gira em torno de dois eixos durante a desmagnetização, de forma que o campo alternado é aplicado em todas as direções da amostra. Este procedimento garante uma maior eficiência na desmagnetização das amostras. Por outro lado, aparelhos deste tipo atingem campos de, no máximo, $100 \mathrm{mT}$ (por exemplo, desmagnetizador por campos alternados da Molspin). Já os desmagnetizadores de 
eixo fixo atingem campos bem maiores, chegando a $200 \mathrm{mT}$, como é o caso do desmagnetizador SI4 da 'Saphire Instruments'.

Campos magnéticos alternados crescentes são sucessivamente aplicados na rocha, visando eliminar componentes com coercividades sucessivamente maiores. Normalmente, para uma amostra piloto, utilizam-se passos de 2,5 mT até o campo de $15 \mathrm{mT}$ e passos de $5 \mathrm{mT}$ (ou $10 \mathrm{mT}$ ) até atingir o limite máximo do aparelho. Após cada etapa de desmagnetização, a magnetização da amostra é medida. Este detalhamento permite investigar os espectros de coercividades associados às componentes de magnetização da rocha.

A eficiência do processo de desmagnetização por campos alternados na separação de componentes é limitada, pois depende dos minerais magnéticos que ela contém e de suas propriedades (espectro de coercividades e estabilidade magnética). O processo é geralmente eficiente para rochas contendo titanomagnetitas como principal portador magnético. Para rochas contendo minerais magnéticos com coercividades muito altas (por exemplo, hematita, goetita, pirrotita), entretanto, o tratamento térmico mostra-se, geralmente, mais eficiente.

Outra característica da desmagnetização CA é que o processo não altera quimicamente os minerais magnéticos do material, afetando apenas a direção e a intensidade da magnetização remanescente.

\subsubsection{Desmagnetização Térmica}

Neste caso, as amostras são aquecidas a uma certa temperatura em ambiente de campo nulo. Assim, todos os grãos magnéticos com temperaturas de bloqueio menores ou iguais a essa temperatura serão termicamente afetados e seus momentos magnéticos terão orientações aleatórias produzindo uma magnetização 
total nula. Quando a rocha é resfriada à temperatura ambiente somente a parte da MRN que não foi afetada permanece.

Os processos de aquecimento, resfriamento e medida são repetidos para etapas crescentes de temperaturas até atingir a temperatura de Curie $\left(\mathrm{Tc}_{\mathrm{c}}\right)$ dos minerais magnéticos presentes nas rochas. Este procedimento separa componentes de magnetização com diferentes temperaturas de bloqueio.

O laboratório de paleomagnetismo do IAG-USP possui dois desmagnetizadores térmicos: um da Schonstedt, com capacidade para 15 amostras e outro, da "Magnetic Measurements" (MMTD60), com capacidade para sessenta amostras. Os dois desmagnetizadores atingem a temperatura máxima em torno de $760-780^{\circ} \mathrm{C}$.

Um procedimento usual de desmagnetização térmica detalhada consiste em aquecer os espécimes a $100^{\circ} \mathrm{C}$ e, depois, em etapas sucessivas com incrementos de $50^{\circ} \mathrm{C}$ até atingir $500^{\circ} \mathrm{C}$ e, em seguida, com incrementos de $20^{\circ} \mathrm{C}$ até atingir $680^{\circ} \mathrm{C}$. Este detalhamento permite investigar o espectro de temperaturas de bloqueio associado às componentes de magnetização das rochas e ajuda a identificar os portadores magnéticos da amostra (McElhinny, 1973; D'Agrella-Filho,1984). Este procedimento é adequado para rochas que tenham magnetita e hematita como portadores magnéticos. Entretanto, para rochas que contenham minerais com temperaturas de Curie mais baixas como, por exemplo, goetita $\left(\mathrm{TC}=\sim 120^{\circ} \mathrm{C}\right.$ ) e pirrotita $\left(\mathrm{TC}=\sim 250^{\circ} \mathrm{C}\right.$ ) adota-se o procedimento de incrementos de $20^{\circ} \mathrm{C}$, para temperaturas $100^{\circ} \mathrm{C}$ abaixo das respectivas temperaturas de Curie.

Durante a desmagnetização térmica, mede-se também a susceptibilidade magnética das amostras, após cada etapa de aumento de temperatura, para verificar possíveis transformações químicas dos minerais magnéticos na rocha. Para isso, o laboratório de Paleomagnetismo dispõe de dois susceptibilímetros: um da marca Bartington e outro da marca Molspin (MINISEP). Desse modo, qualquer 
variação na susceptibilidade magnética evidencia uma mudança da composição química da rocha (D'Agrella-Filho, 1984).

\subsection{Análise das Componentes de Magnetização}

Após a desmagnetização progressiva das amostras, a estabilidade de uma magnetização remanescente é investigada através de dois tipos de projeções vetoriais: a projeção estereográfica ou de Wulff e a projeção ortogonal ou de Zijdzerveld.

$\mathrm{Na}$ projeção estereográfica as direções de magnetização medidas são consideradas como vetores unitários sobre uma esfera de raio unitário. Projeta-se então o vetor no plano equatorial da esfera, unindo a ponta do vetor ao pólo sul da esfera, no caso de inclinações negativas, ou ao pólo norte da esfera para inclinações positivas (Figura 3.1a). No plano do equador (Figura 3.1b), a declinação do vetor varia de 0 a $360^{\circ}$ e a inclinação varia de $0^{\circ}$ (na borda do círculo) até $90^{\circ}$ (no centro do círculo). Por convenção, inclinações positivas são representadas por símbolos cheios e inclinações negativas por símbolos vazios.

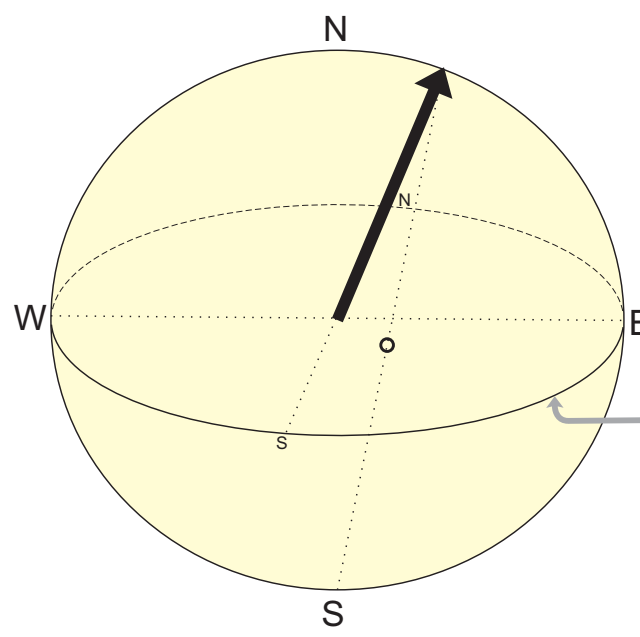

(A)

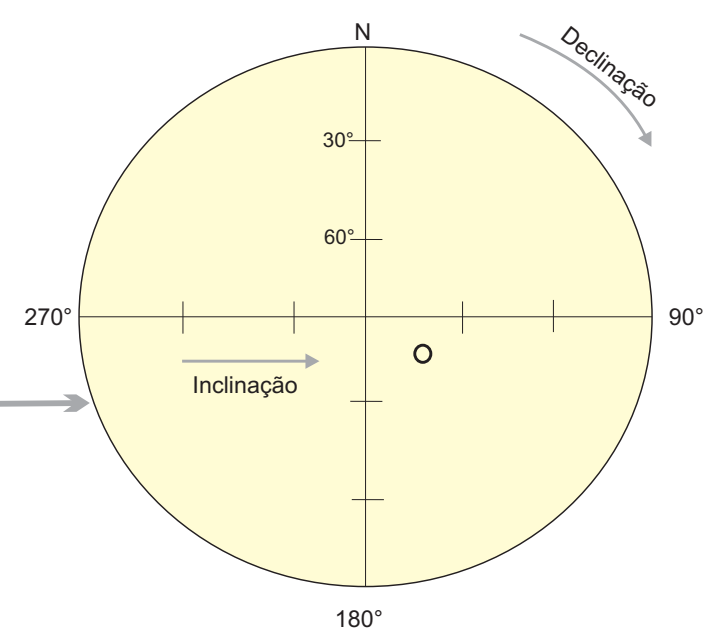

(B)

Figura 3.1: (a) Representação do vetor na esfera e sua projeção no plano equatorial, (b) projeção estereográfica (plano equatorial da esfera) 
Assim, nesta projeção podemos acompanhar a estabilidade direcional após cada etapa do processo de desmagnetização. Entretanto, este método considera somente a direção do vetor de magnetização não apresentando informação sobre sua intensidade (D'Agrella-Filho, 1984). A intensidade de magnetização (geralmente normalizada pela intensidade da NRM) é representada por um gráfico em função do campo alternado ou da temperatura. Este gráfico fornece o espectro de coercividades ou de temperaturas de bloqueio dos minerais magnéticos presentes nas rochas.

O método de projeções ortogonais, desenvolvido por Zijderveld (1967) é considerado mais eficaz na identificação das componentes de magnetização presentes na rocha. Nesta projeção, a ponta do vetor resultante, é projetada nos planos vertical e horizontal do sistema de referência ortogonal. O plano horizontal é então rebatido para o plano vertical ao longo do eixo N-S ou, mais comumente, ao longo do eixo E-W, sendo assim, possível representar as duas projeções no mesmo plano (Figura 3.2). Projeções horizontais são representadas por círculos cheios e projeções verticais por círculos vazios (Lowrie, 1997).

Os componentes da MRN que tem espectros distintos de coercividades ou de temperaturas de bloqueio são visualizados no diagrama de desmagnetização vetorial como retas. Quando os espectros de coercividades ou de temperaturas de bloqueio são parcialmente superpostos, as projeções ortogonais definem uma curva neste intervalo superposto (Figura 3.3c, d). Portanto, este método não permite separar componentes que apresentam espectros de coercividades ou de temperaturas de bloqueio que se superpõem totalmente. 

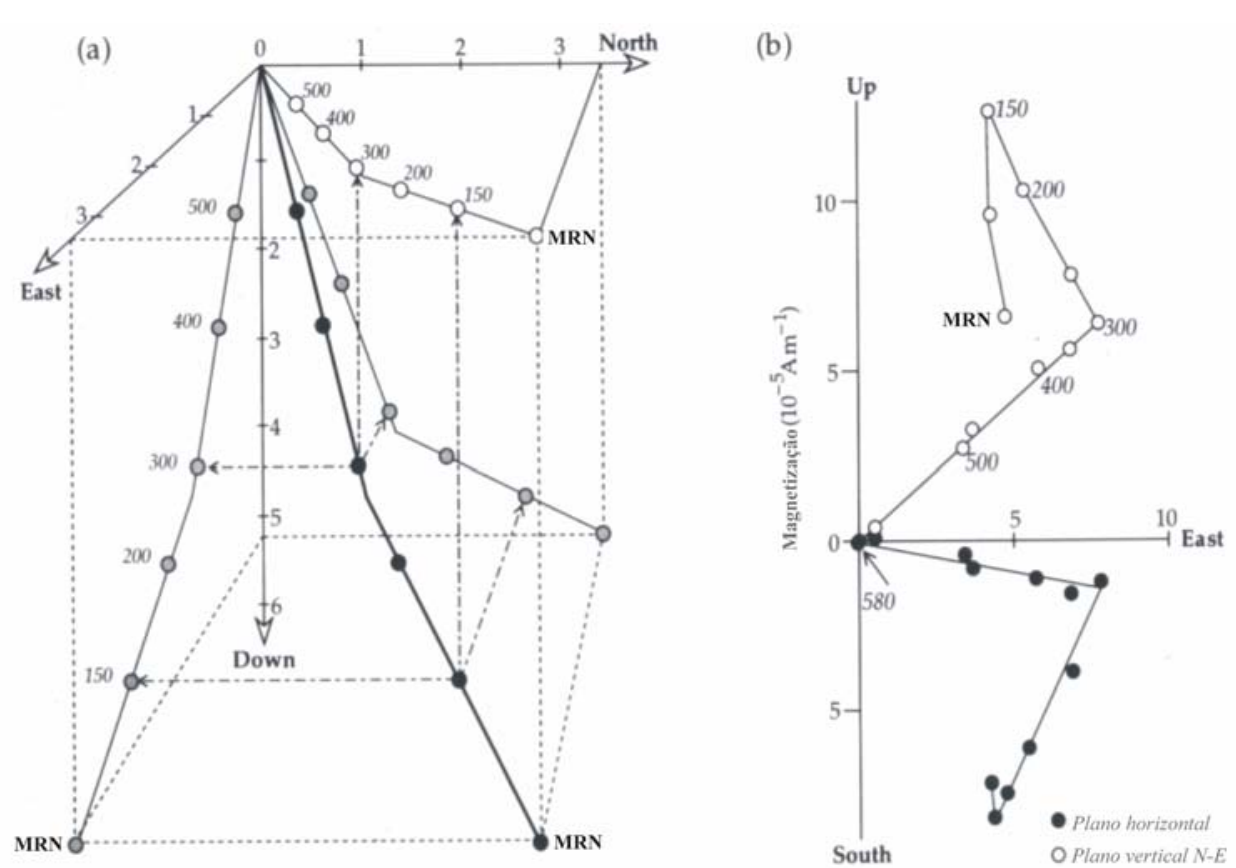

Figura 3.2: (a) Esquema mostrando a projeção da MRN em três planos ortogonais para cada estágio de desmagnetização; (b) projeção de Zijderveld para amostras de calcários (modificada de Lowrie, 1997).

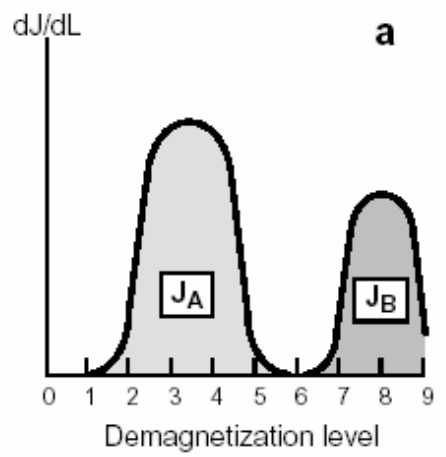

b
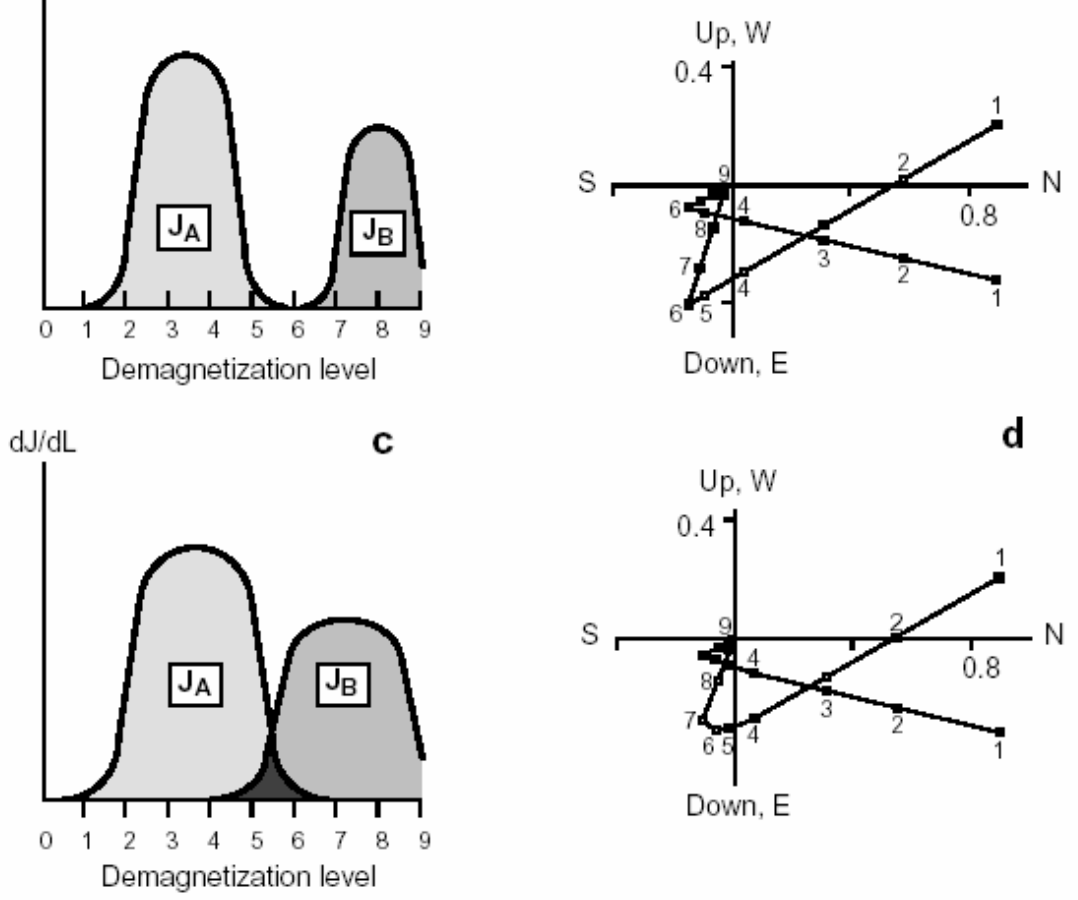

Down, $E$

d

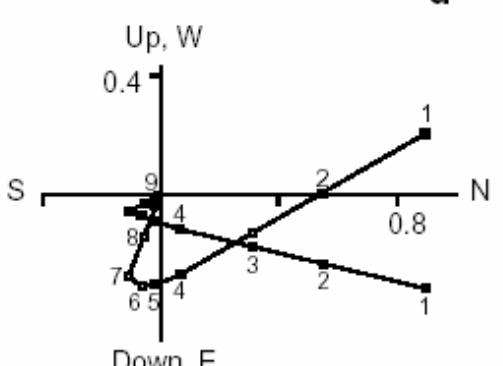

Down, E

Figura 3.3: (a) Espectros de desmagnetização e projeções ortogonais representando duas componentes com espectros distintos $(a, b)$ e com espectros que se sobrepõem parcialmente $(c, d)$, (Butler, 1992). 
Utilizando o método de Zijderveld, Kirschvink (1980) aplicou a técnica de análise dos componentes principais (ACP) para estimar a colinearidade $\mathrm{e}$ coplanariedade dos pontos ao longo da trajetória de desmagnetização do espécime. A direção de magnetização é determinada pelo ajuste por mínimos quadrados. Determina-se a reta que melhor se ajusta aos pontos sucessivos, cuja precisão é estimada pelo desvio angular máximo (mean angular deviation - MAD).

Embora não exista uma regra geral, quando analisamos as direções através da análise dos componentes principais, descartamos o ajuste do componente principal que produz um $\mathrm{MAD} \geq 15^{0}$. Todavia, na literatura costuma-se considerar um $\mathrm{MAD} \leq 10^{\circ}$ como sendo o mais aceitável para os resultados paleomagnéticos (Tauxe, 2002).

\subsection{Estudo da Mineralogia Magnética}

\subsubsection{Identificação dos Minerais "Ferromagnéticos"}

A identificação dos minerais magnéticos portadores das direções de magnetização nas rochas é feita através da análise dos experimentos de desmagnetização, do estudo das propriedades magnéticas da rocha e de observações petrográficas. Este procedimento é importante para os resultados paleomagnéticos, porque quando associados às suas origens, se primárias ou secundárias, estes minerais podem indicar as idades relativas das magnetizações presentes na rocha (D'Agrella-Filho, 1992).

Os minerais magnéticos podem ser identificados através de curvas termomagnéticas que fornecem a temperatura de Curie e/ou de Néel dos mesmos, curvas de aquisição de magnetização remanescente (MRI) e curvas de histerese. 
É importante conhecer as características dos portadores magnéticos dos espécimes, visto que, minerais associados com intemperismo ou metamorfismo, por exemplo, são portadores de uma magnetização secundária, geralmente, de origem química e que, muitas vezes, apresenta estabilidade magnética igual a da magnetização primária (Tarling, 1983).

\subsubsection{Curvas de Histerese}

As curvas de histerese são obtidas através do Magnetômetro de amostra vibrante (VSM) fabricado pela MOLSPIN, instrumento que pertence ao Laboratório de Anisotropias Magnéticas do IGc-USP. Para tais medidas as amostras são transformadas em pó para serem usadas no porta-amostra do equipamento.

O procedimento consiste em medir a magnetização induzida na amostra por um campo magnético que varia até $1000 \mathrm{mT}$, podendo ser revertido para produzir um ciclo de histerese completo. O efeito de histerese ocorre porque a magnetização de um mineral ferromagnético não cai a zero quando o campo magnético externo que foi aplicado é retirado.

Podemos observar o ciclo de histerese na figura 3.4, onde no ponto 0 a magnetização do material e o campo externo são nulos. Quando o campo é aplicado de forma crescente a magnetização $M$ também se eleva; isso faz com que os momentos magnéticos dos grãos se alinhem na direção do campo que está sendo aplicado (ponto 1). Quando o campo atinge um valor crítico para a substância, todos os momentos magnéticos dos grãos estarão alinhados na direção desse campo e a substância atinge o que chamamos de magnetização de saturação (Ms, ponto 2). Se o campo aplicado agora, decresce até um valor nulo, a magnetização não cai para zero, porque alguns grãos permanecem com seus 
momentos magnéticos orientados preferencialmente na direção mais próxima da direção do campo de saturação (ponto 3), indicando que parte da magnetização induzida foi retida pela substância, apresentando o que chamamos de magnetização remanescente de saturação (Mrs). Quando se aplica um campo magnético contrário (reverso), a magnetização volta a ser nula e os momentos magnéticos dos grãos também voltam a ficar orientados aleatoriamente (ponto 4). Chamamos esse campo contrário que é capaz de trazer a magnetização novamente para zero de campo de coercividade ou coercividade (Hc).

Entretanto, nessa fase se o campo reverso for retirado, a substância permanece com uma remanência residual e para reduzi-la realmente a zero é necessário aplicar um campo reverso mais forte (Hcr na Figura 3.4), o qual é denominado de coercividade de remanência. Para maiores detalhes sobre os ciclos de histerese veja Butler (1992), McElhinny \& McFadden (2000), Tarling (1983) e Tauxe (2002). 


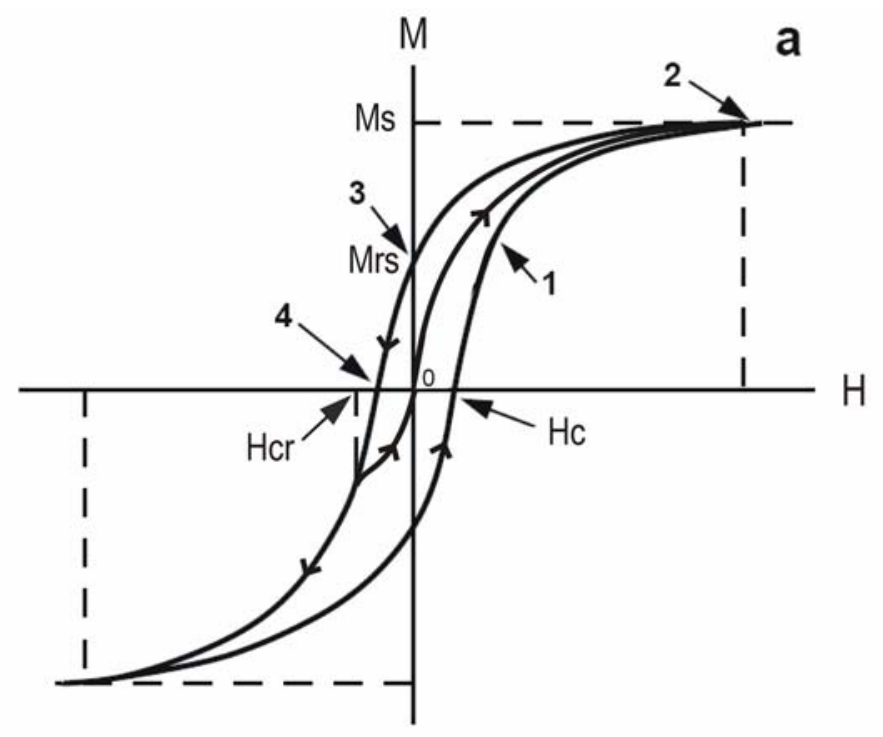

Ponto 1

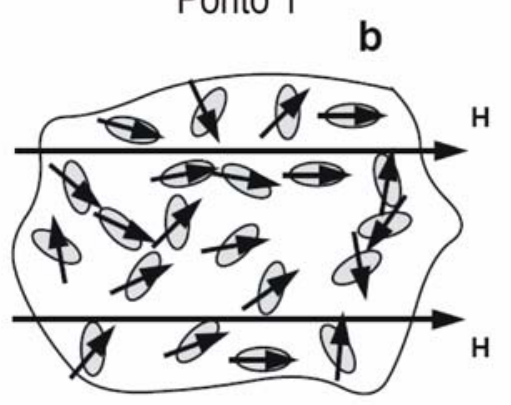

Ponto 2

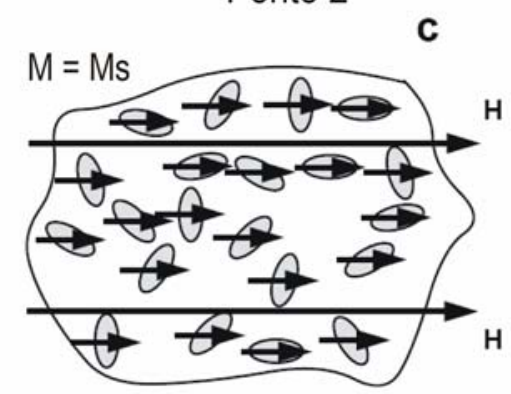

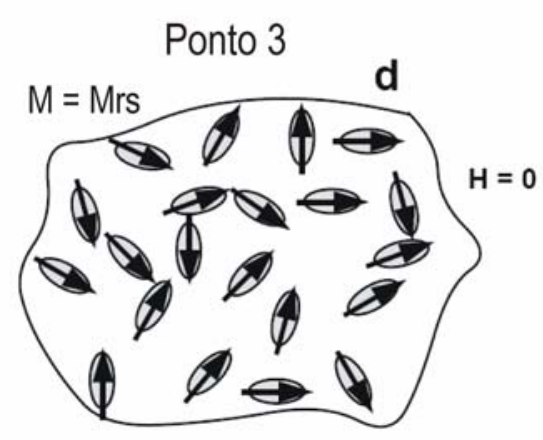

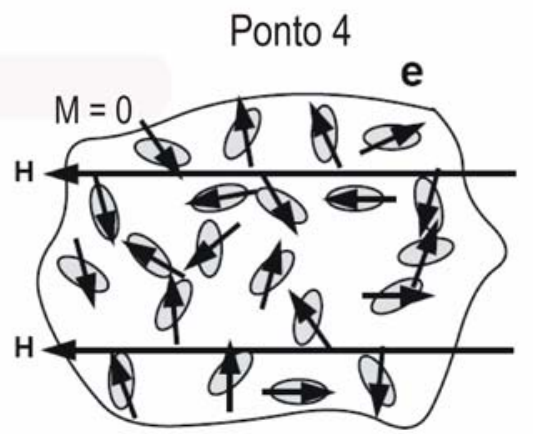

Figura 3.4: Representação de um ciclo de histerese típico de partículas SD: (a) Curva de histere; (b) momentos magnéticos dos grãos começam a se alinhar na direção do campo (ponto 1); (c) ponto de saturação, todos os momentos magnéticos dos grãos totalmente alinhados com o campo aplicado (ponto 2); (d) mesmo após a retirada do campo aplicado, parte da magnetização induzida é retida pela substância (ponto 3), (e) magnetização volta a ser nula, momentos magnéticos dos grãos orientados aleatoriamente (ponto 4). Onde M (magnetização), Ms (magnetização de saturação), Mrs (magnetização remanescente de saturação, H (campo magnético aplicado), Hcr (campo de coercividade de remanescência) e Hc (campo de coercividade). Figura modificada de Butler (1992). 
Entretanto, além de minerais ferromagnéticos, as rochas apresentam minerais paramagnéticos e diamagnéticos, cuja influência nas curvas de histerese dependerá das quantidades relativas destes minerais. Assim, depois de obter a curva de histerese, o componente relativo aos minerais paramagnéticos e diamagnéticos pode ser subtraído, resultando em uma curva de histerese corrigida que evidencia apenas o comportamento dos minerais ferromagnéticos. Com o ciclo de histerese obtemos parâmetros que contribuem para a identificação de minerais magnéticos e para a caracterização dos domínios magnéticos dos minerais.

\subsubsection{Curvas termomagnéticas}

Para a obtenção das curvas termomagnéticas as amostras são transformadas em pó, medindo-se a susceptibilidade magnética em baixo campo em função da temperatura, para cada uma delas. A amostra é aquecida progressivamente até $700^{\circ} \mathrm{C}$ e, logo em seguida, resfriada até a temperatura ambiente.

Dois aparelhos estão disponíveis para a realização das curvas termomagnéticas: um aparato da Bartington (MS2W) pertencente ao laboratório do IAG e um aparato CS-3 acoplado ao instrumento KLY-3 ("KappaBridge"), pertencente ao laboratório de Anisotropias Magnéticas do Instituto de Geociências (IGc). Entretanto, o aparato da Bartington apresenta sensibilidade bem menor, podendo ser utilizado somente para amostras com suscetibilidades altas (rochas máficas). Além disso, o Kappabridge dispõe de um sistema que permite realizar as medidas em atmosfera de Argônio que ajuda a evitar que ocorram processos de oxidação dos minerais presentes na rocha durante o aquecimento. 

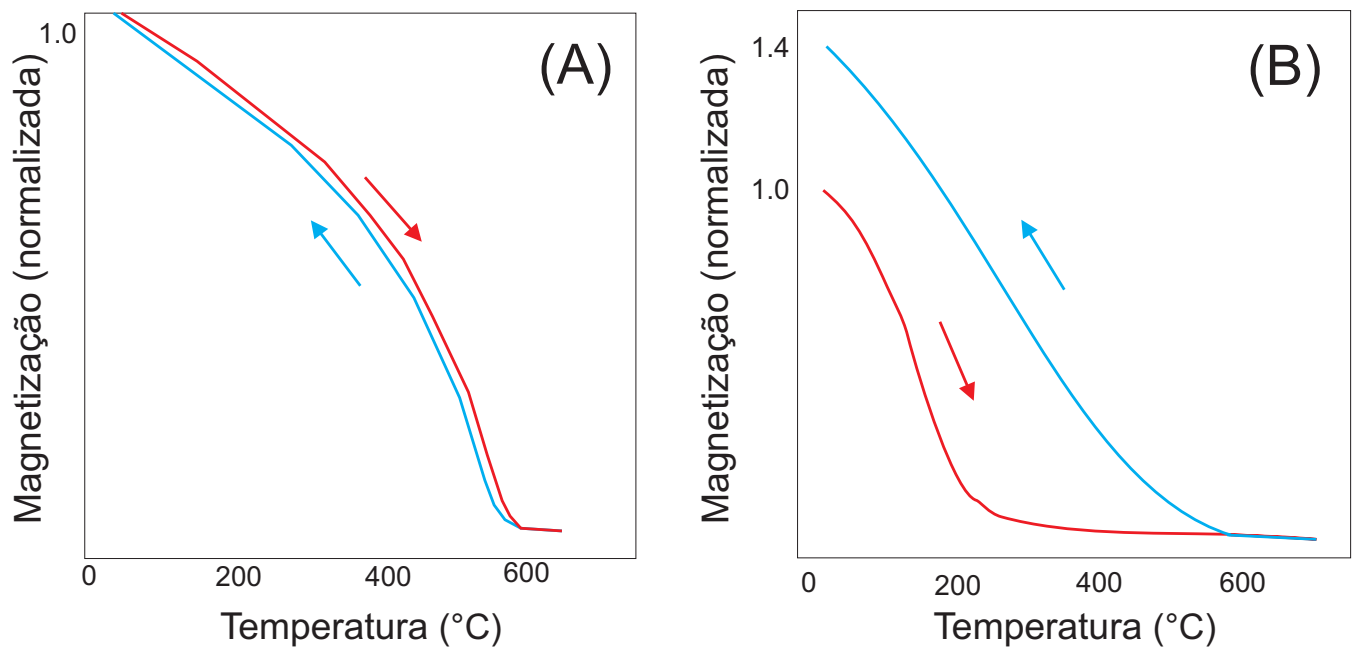

Figura 3.5: Curvas termomagnéticas (a) reversíveis: característica de titanomagnetita pobre em titânio e rica em ferro; (b) irreversíveis: presença de titanomagnetita pouco oxidada formando durante o aquecimento titanomaghemita (Carvallo et al, 2004).

Com as curvas termomagnéticas é possível identificar os minerais magnéticos das rochas através de suas temperaturas de Curie (Tc) indicadas pelos pontos de inflexões nas curvas durante o aquecimento e resfriamento. Se as curvas apresentam a mesma trajetória no aquecimento e no resfriamento, elas são consideradas reversíveis (Figura 3.5a) e indicam que o mineral magnético não sofreu nenhuma transformação durante o ciclo. Por outro lado, se estas apresentam uma trajetória diferente, são consideradas irreversíveis (Figura 3.5b) e indicam que ocorreu uma transformação mineralógica durante o ciclo ou que existe uma combinação complexa de minerais ferromagnéticos, que pode dificultar a interpretação.

\subsubsection{Curvas de Aquisição de Magnetização Remanescente Induzida (MRI)}

A magnetização remanescente induzida (MRI) é obtida quando uma amostra de rocha fica exposta a um campo magnético em uma temperatura 
constante. O laboratório do IAG-USP dispõe do magnetizador de pulso (MMPM10) fabricado pela Magnetic Measurements para a obtenção de curvas de magnetização remanescente induzida (MRI).

O procedimento consiste em induzir uma MRI no espécime através de um campo magnético que aumenta progressivamente em cada etapa. No magnetizador de pulso, o espécime é colocado em um compartimento circundado por bobinas que liberam a energia armazenada em seus capacitores (Robertson \& France, 1994) através de pulsos magnéticos que podem alcançar nas etapas finais até 2,8 T. Esses pulsos provocam o alinhamento parcial dos momentos magnéticos dos grãos do espécime com o campo que está sendo aplicado.

Em seguida, retira-se o espécime do magnetômetro e mede-se a magnetização adquirida (MRI) através do magnetômetro Minispin fabricado pela MOLSPIN. Ao expor o espécime a campos cada vez mais altos, a MRI também aumentará e alcancará um valor máximo denominado magnetização remanescente induzida de saturação (MRIS).

A forma das curvas de aquisição da MRI e o campo necessário para atingir a saturação (MRIS) dependem das coercividades dos grãos magnéticos que a rocha possui (Lowrie, 1997). Assim, esse procedimento fornece informações sobre o tipo de mineral magnético presente na rocha. É importante ressaltar que para realizar este procedimento é necessário que o espécime já tenha sido desmagnetizado por campos alternados.

\subsection{Análise Estatística das Direções}

As direções paleomagnéticas estão sujeitas a um grande número de fatores que levam a dispersão dos dados direcionais. Alguns dos fatores são: 
1. Incerteza na medida causada por ruídos em instrumentos ou erro no posicionamento das amostras no magnetômetro;

2. Incerteza na orientação da amostra no campo;

3. Variações nas direções de magnetização das amostras devido à remoção incompleta (inadequada) de componentes secundárias;

4. Incerteza causada pelos processos de aquisição da magnetização das rochas;

5. A variação secular do campo magnético da Terra.

Diante de tantas incertezas, torna-se necessária uma análise estatística das direções paleomagnéticas de uma coleção de amostras com o objetivo de minimizar essas incertezas, melhorando de forma adequada os resultados dos dados paleomagnéticos.

A estatística utilizada no paleomagnetismo é a desenvolvida por Fisher (1953). Neste método, cada direção é considerada como um vetor unitário, cuja ponta é representada sobre uma esfera de raio unitário. Assim, um conjunto de direções será representado como uma distribuição de pontos sobre a esfera.

Nesta estatística, a melhor estimativa da direção média de uma população de $\mathrm{N}$ vetores unitários é a soma vetorial destes $\mathrm{N}$ vetores, de módulo $\mathrm{R} \leq \mathrm{N}$. Por exemplo, se consideramos cinco direções paleomagnéticas, cada uma representada por um vetor unitário, quando estes são adicionados vetorialmente sua resultante tem comprimento $R \leq 5$. Somente quando todos os vetores são paralelos, a direção média resulta em um vetor cujo módulo R é igual ao número de vetores $\mathrm{N}$ (Butler, 1992).

Fisher (1953) sugere dois parâmetros estatísticos para definir o agrupamento dos pontos e a confiabilidade da direção média obtida.

O parâmetro de precisão $\mathrm{k}$ define a dispersão das direções sobre a esfera. A melhor estimativa para o valor de $\mathrm{k}$ (para $\mathrm{N}>3$ ) é dada pela eq.(3.3): 


$$
K=\frac{N-1}{N-R}
$$

Para valores de $\mathrm{K}$ muito baixos, os pontos tendem a uma distribuição uniforme sobre a esfera. Quando K tende a um número infinito, os pontos estão fortemente agrupados.

Outro parâmetro definido por Fisher (1953) é o limite de confiança de uma determinada direção média. Ele determina a probabilidade de a direção verdadeira estar dentro de um cone em torno da direção média. Para os dados paleomagnéticos, o nível de probabilidade utilizado é de 95\%. Assim, o cone de confiança de $95 \%$ de probabilidade ( $\left.\alpha_{95}\right)$ é dado pelo semi-ângulo do cone em torno da direção média e indica que a direção verdadeira tem $95 \%$ de probabilidade de estar situada dentro deste cone.

No paleomagnetismo, uma aproximação para determinar o semi-ângulo do cone de confiança é dada pela expressão da eq.(3.4):

$$
\alpha_{95}=\frac{140^{\circ}}{\sqrt{k N}}
$$

O valor do limite de confiança $\left(\alpha_{95}\right)$ depende do número de direções $(\mathrm{N})$ e do parâmetro de precisão (K), ou seja, quanto maior o número de direções e maior o parâmetro de precisão (menor dispersão das direções), menor será o valor do limite de confiança $\left(\alpha_{95}\right)$.

\subsection{Testes de Campo da Estabilidade da Magnetização}

O estudo das propriedades magnéticas das rochas e a análise petrográfica podem trazer indícios importantes sobre a origem da magnetização encontrada nas rochas. Entretanto, testes de campo representam o melhor modo de demonstrar a estabilidade da magnetização remanescente ao longo do tempo geológico. Todavia, 
testes de campo nem sempre são possíveis de serem realizados, pois dependem de situações geológicas adequadas.

Os testes de campo geralmente usados são: da dobra, do conglomerado, do contato cozido e o de reversão. O teste de contato cozido é um dos mais importantes e tem sido usado no estudo de intrusões ígneas (Tauxe, 2002).

\subsubsection{Teste do Contato Cozido}

Durante a intrusão do magma, as bordas adjacentes da rocha encaixante são cozidas no contato e durante o resfriamento ela adquire uma magnetização remanescente térmica (MRT). Com isso, o teste verifica se o dique e as bordas adjacentes (contato) possuem a mesma direção de magnetização e se a rocha hospedeira longe do contato possui uma direção distinta da apresentada pela intrusão (figura 3.6). Um teste do contato cozido positivo significa que a intrusão possui uma direção paleomagnética estável desde a formação da rocha indicando uma magnetização remanescente primária (MRP). Entretanto, se a rocha encaixante apresenta a mesma direção da intrusão, significa que o teste de contato é negativo, ou seja, a intrusão e a rocha encaixante sofreram algum tipo de remagnetização.

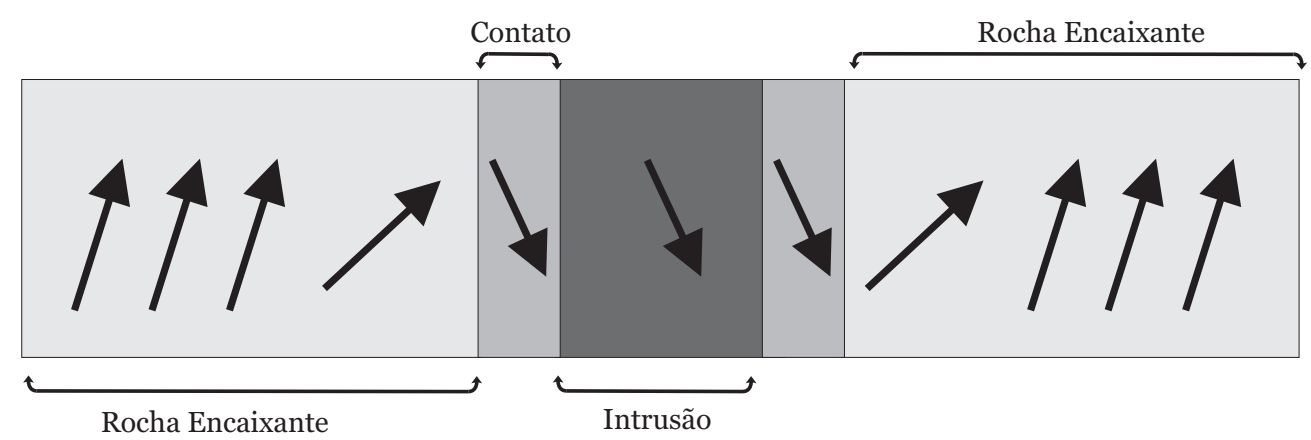

Figura 3.6: Teste de contato positivo indicando um vetor paleomagnético estável. 


\subsubsection{Teste da Reversão}

O teste de reversão geralmente é aplicado quando as amostras coletadas representam um intervalo suficientemente grande do tempo geológico, para que possa ter ocorrido o registro de polaridades normais e reversas do campo geomagnético. Considerando a hipótese do DGA, as direções médias do campo geomagnético durante um intervalo de polaridade normal e reverso, respectivamente, terão uma diferença de $180^{\circ}$ na declinação.

Assim, um teste de reversão "positivo" ocorre quando a média das direções com polaridades normais é (dentro de uma determinada probabilidade; em geral, de 95\%) antiparalela a média das direções de polaridades reversas, indicando que a magnetização remanescente característica está livre de componentes secundárias e que a amostragem dos dados paleomagnéticos eliminou adequadamente a variação secular do campo geomagnético (Lowrie, 1997; Butler, 1992).

\subsection{Pólo Paleomagnético}

A premissa básica do paleomagnetismo é a de que o campo geomagnético, na média, pode ser representado pelo campo de um dipolo geocêntrico axial. Nestas circunstâncias, quando obtemos a direção média de magnetização para um conjunto de sítios amostrados, ela deve representar a direção média do campo geomagnético na época em que as rochas adquiriram suas magnetizações.

Entretanto, cada sítio amostrado (derrame de lavas, dique, nível sedimentar, etc.) pode representar um instante do tempo geológico e assim, o registro magnético estará afetado pela variação secular do campo geomagnético. O pólo geomagnético determinado para cada direção média por sitio é denominado de Pólo Geomagnético Virtual (PGV) (Tauxe, 2002). A média dos PGVs determinados 
para cada sítio amostrado representa o pólo paleomagnético para a formação em estudo e, se a variação do campo geomagnético foi eliminada, ele deve coincidir com o pólo geográfico.

Pela própria simetria do modelo de dipolo geocêntrico axial, a direção de magnetização média apresenta declinação $0^{\circ}$ para o campo atual ou $180^{\circ}$ se considerarmos um campo reverso. A paleolatitude $(\lambda)$ é dada por:

$$
\operatorname{tg} I=2 \operatorname{tg} \lambda
$$

onde, I é a inclinação média (ver Figura 3.7).

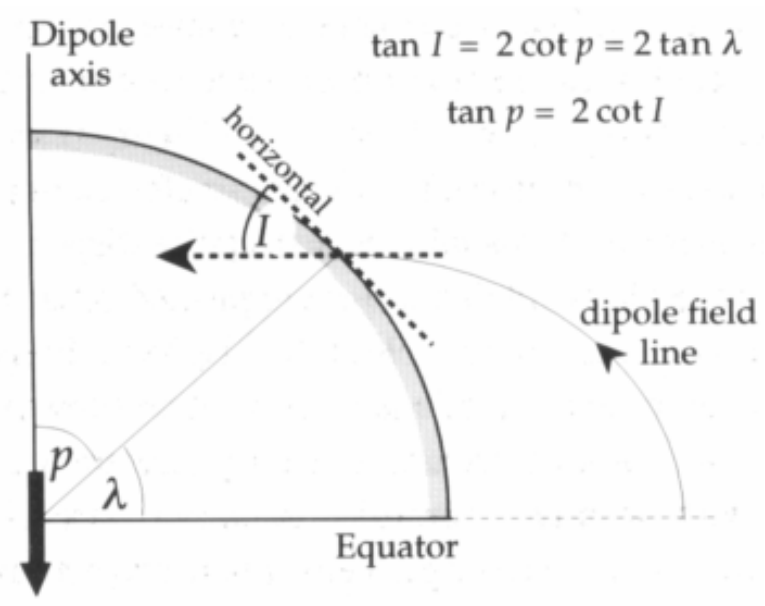

Figura 3.7: A hipótese do dipolo geocêntrico axial prevê a relação $\operatorname{tg} I=2 \operatorname{tg} \lambda$ entre a inclinação I de um campo dipolar e a latitude geográfica $\lambda$; p é a colatitude (Lowrie, 1997).

\subsection{Curva de Deriva Polar Aparente e as Reconstruções Paleogeográficas}

Para rochas com idades mais recentes, os pólos paleomagnéticos estão agrupados próximos ao pólo geográfico. Isso está de acordo com a hipótese do dipolo geocêntrico axial. Quando pólos paleomagnéticos são calculados para rochas mais antigas de um mesmo continente, eles situam-se distantes do pólo geográfico. Se o modelo de dipolo geocêntrico axial é valido para rochas de todas 
as idades e o pólo geográfico não muda no tempo geológico, o que acontece é que os continentes se movem em relação ao pólo.

Assim, pólos paleomagnéticos podem ser usados para determinar a paleogeografia dos continentes no passado. A reconstrução paleogeográfica pode ser feita através da rotação do pólo paleomagnético fazendo-o coincidir com o pólo geográfico, realizando a mesma rotação para o continente. Podemos também determinar a posição antiga do continente através da direção média obtida para a formação em estudo. Nesta reconstrução, a declinação média representa a rotação do corpo em torno do sitio de amostragem e a paleolatitude, determinada através da inclinação média (Eq. 3.5), define a distância do sítio de amostragem ao pólo geográfico (Figura 3.8). É interessante notar que devido à simetria do campo de dipolo geocêntrico axial, a paleolongitude do continente fica indeterminada.

Entretanto, ao invés de fazermos reconstruções continentais, é comum construir a trajetória polar aparente de um continente, através da determinação de pólos paleomagnéticos obtidos de unidades geológicas de diferentes idades. Esse movimento aparente do pólo paleomagnético é o que denominamos de Curva de deriva polar aparente (CDPA). Curvas de deriva polar aparente traçadas para diferentes continentes para um mesmo intervalo de tempo, podem ser usadas para determinar movimentos relativos entre eles. 


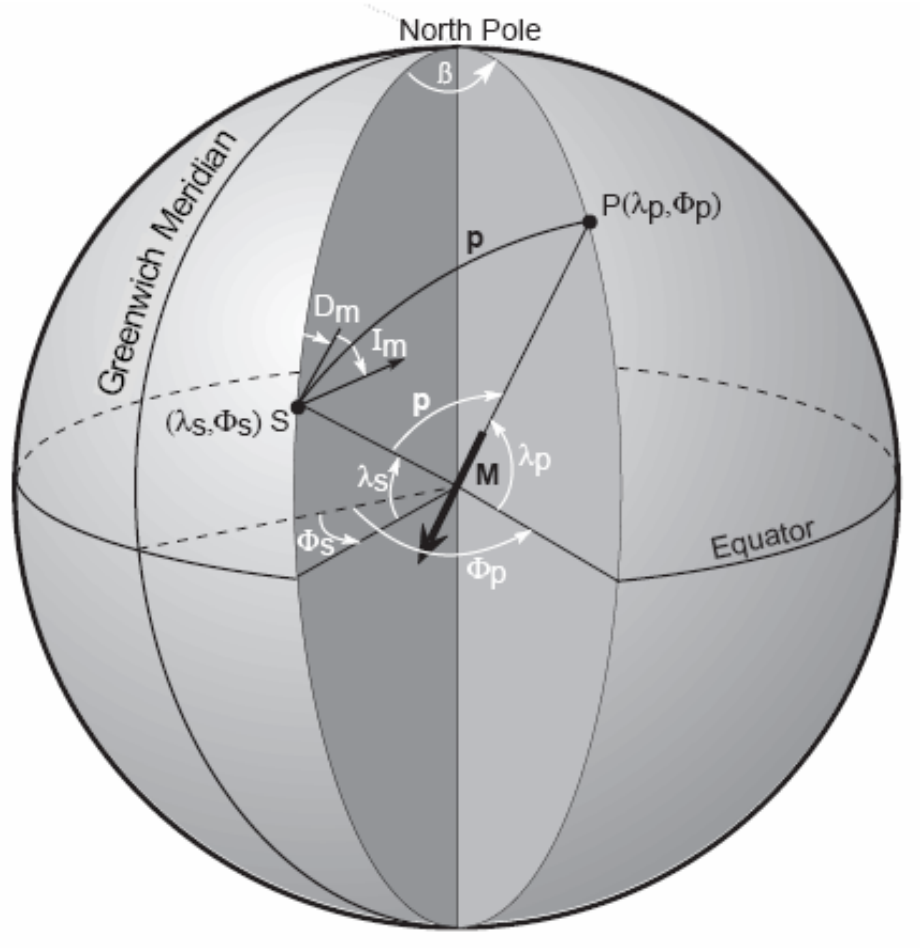

Figura 3.8: Localização do Pólo Paleomagnético $\mathrm{P}\left(\lambda_{P}, \Phi_{P}\right)$ com declinação média ( $\left.\mathrm{D}_{\mathrm{m}}\right)$ e inclinação média $(\mathrm{Im})$ calculada para uma formação geológica. A localização do sítio amostrado é $S\left(\lambda_{S}, \Phi_{S}\right)$, p é a colatitude do sítio amostrado em relação ao pólo paleomagnético (Butler, 1992).

Entretanto, para construir CDPAs para os diversos blocos continentais e, assim, estabelecer a paleogeografia destes diversos fragmentos nas reconstruções continentais, é de fundamental importância que sejam obtidos pólos paleomagnéticos de referência (Buchan et al., 2000).

Com esses pólos podemos traçar CDPAs que identificam trajetórias independentes destes fragmentos. Os pólos do Pré-Cambriano, entretanto, possuem, de modo geral, uma grande incerteza em suas idades e por isso são de baixa qualidade, não permitindo que CDPAs confiáveis sejam construídas (Pesonen et al. 2003). 
Somente com o avanço das análises paleomagnéticas e com determinações geocronológicas mais precisas, através dos métodos U-Pb e ${ }^{40} \mathrm{Ar} /{ }^{39} \mathrm{Ar}$ é que será possível a obtenção de pólos de referência com maior confiabilidade.

Van der Voo (1990) estabeleceu alguns critérios de confiabilidade para qualificar pólos paleomagnéticos. Estes critérios são:

1) A idade da unidade estudada deve apresentar um erro inferior a $\pm 4 \%$, além de demonstrar que esta idade equivale à idade de aquisição da magnetização remanescente;

2) Possuir parâmetros estatísticos satisfatórios: número de amostras $(\mathrm{N})$ superior a 24, parâmetro $\mathrm{K}$ maior que 10,0 e $\alpha_{95}$ inferior a $16^{\circ}$;

3) Apresentar desmagnetização adequada, a qual deve ser demonstrada a partir da subtração de componentes secundárias em diagramas vetoriais ou através de análise por componentes principais;

4) Apresentar testes de campo (testes da dobra, do contato cozido ou do conglomerado) positivos e estatisticamente significativos, que confirmem o caráter primário da magnetização;

5) Apresentar controle estrutural e tectônico coerentes para a unidade estudada;

6) Presença de reversões, indicando um intervalo de tempo significativo durante a aquisição da remanescência;

7) O paleopólo obtido não deve coincidir com a posição de pólos paleomagnéticos mais jovens.

A quantidade de critérios satisfeitos é representada pelo fator $Q$, que possui valor mínimo de zero e máximo de sete, ou seja, $0 \leq \mathrm{Q} \leq 7$. O fator $\mathrm{Q}$ indica a confiabiliadade do pólo. Assim, quanto maior o número de critérios atendidos, mais confiável será o pólo paleomagnético a ser usado na construção de CDPAs e nas reconstruções paleogeográficas. 


\section{Capítulo 4}

\section{RESULTADOS PALEOMAGNÉTICOS}

\subsection{Mineralogia Magnética}

Neste trabalho, o estudo da mineralogia magnética foi realizado com o intuito de identificar os portadores magnéticos responsáveis pela magnetização remanescente (MRN) das amostras, bem como, obter informações sobre a estabilidade magnética das mesmas. Os experimentos realizados para se atingir esses objetivos foram: desmagnetizações por CA e térmicas, curvas termomagnéticas, curvas de histerese e curvas de magnetização remanente induzidas.

Através dos tratamentos por CA e térmico foram identificadas as presenças de alguns minerais magnéticos sugerindo-os como possíveis e principais portadores da magnetização remanescente das amostras, entretanto, esta indicação torna-se mais confiável e coerente com a análise das curvas de histerese, termomagnéticas e de indução.

\subsubsection{Tratamentos térmicos e por Campos Alternados (CA)}

A desmagnetização térmica para a maior parte das rochas máficas mostrou temperaturas de bloqueio entre $550^{\circ} \mathrm{C}$ e $570^{\circ} \mathrm{C}$ que indicam a presença de titanomagnetita pobre em titânio, como sendo o principal portador magnético destas amostras. Como exemplos típicos, podemos citar as amostras dos sítios 6 e 
14 (Figura 4.1b). As amostras destes sítios apresentaram também uma boa estabilidade magnética no tratamento por campos alternados, evidenciando coercividades típicas deste mineral (Figura 4.1a).

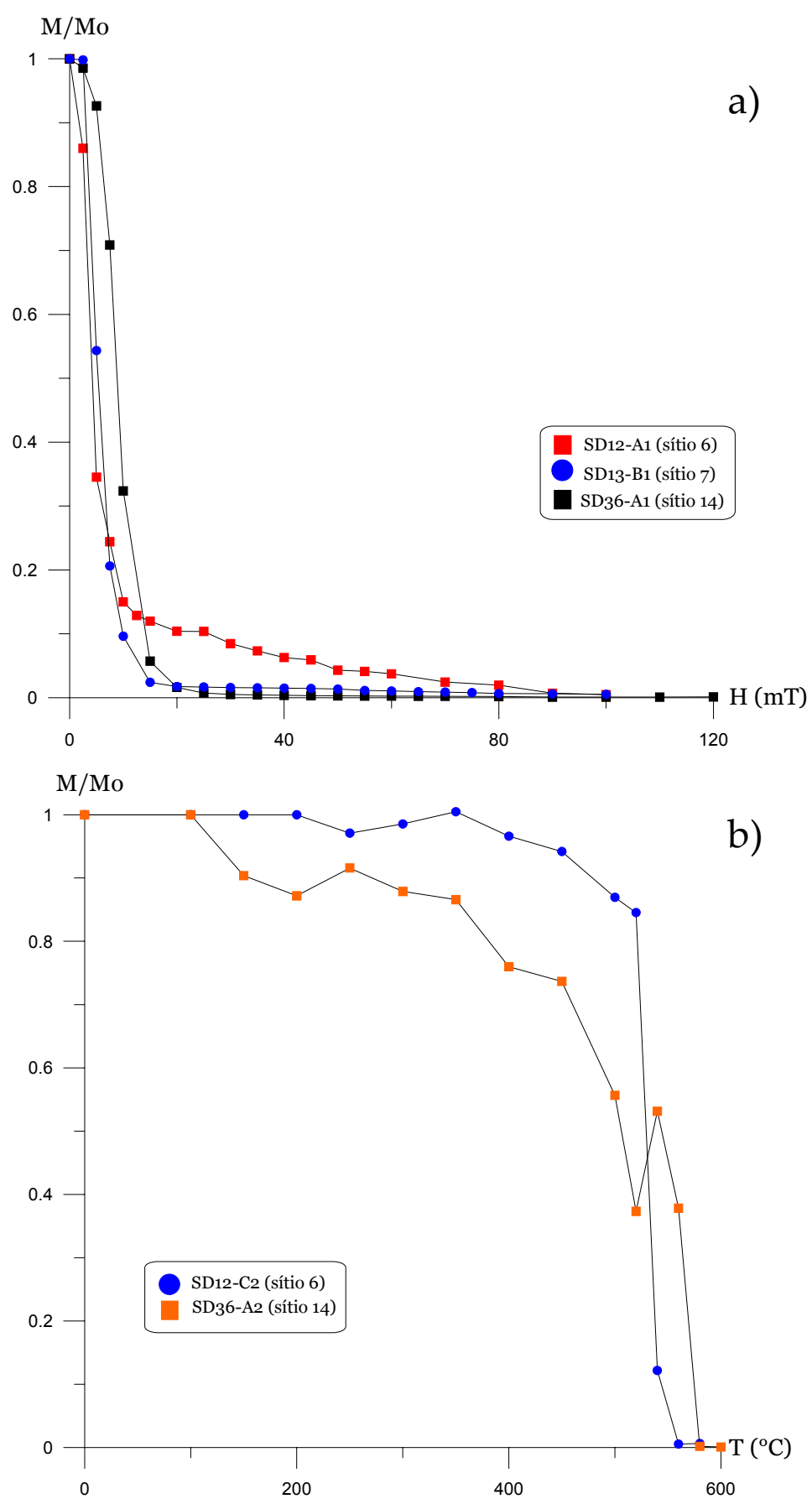

Figura 4.1: Curvas de intensidade de magnetização normalizada em função do campo alternado (a), e em função da temperatura (b).Estas curvas indicam a presença de titanomagnetita pobre em titânio como sendo o principal portador magnético nestas rochas. 
Para amostras pertencentes ao sítio 5 (granodiorito, Tabela 2.1), a desmagnetização por CA (Figura 4.2a) mostra a presença de minerais magnéticos com coercividades relativamente altas, apresentando campos destrutivos médios acima de $80 \mathrm{mT}$. O tratamento térmico, para estas amostras, indica uma queda significativa no valor da intensidade relativa $(\mathrm{M} / \mathrm{Mo})$ da magnetização, após serem desmagnetizadas a $350^{\circ} \mathrm{C}$ e uma pequena queda a temperaturas pouco abaixo de $580^{\circ} \mathrm{C}$ (Figura $4.2 \mathrm{~b}$ ). Estas curvas sugerem a maghemita como sendo o principal portador magnético, com a possibilidade de uma pequena porcentagem de titanomagnetita pobre em titânio estar também presente nestas rochas. Curvas termomagnéticas apresentadas mais adiante comprovam a presença destes minerais.
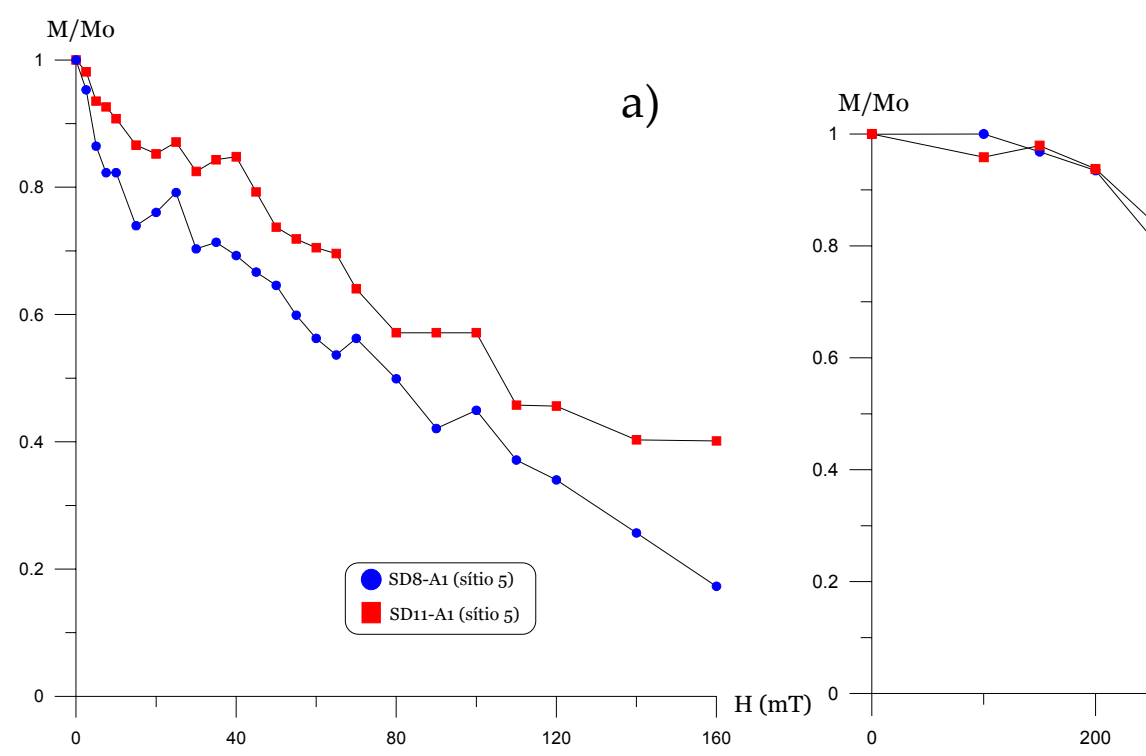

b)

Figura 4.2: Gráficos de intensidade de magnetização normalizadas em função do campo alternado (a); em função da temperatura (b). Estas curvas evidenciam a presença da maghemita e da titanomagnetita pobre em titânio como os principais portadores magnéticos presentes nestas rochas.

As curvas de desmagnetização por campos alternados e térmica para os espécimes dos sítios 9 e 10, representados por rochas ácidas, mostram a presença 
de minerais magnéticos com coercividades altas e temperaturas de bloqueio altas, bem próximas da temperatura de Curie da hematita $\left(680^{\circ} \mathrm{C}\right)$, indicando este mineral como sendo o principal portador magnético presente nestas rochas (Figura 4.3). Porém, percebemos que em alguns espécimes, a MRN apresenta a contribuição de outro mineral magnético, nesse caso, pouco dominante, que apresenta temperaturas de bloqueio inferiores a $580^{\circ} \mathrm{C}$, sugerindo também a presença de magnetita (veja exemplos das amostras SD18-B2, SD16-A2 e SD17-B2 na figura $4.3 \mathrm{~b})$.

Embora este comportamento típico tenha sido encontrado para a maior parte das rochas ácidas, as amostras pertencentes aos sítios 3 e 12 apresentaram coercividades baixas durante o tratamento por CA (Figura 4.4), sugerindo um predomínio de titanomagnetitas pobres em titânio, como sendo o principal portador magnético destas rochas.
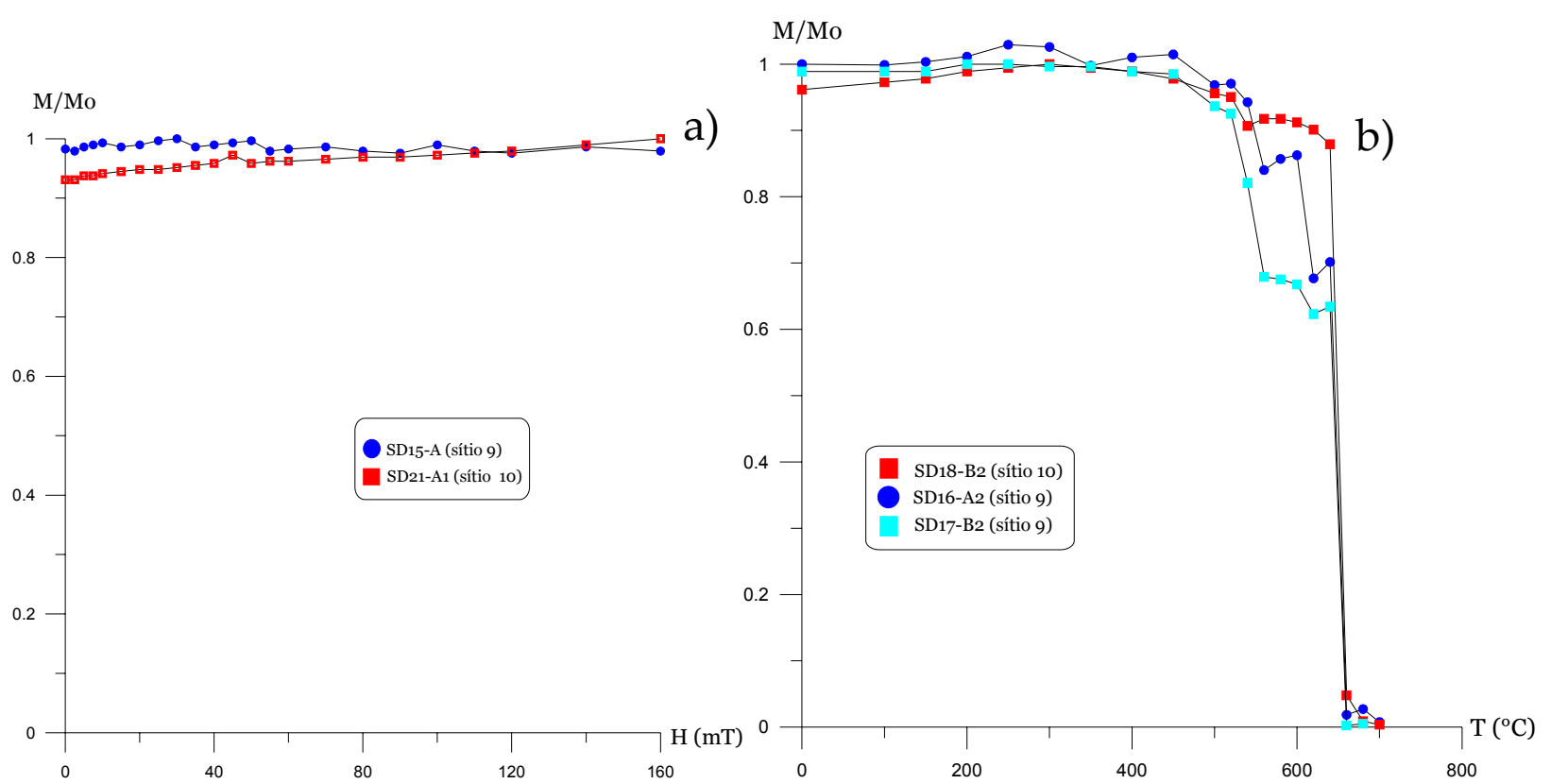

Figura 4.3: Gráficos de intensidade de magnetização em função do campo alternado (a), evidenciando a alta coercividade dos minerais magnéticos; e em função da temperatura (b), demonstrando a presença de hematita e magnetita como os principais portadores magnéticos. 


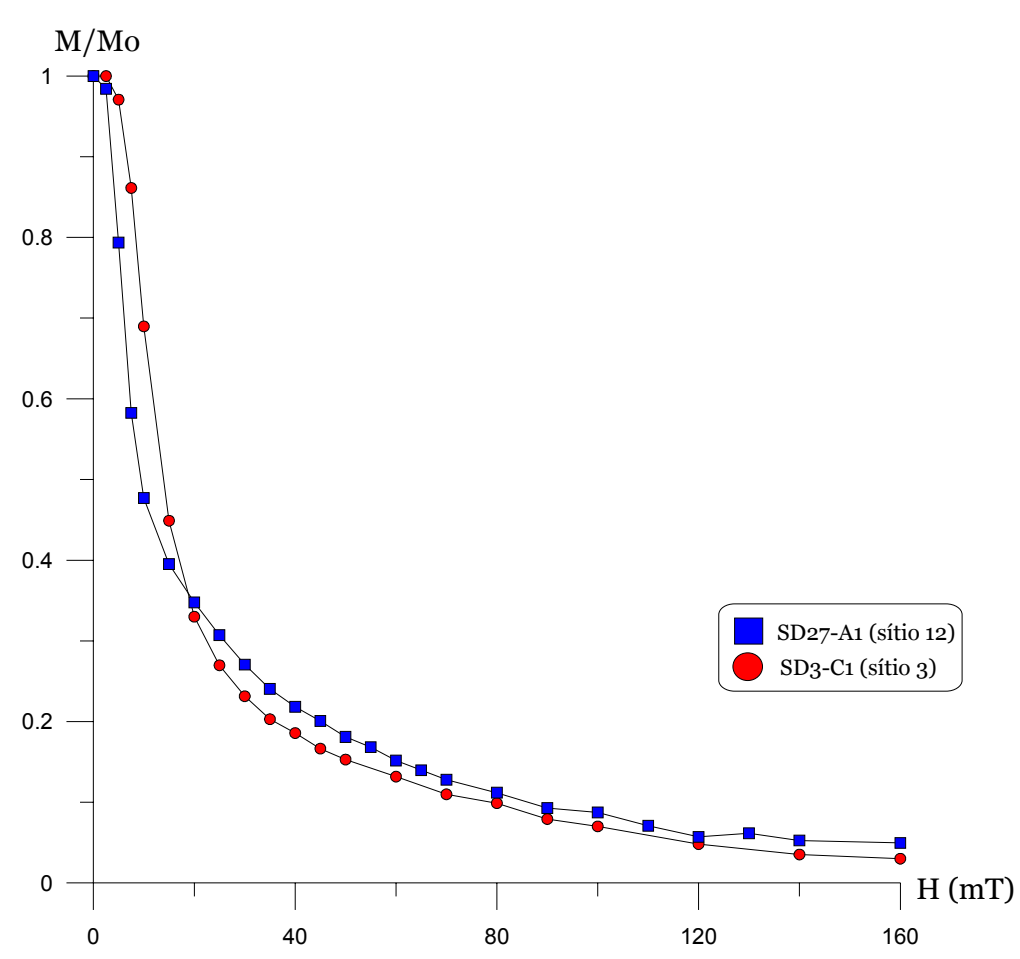

Figura 4.4: Gráfico de intensidade de magnetização normalizada em função do campo alternado, mostrando a baixa coercividade apresentada por espécimes de rocha ácida do sítio 3 e 12.

\subsubsection{Histerese Magnética}

Curvas de histereses para algumas amostras são apresentadas nas figuras 4.5 e 4.6. Os parâmetros obtidos das curvas de histerese, a coercividade volumétrica (Hc), a coercividade de remanescência (Hcr), a magnetização de saturação (Ms) e a magnetização remanescente de saturação (Mrs) são apresentados na tabela 4.1, juntamente com as razões Mrs/Ms e Hcr/Hc. Estes parâmetros foram calculados depois da correção da contribuição paramagnética, considerando-se que as amostras alcançaram a saturação em $1 \mathrm{~T}$, capacidade máxima do aparato VSM.

Com as razões Mrs/Ms e Hcr/Hc construiu-se o gráfico de Day (figura 4.7) através do qual, obtem-se informações sobre a estrutura de domínio magnético das amostras, visto que as razões possuem valores característicos para grãos de 
domínio simples (DS), pseudo-domínio simples (PDS) e multidomínio (MD) (Day et al., 1977).

Tabela 4.1: Valores dos parâmetros obtidos das curvas de histerese, bem como, as razões Mrs/Ms e Hcr/Hc.

\begin{tabular}{|cccccccc|}
\hline Amostra & Mrs & Ms & Hcr & Hc & Hcr/Hc & Mrs/Ms & Domínio \\
SD1-D1 & 16.02 & 263.13 & 27.4 & 6 & 4.56667 & 0.06088 & \\
SD2-C & 20.4 & 272.37 & 27.07 & 7.06 & 3.83428 & 0.0749 & PSD \\
SD3-C1 & 1.19 & 23.24 & 44.7 & 4.44 & 10.0676 & 0.0512 & MD \\
SD7-F3 & 97.97 & 504.81 & 32.88 & 15.36 & 2.14063 & 0.19407 & PDS \\
SD8-A & 2.25 & 7.65 & 35.46 & 21.12 & 1.67898 & 0.29412 & PDS \\
SD10-C & 1.53 & 5.92 & 36.48 & 19.92 & 1.83133 & 0.25845 & PDS \\
SD12-D1 & 21.83 & 579.47 & 22.71 & 3.26 & 6.96626 & 0.03767 & MD \\
SD13-J & 95.29 & 1124.14 & 25.83 & 7.18 & 3.59749 & 0.08477 & PDS \\
SD14-B1 & 77.44 & 1265.83 & 18.31 & 5.02 & 3.64741 & 0.06118 & PDS \\
SD16-A & 0.66 & & 487.1 & 192.56 & 2.5296 & & \\
SD20-A & 0.69 & & 420 & 82.96 & 5.06268 & & \\
SD24-B1 & 0.47 & & 62.09 & 11.51 & 5.39444 & & \\
SD27-C2 & 0.23 & 1.28 & 42.14 & 15.73 & 2.67896 & 0.17969 & PDS \\
SD28-C1 & 0.25 & 1.37 & 40.83 & 9.86 & 4.14097 & 0.18248 & \\
SD33-C4 & 0.43 & 4.56 & 48.17 & 9.7 & 4.96598 & 0.0943 & \\
SD34-E1 & 233.89 & 1911.99 & 27.22 & 10.76 & 2.52974 & 0.12233 & PDS \\
SD35-B1 & 110.54 & 833.14 & 22.2 & 10 & 2.22 & 0.13268 & PDS \\
SD37-A1 & 95.76 & 1122.64 & 18.68 & 6.93 & 2.69553 & 0.0853 & PDS \\
SD38-B1 & 103.21 & 1213.28 & 19.1 & 7.12 & 2.68258 & 0.08507 & PDS \\
SD39-E1 & 63.37 & 435.99 & 22.99 & 11.31 & 2.03271 & 0.14535 & PDS \\
SD40-C1 & 108.39 & 1117.93 & 21.69 & 8.24 & 2.63228 & 0.09696 & PDS \\
& & & & & & & \\
\hline
\end{tabular}

Mrs=magnetização remanente de saturação, Ms=magnetização de saturação, Hcr=coercividade remanescência e Hc= coercividade volumétrica.

A figuras 4.5 mostra exemplos típicos de curvas de histerese obtidas para as rochas ácidas. Observe que o espécime SD3-C1 (Figura 4.5a), com coercividade de $4.44 \mathrm{mT}$ apresenta uma curva de histerese do tipo cintura fina (narrow-waisted), típica de grãos de magnetita de baixa coercividade, como sugerido pelo tratamento 
por CA (Figura 4.4). Os grãos magnéticos desta amostra apresentam estruturas de multi-domínio (MD), de acordo com a tabela 4.1 e a figura 4.7. O espécime SD28C1 (Figura 4.5d), entretanto, apresenta uma coercividade um pouco maior que o exemplo anterior $(\mathrm{Hc}=9,86 \mathrm{mT})$ e mostra uma curva de histerese do tipo cintura de vespa (wasp-waisted) que é resultante da presença de pelo menos duas fases magnéticas com coercividades distintas.
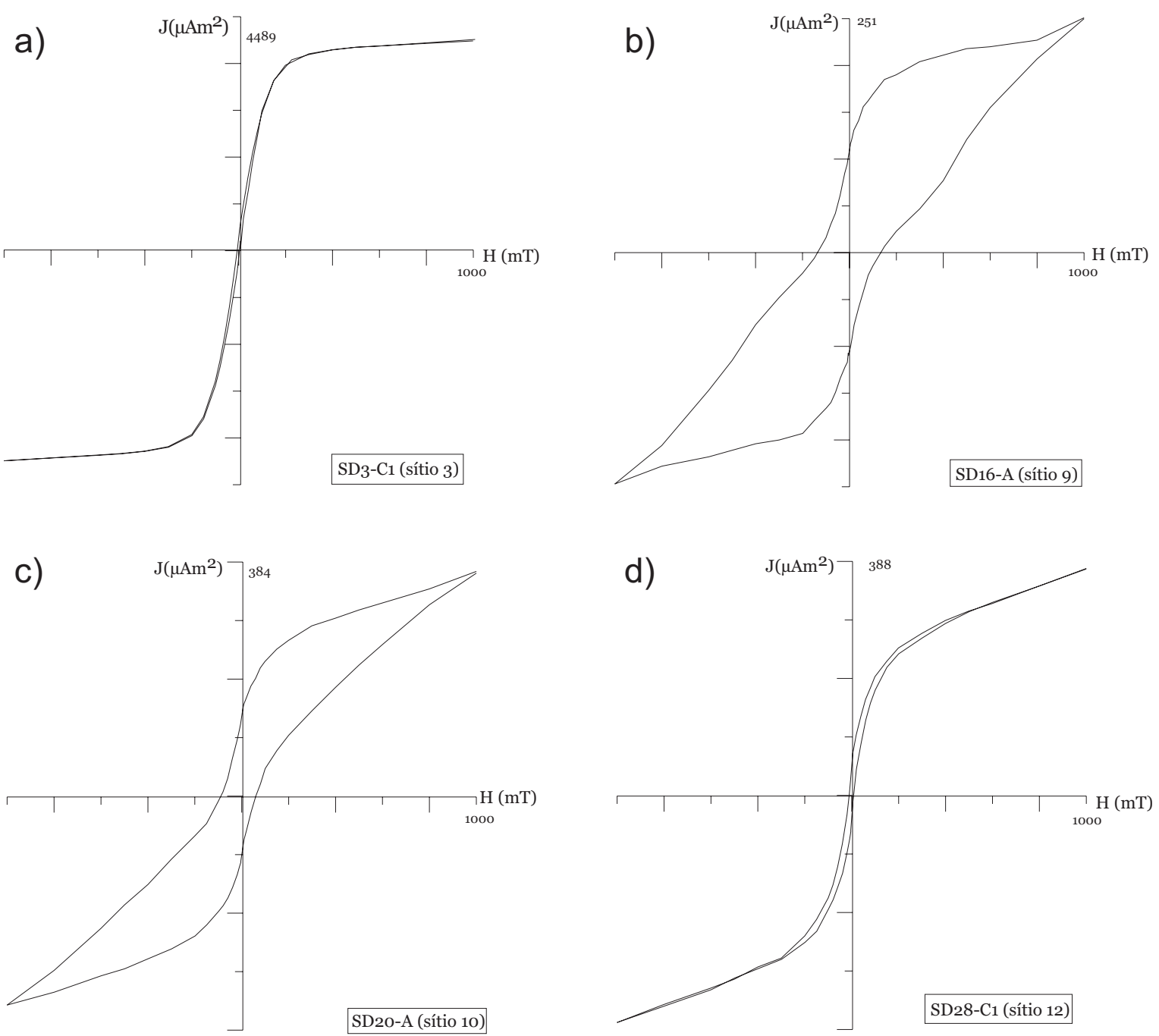

Figura 4.5: Curvas de histerese para as amostras de rochas ácidas analisadas. 
Por outro lado, as figuras $4.5 \mathrm{~b}$ e $4.5 \mathrm{c}$ mostram curvas de histerese obtidas para a maior parte das rochas ácidas, as quais são do tipo cintura de vespa bem definidas, sendo que, nenhuma destas amostras atingiu a saturação quando sujeitas ao campo de 1 Tesla. Este comportamento sugere a presença de uma mistura de dois minerais magnéticos representados por fases ferromagnéticas de diferentes coercividades, uma fração de alta coercividade e outra de baixa coercividade. Como sugerido pelas desmagnetizações térmicas e por CA (Figura 4.3), estes minerais são, provavelmente, a magnetita e a hematita, estando este último mineral presente em maior quantidade. Como não é possível calcular para estas amostras a magnetização de saturação e, conseqüentemente, a razão Mrs/Ms, estas não foram incluídas no diagrama de Day.

A figura 4.6 mostra exemplos típicos de curvas de histerese obtidas para as amostras SD7-F3, SD14-B1 e SD39-E1 as quais representam rochas máficas. Estas apresentam curvas de histerese do tipo cintura estreita, indicando coercividades baixas (15,36 mT, 5,02 $\mathrm{mT}$ e 11,31 $\mathrm{mT}$, respectivamente) e magnetização de saturação (Ms) em torno de $300 \mathrm{mT}$, que caracterizam o comportamento magnético do mineral titanomagnetita. A figura 4.7 mostra que estas amostras localizam-se no campo de estrutura de pseudo-domínio simples (PSD), como é o caso da maior parte das rochas máficas estudadas, o que é coerente com a boa estabilidade encontrada durante os tratamentos por CA e térmico efetuados para estas amostras.

A curva de histerese (Figura 4.6b) obtida para o espécime SD8-A (granodiorito, sítio 5) indica a presença de um mineral com coercividade um pouco mais alta $(\mathrm{Hc}=21,12 \mathrm{mT})$, o qual pode ser representado pela maghemita, como sugerido pelos tratamentos por CA e térmico (Figura 4.2). Esta curva revela também uma contribuição de mais de $50 \%$ de minerais paramagnéticos. 
No diagrama de Day alguns espécimes analisados entre os máficos e os ácidos estão fora dos intervalos PSD e MD (Figura 4.7), podendo ser resultado de uma mistura de magnetita grãos SD estáveis e grãos finos superparamagnéticos (SP) com tamanhos entre 9 a 12 nm (Dunlop, 2002a, b).

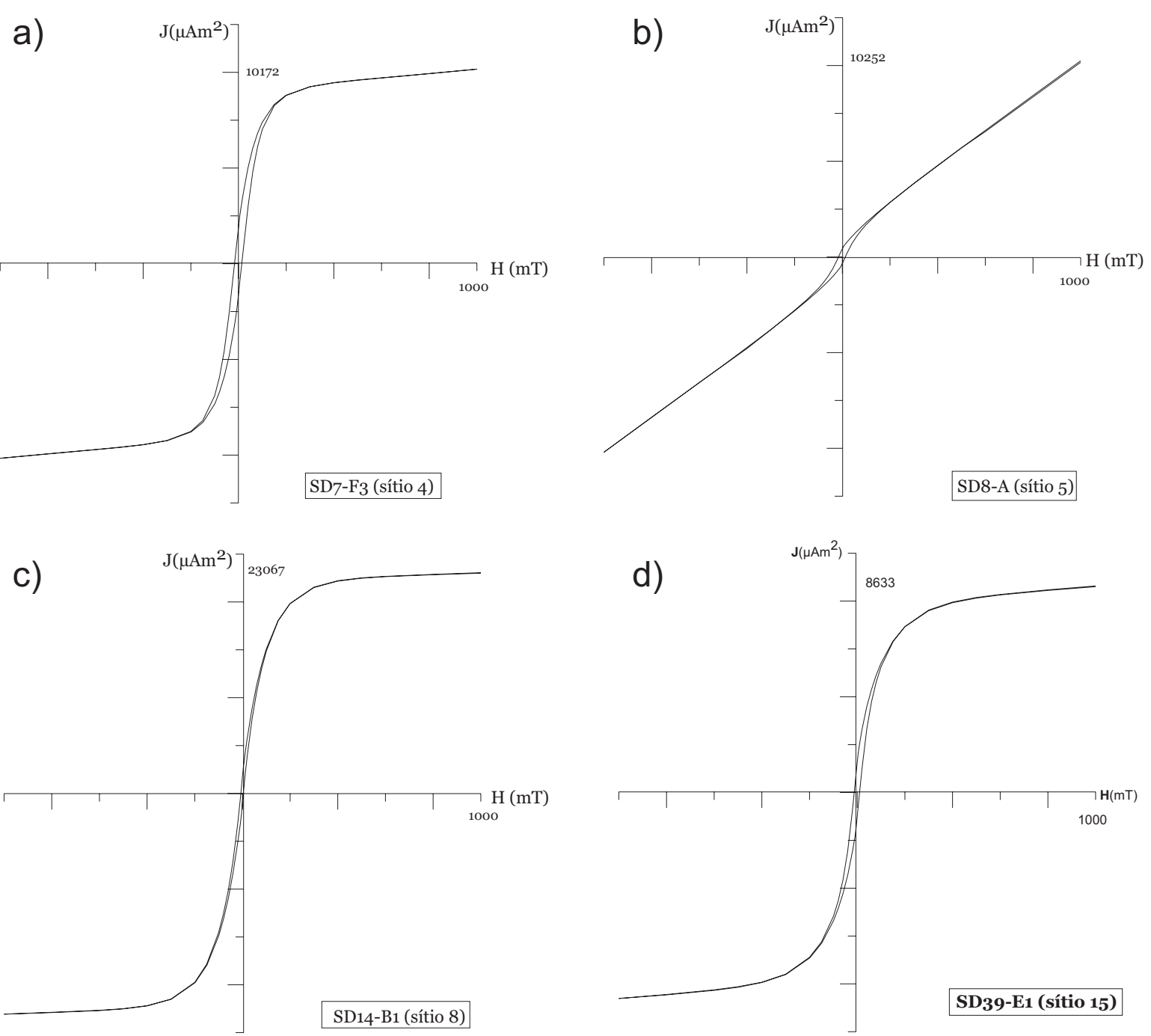

Figura 4.6: Curvas de histerese para as amostras de rochas máficas analisadas. 


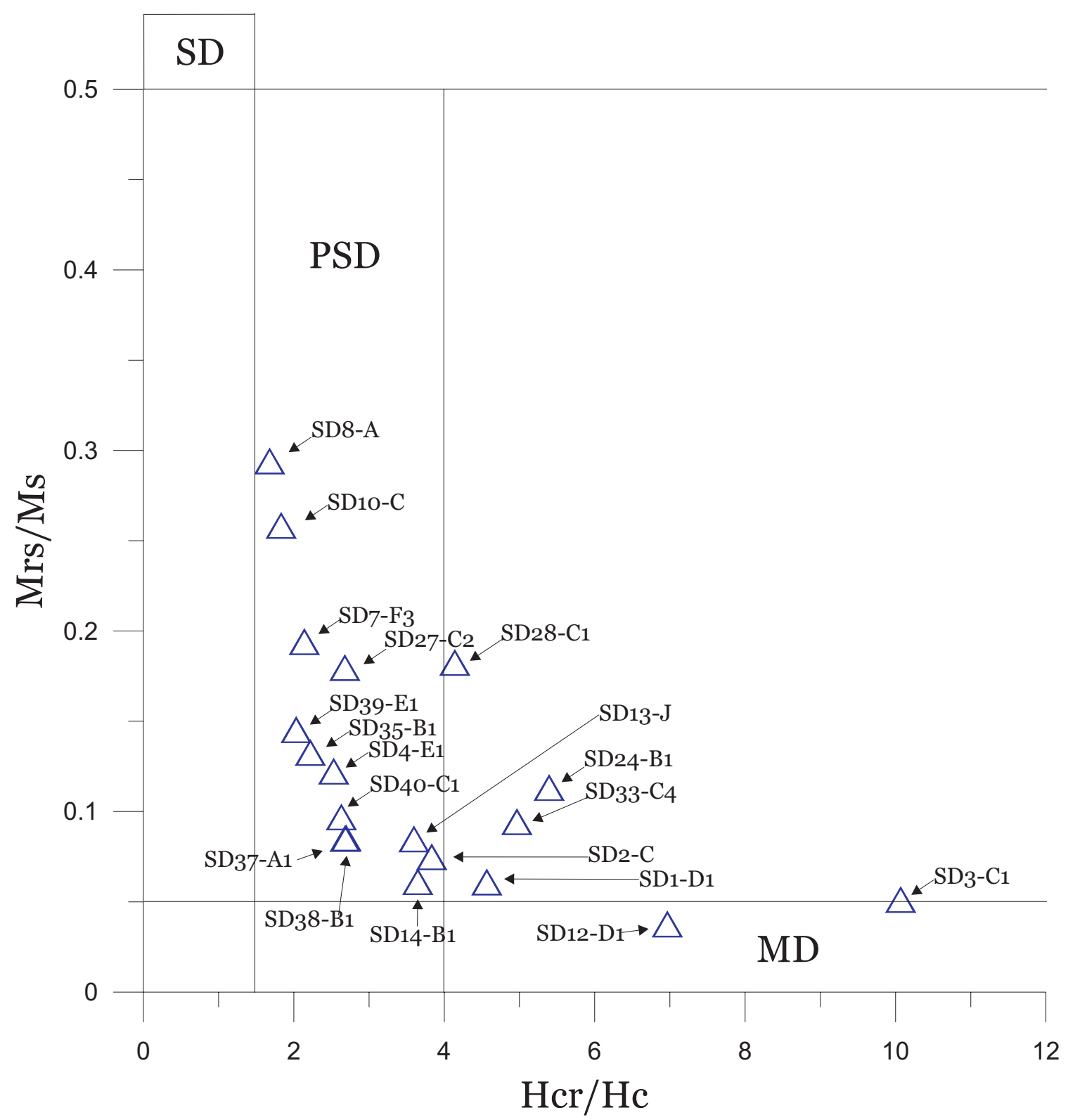

Figura 4.7: Diagrama de Day (1977) indicando a estrutura de domínios magnéticos das amostras analisadas.

\subsubsection{Curvas Termomagnéticas}

Curvas termomagnéticas foram obtidas para rochas máficas utilizando-se o aparelho da Bartington (MS2W). Para as rochas ácidas utilizou-se um aparato CS-3 
acoplado ao instrumento KLY-3 ("KappaBridge”) (Seção 3.4.3), devido a maior sensibilidade deste aparelho para medidas de suscetibilidades muito baixas.

As curvas de aquecimento e resfriamento obtidas nesse estudo termomagnético revelaram em algumas amostras, mudanças mineralógicas que ocorreram como resultado do ciclo térmico que as amostras foram submetidas.

Curvas termomagnéticas obtidas para as rochas ácidas mostram comportamento irreversível caracterizadas por trajetórias diferentes no aquecimento e no resfriamento (vide exemplos na Figura 4.8). O restante pode ser considerado como curvas reversíveis (Figura 4.9), com temperaturas de Curie próximas de $580^{\circ} \mathrm{C}$ e a presença, em muitas delas, do pico de Hopkinson. Estas curvas são típicas de grãos SD/PSD de titanomagnetitas pobres em Ti termicamente estáveis (Dunlop e Ozdemir, 1997), o que concorda com a indicação de estrutura PSD para as rochas máficas, fornecidas pelo diagrama de Day (Figura $4.7)$.

Com relação às rochas ácidas, a curva termomagnética obtida para a amostras SD3-C1 do sítio 3 (Figura 4.8a) apresenta uma queda em torno de $580^{\circ} \mathrm{C}$, confirmando a presença de magnetita nas amostras deste sítio.

A presença de hematita nas rochas ácidas, bem evidente nos experimentos de desmagnetização por CA e térmico e nas curvas de histerese, não é observada nas curvas termomagnéticas, provavelmente, em decorrência da susceptibilidade muito baixa deste mineral. Outra característica das amostras analisadas é um aumento na intensidade da susceptibilidade dos espécimes durante os processos de aquecimento e resfriamento indicando a formação de magnetita ( $\mathrm{Tc}_{\mathrm{c}} \sim 580^{\circ} \mathrm{C}$ ) como conseqüência de alterações de minerais pré-existentes (Figura 4.8).

A figura 4.9a mostra a curva termomagnética obtida para a amostra SD8-C1 pertencente ao sítio 5 (granodiorito). Apesar da suscetibilidade baixa associada a esta rocha máfica, a curva mostra uma pequena queda na suscetibilidade em 
temperaturas próximas de $580^{\circ} \mathrm{C}$, indicando a presença, embora pequena, de titanomagnetita nesta rocha, como já sugerido pelas curvas de intensidades relativas obtidas no tratamento térmico, apresentadas anteriormente (Figura 4.2). A curva termomagnética mostra também uma queda mais acentuada em temperaturas próximas de $350^{\circ} \mathrm{C}$, sendo que este mineral não aparece mais durante o resfriamento. Este comportamento é típico da maghemita, que é metaestável e se transforma em hematita em temperaturas próximas de $350^{\circ} \mathrm{C}$ (Dunlop e Özdemir, 1997).

a)

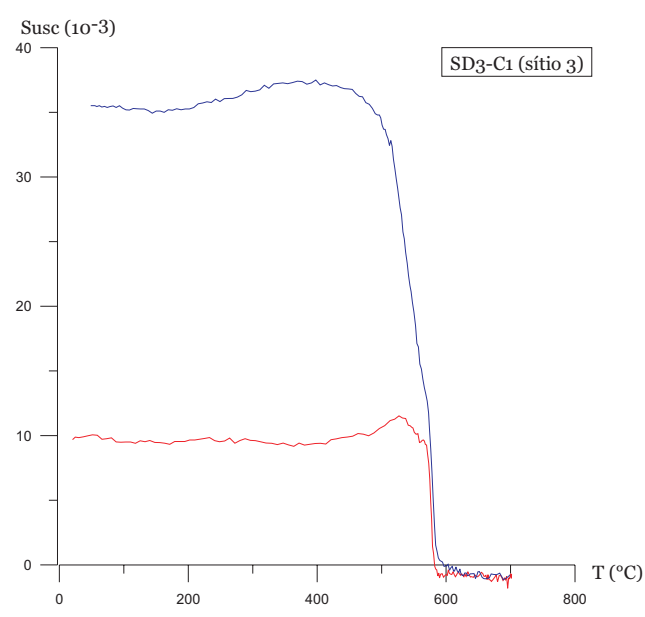

c)

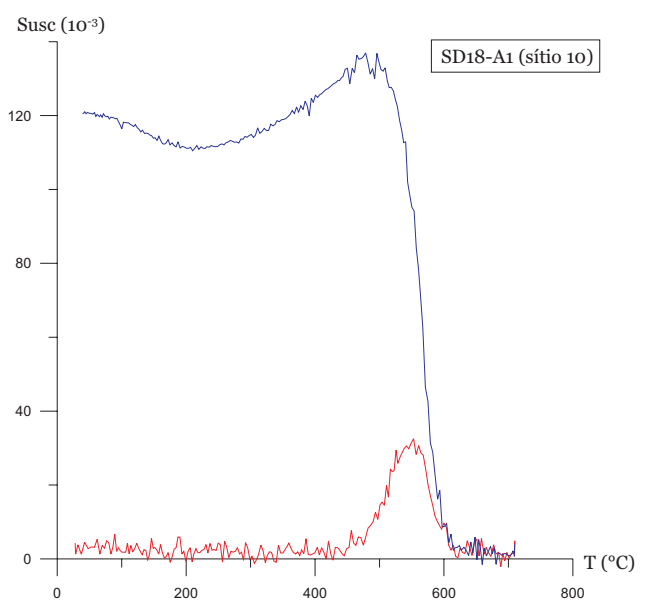

b)

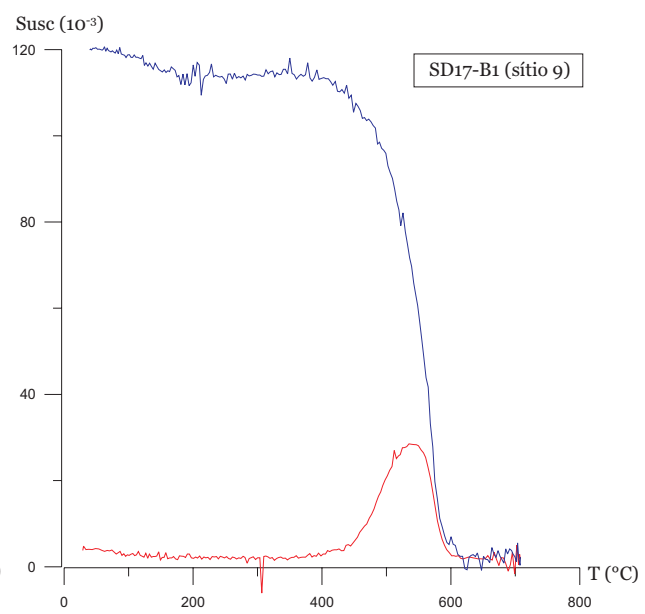

d)

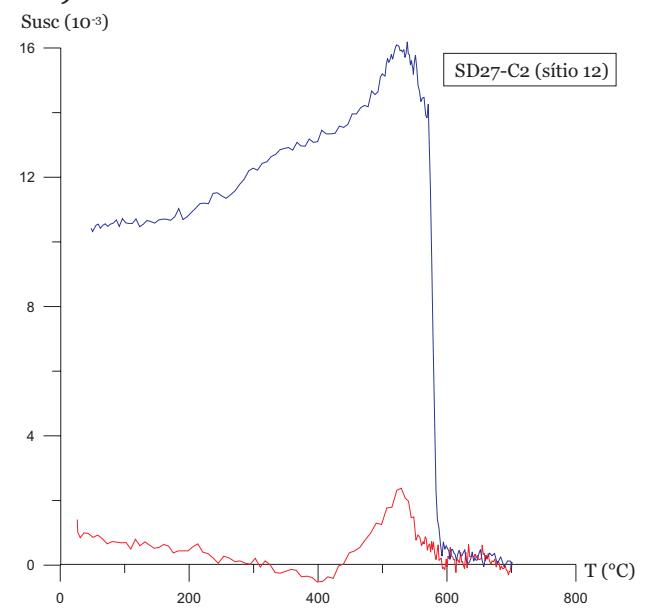

Figura 4.8: Curvas termomagnéticas para os espécimes de rochas ácidas analisados. As cores vermelhas e azuis indicam aquecimento e resfriamento, respectivamente. 
a)

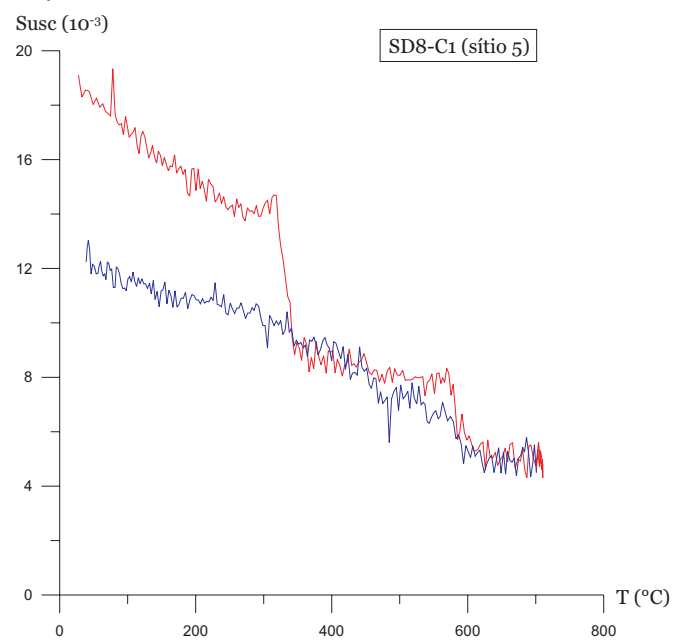

c)

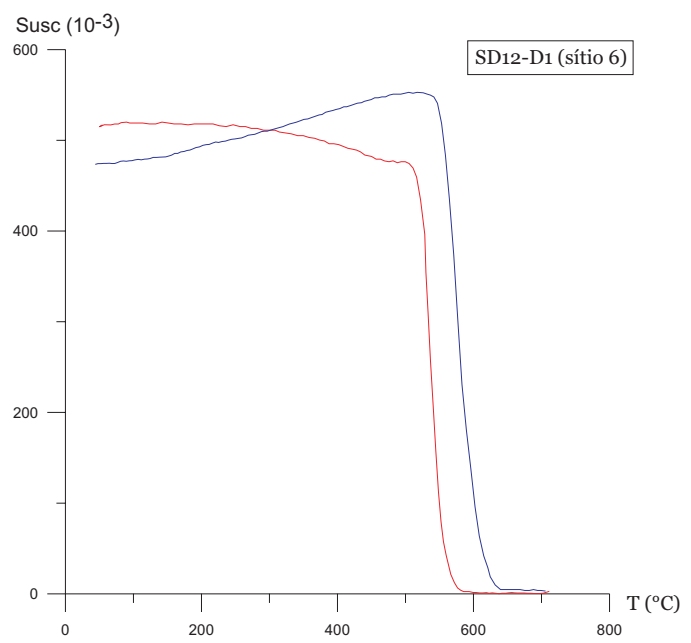

e)

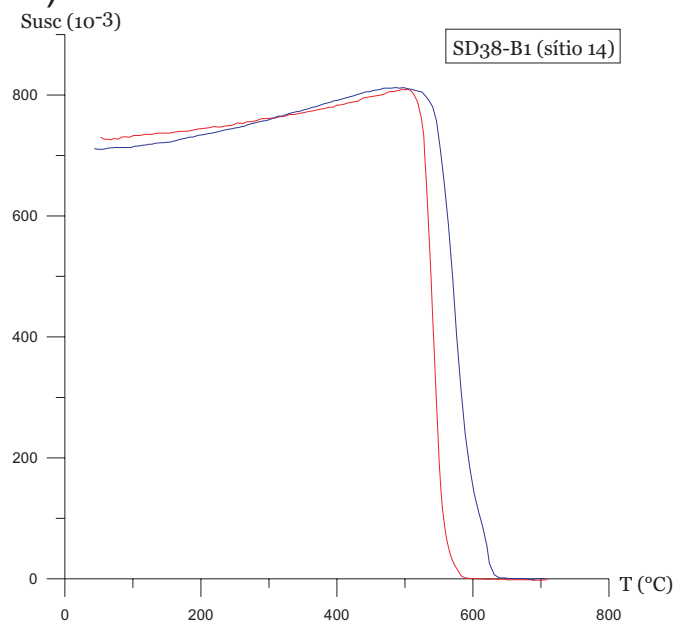

b)

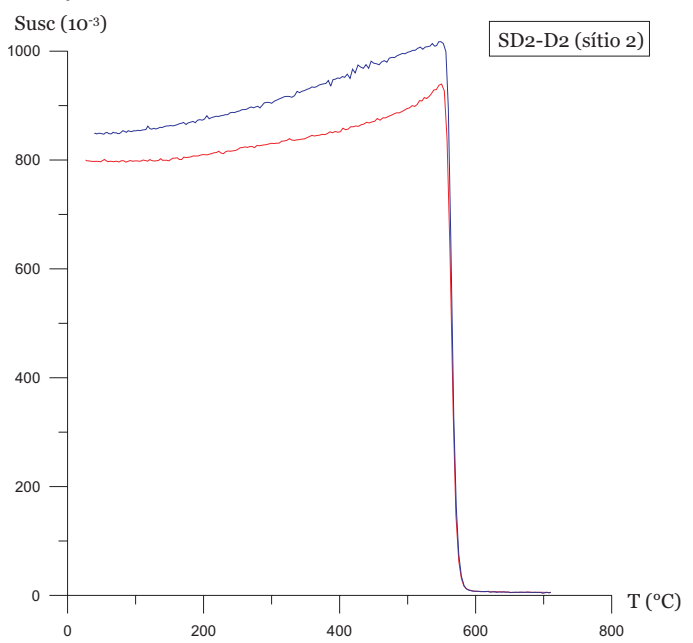

d)

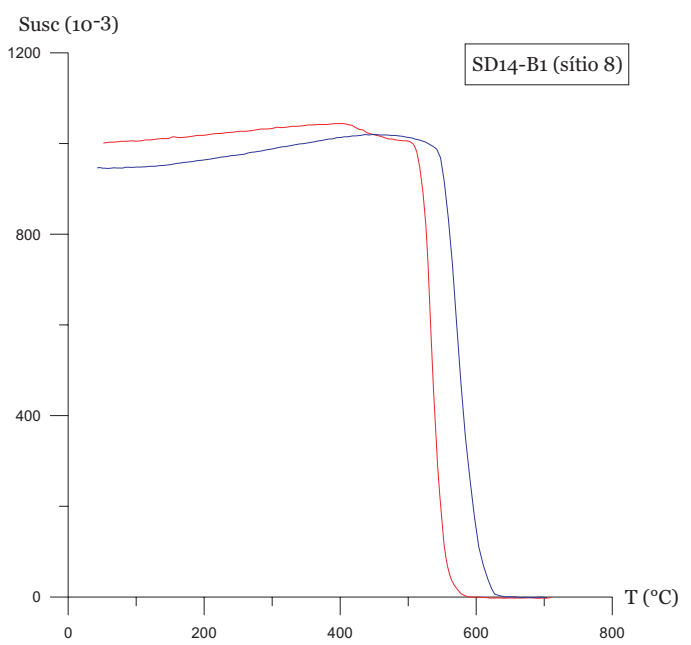

f)

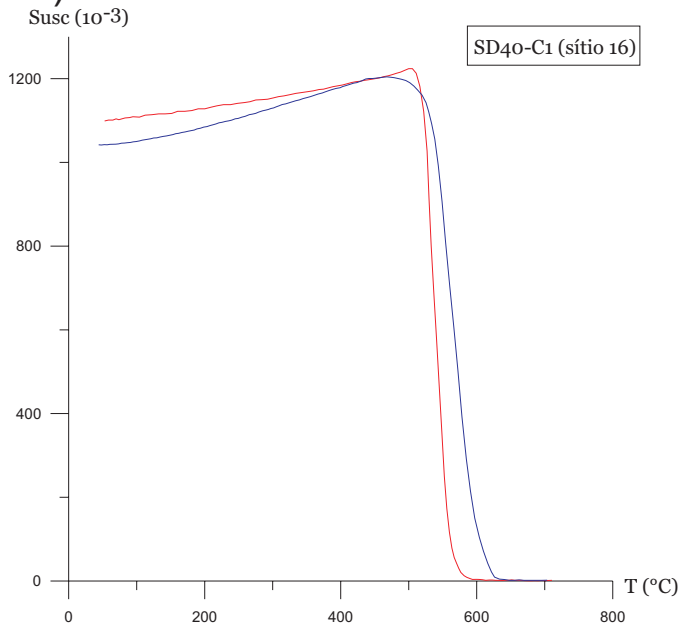

Figura 4.9: Curvas termomagnéticas para os espécimes de rochas máficas analisados. As cores vermelhas e azuis indicam aquecimento e resfriamento, respectivamente. 


\subsubsection{Curvas de Magnetização Remanescente Induzida}

As curvas de magnetização remanescente induzida (MRI) foram obtidas usando um magnetômetro de pulso (Seção 3.4.4). Algumas amostras alcançam a saturação em campos baixos $(<0,2 \mathrm{~T})$, enquanto que outras não atingem a saturação em campos de até 2 Teslas.

As curvas de MRI adquiridas para as amostras ácidas indicam a presença de minerais magnéticos de altas coercividades que não atingem a saturação em campos magnéticos de até $2 \mathrm{~T}$, sugerindo a presença da hematita como o mineral "ferromagnético" dominante em muitas delas (Figura 4.10a). Em todas as curvas mostradas nesta figura, entretanto, existe também a indicação de minerais com baixas coercividades $(<0,2 \mathrm{~T})$, sugerindo a presença de magnetita nestas rochas, com proporções variadas. Este mineral é dominante na amostra SD5-A1 (sítio 3), com já havia sido mostrado anteriormente, através do tratamento térmico e da curva de histerese obtidos para outra amostra deste mesmo sítio (Seção 4.1.1 e 4.1.2).

Por outro lado, as curvas de MRI obtidas para a maioria das rochas máficas (amostras SD7-A1 e SD34-B1 na figura 4.10b) alcançam a magnetização remanescente de saturação em campos inferiores a $200 \mathrm{mT}$, indicando uma distribuição de baixas coercividades que são tipicamente atribuídas a grãos de magnetita ou de titanomagnetita.

A curva de MRI obtida para a amostra SD11-E1 (granodiorito) pertencente ao sítio 5 (Figura 4.10b) indica a presença de dois minerais: um com baixas coercividades $(<0,2 \mathrm{~T})$, sugerindo a presença de magnetita e outro com altas coercividades (saturação alcançada em 1,4 T), o qual pode ser o mineral maghemita como sugerido pela desmagnetização térmica (Seção 4.1.1) e confirmado pelas curvas termomagnéticas (Seção 4.1.3). 

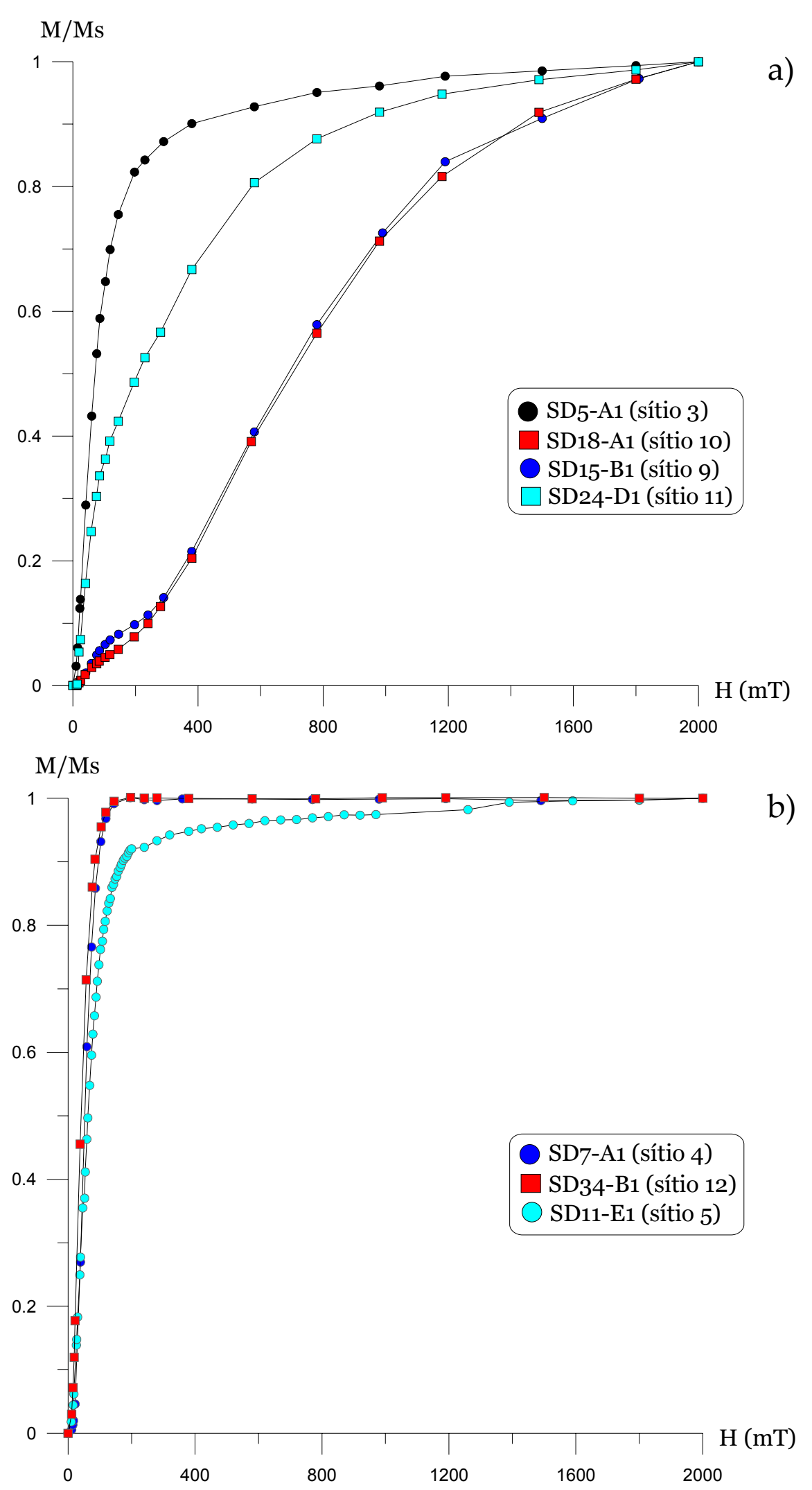

Figura 4.10: Exemplos de curvas de aquisição de MRI obtidas para rochas ácidas (a) e máficas (b). 


\subsection{Análise Paleomagnética}

Durante a amostragem paleomagnética foram coletadas rochas ácidas, máficas e intermediárias como descrito na seção 2.4. Visando a separação de componentes de magnetização as amostras foram, inicialmente, submetidas a desmagnetizações por campos magnéticos alternados (CA). Em alguns espécimes, também foram realizadas desmagnetizações térmicas e, quando necessário, utilizou-se à desmagnetização mista (desmagnetização por CA seguida de térmica).

Devido a variações na litologia, as amostras apresentaram diferentes comportamentos quando submetidas aos tratamentos de desmagnetização no laboratório. Espécimes pertencentes aos sítios 1, 11, 13 e 15 apresentaram direções instáveis ou não foi possível isolar componentes de magnetização característica coerentes entre as amostras analisadas. Um exemplo típico deste comportamento pode ser observado na Figura 4.11 em que não foi possível isolar uma componente característica devido a instabilidade magnética em campos alternados mais altos. Sendo assim, estas amostras foram descartadas da análise estatística dos resultados.

A maioria dos espécimes restantes, entretanto, apresentou direções estáveis e coerentes dentro de cada sítio. A desmagnetização por campos alternados (CA) mostrou-se mais adequada para isolar a magnetização característica (MRC) de boa parte das rochas máficas, quando comparada ao tratamento térmico, como mostram os exemplos da Figura 4.12. O tratamento por campos alternados isola a magnetização remanente característica (MRC), após a eliminação de uma componente secundária com coercividades baixas. Observa-se que a intensidade de magnetização decai rapidamente em campos inferiores a $25 \mathrm{mT}$, indicando uma 
predominância de minerais com baixas coercividades como portadores da magnetização secundária (Figura 4.11). O tratamento térmico, por outro lado, produz pouquíssimo efeito na magnetização remanente natural, não conseguindo eliminar a componente secundária. $\mathrm{O}$ tratamento térmico, entretanto, mostra temperaturas de bloqueio, geralmente, entre $550^{\circ} \mathrm{C}$ e $580^{\circ} \mathrm{C}$, as quais estão, como demonstrado pela mineralogia magnética, relacionadas a titanomagnetitas pobres em Ti.

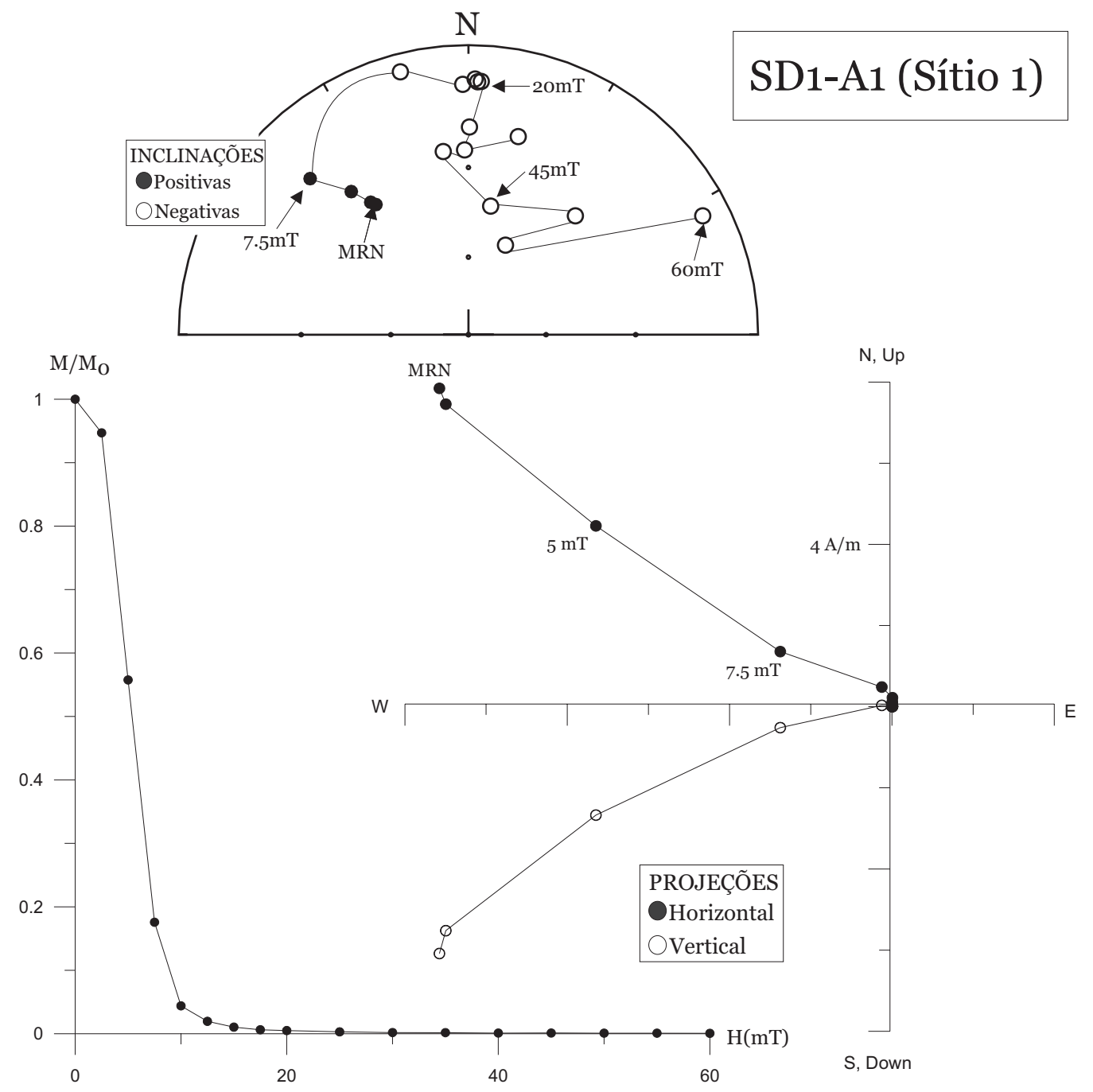

Figura 4.11: Exemplo de desmagnetização em que não foi possível isolar a magnetização característica da amostra devido a instabilidade magnética em campos alternados mais altos. A figura mostra a projeção estereográfica, as projeções ortogonais e a curva de intensidades relativas em função do campo alternado aplicado. 
Em decorrência do exposto acima, para as rochas máficas adotou-se a desmagnetização por CA como padrão para isolar a MRC e, a desmagnetização térmica serviu como identificador do principal portador magnético de remanescência da rocha.

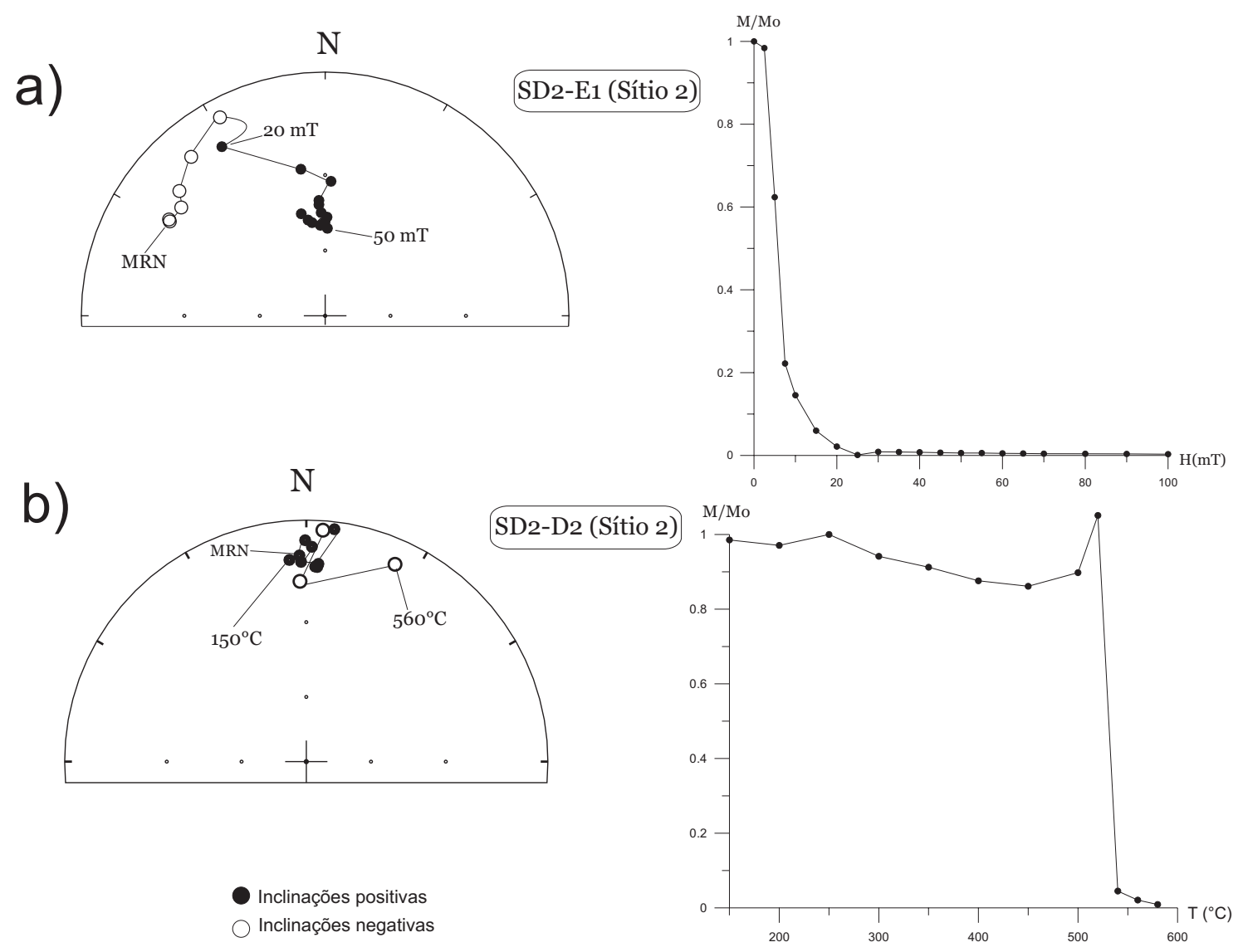

Figura 4.12: Projeções estereográficas e curvas de intensidades relativas para amostras máficas indicando: (a) a eficiência da desmagnetização por CA em isolar a direção de magnetização, (b) ineficiência da desmagnetização térmica para as rochas máficas analisadas.

Por outro lado, para a maior parte das rochas ácidas a desmagnetização térmica foi necessária para determinar a magnetização característica através da análise de componentes principais, em vista da presença de hematita nestas rochas, como mostram os exemplos da figura 4.13. Este mineral apresenta coercividades altas e mesmo quando campos desmagnetizantes de 160 mT (1600 Oe) foram aplicados, a 
intensidade da magnetização dos espécimes permaneceu inalterada mantendo também a sua magnetização remanente. Exceção à regra são as amostras pertencentes aos sítio 3 e 12, em que a desmagnetização por CA foi eficiente para isolar a magnetização característica presente nestas rochas (Seção 4.1.1).

a)

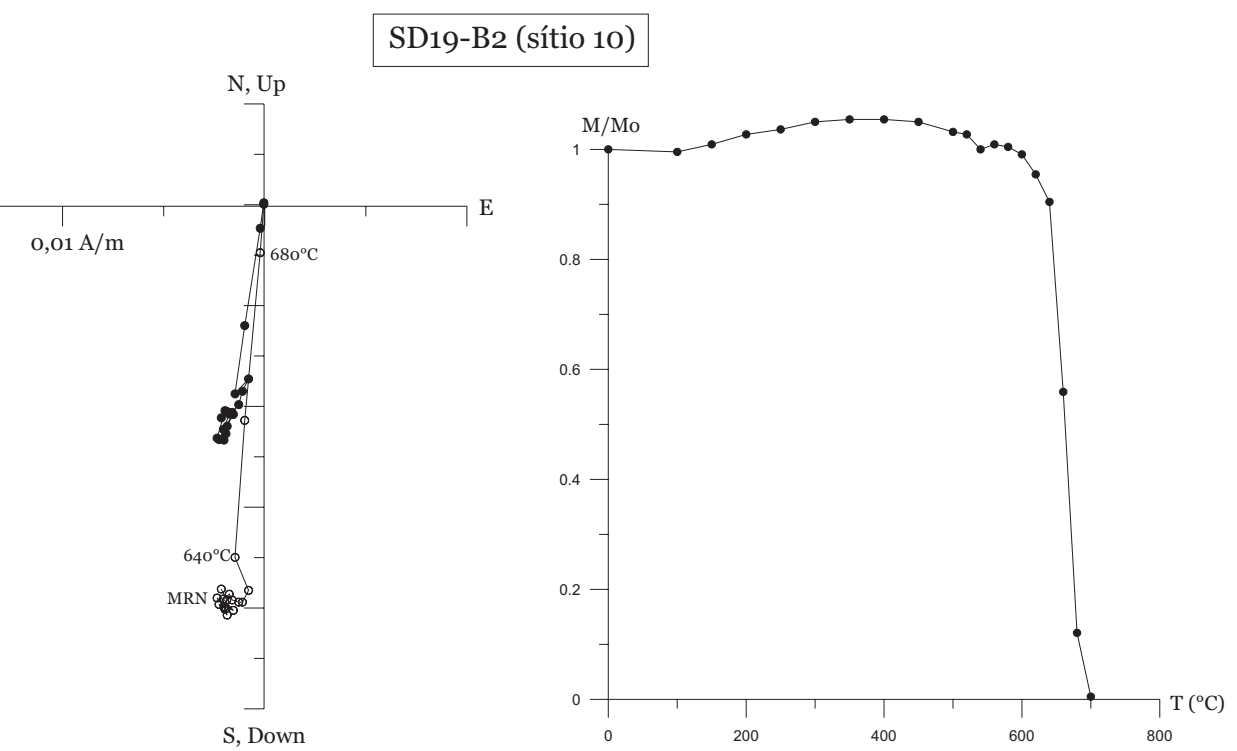

b)

SD19-B1 (sítio 10)

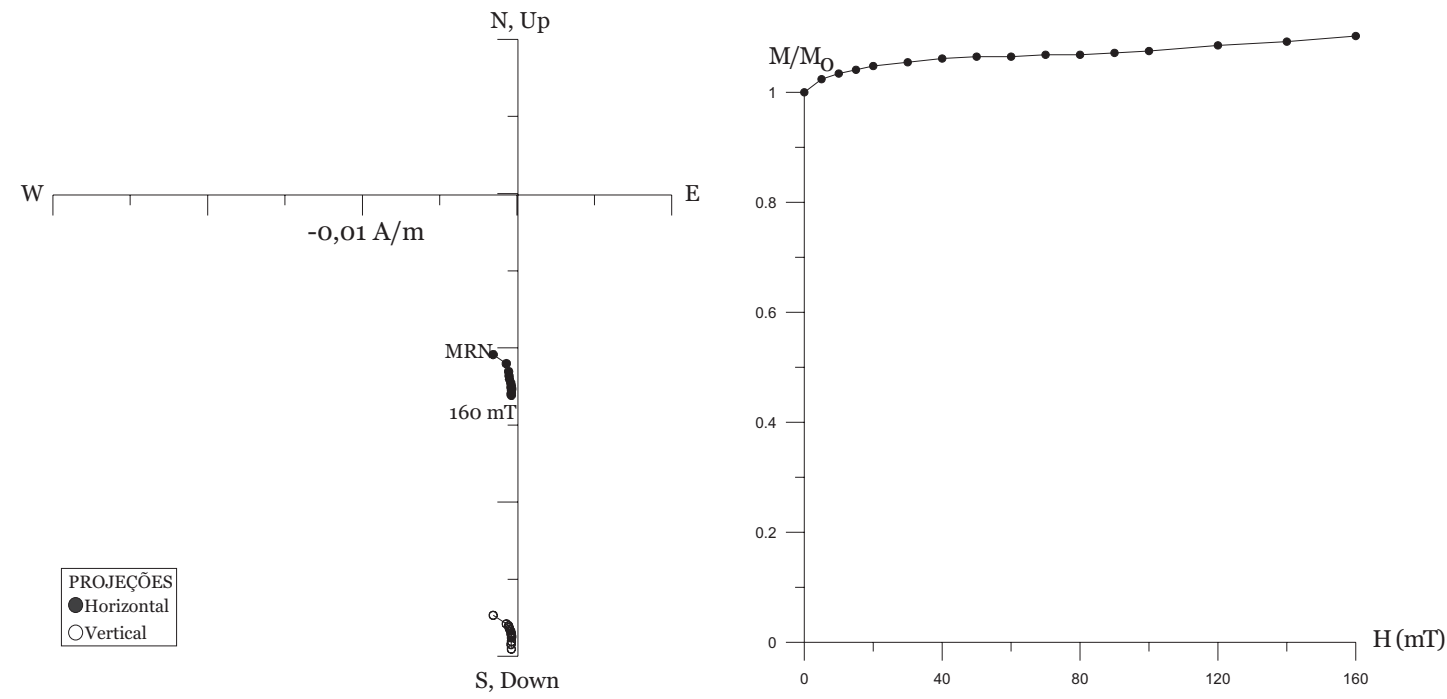

Figura 4.13: Projeções ortogonais e curvas de intensidade relativas obtidas para amostras do sítio 10 durante o tratamento térmico (a) e por campos alternados (b), mostrando a maior eficiência do tratamento térmico para determinar a magnetização característica através da análise de componentes principais. 


\subsubsection{Componentes de Magnetização}

De modo geral, as amostras analisadas apresentaram comportamento de multicomponentes bem definidas nas projeções ortogonais (diagramas de Zijdzerveld) (Figuras 4.14 a 4.20). Para a maioria das amostras, as componentes direcionais de baixa estabilidade foram isoladas na média entre 0-30 mT nos tratamentos por campos alternados e entre $0-300^{\circ} \mathrm{C}$ no tratamento térmico, as quais foram interpretadas como sendo magnetizações secundárias adquiridas depois da cristalização da rocha. De modo geral, estas componentes secundárias não mostram coerência entre os sítios, tendo sido adquiridas, provavelmente, em diferentes épocas do tempo geológico.

Dois grupos de direções características são evidentes após os tratamentos de laboratório. Um grupo é composto por direções norte com inclinações positivas moderadas (componente A), encontradas para amostras de três sítios (2, 4 e 16) de rochas máficas. Exemplos de desmagnetização por campos alternados em que esta componente foi isolada são apresentados na figura 4.14 e 4.15 .

O outro grupo é composto por direções norte (sul) com inclinações negativas (positivas) de moderada a alta (componente B), identificadas para a maior parte das amostras (máficas e ácidas). Exemplos de desmagnetizações térmicas e por campos alternados em que esta componente foi isolada são apresentados nas figuras 4.16, 4.17, 4.18, 4.19 e 4.20. Note que o tratamento por campos alternados foi suficiente para isolar a componente B (inclinação negativa) da amostra SD3-A1 do sítio 3 (Figura 4.16) representada por uma rocha ácida. A amostra SD11-E1 do sítio 5 (Figura 4.20), representada por um granodiorito, cujo portador magnético é, na maior parte, composto pelo mineral maghemita, também apresentou a componente B (inclinação positiva). 


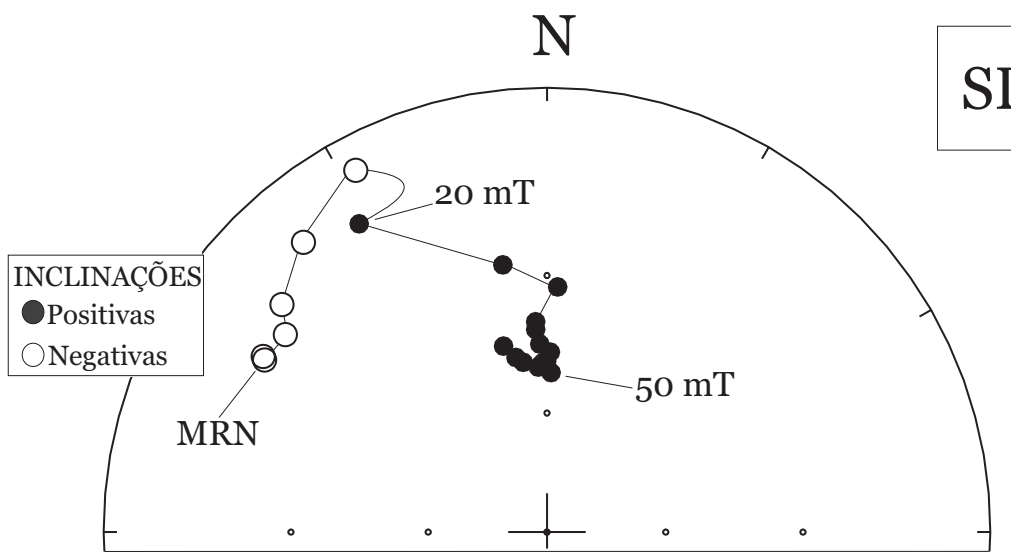

SD2-E1 (Sítio 2)
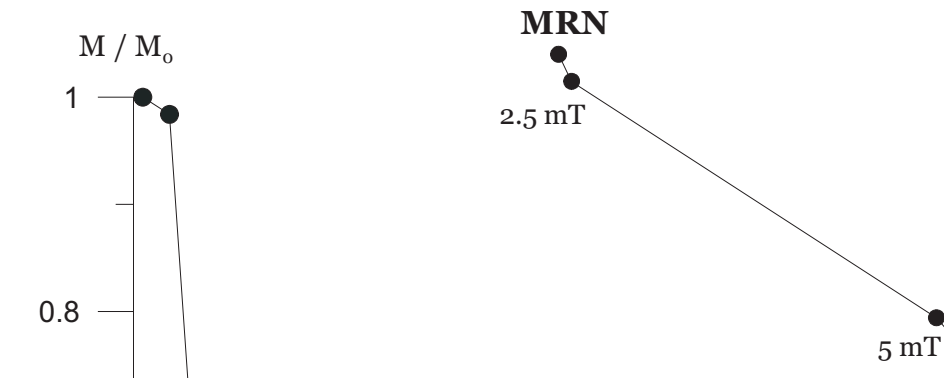

$\mathrm{N}, \mathrm{Up}$

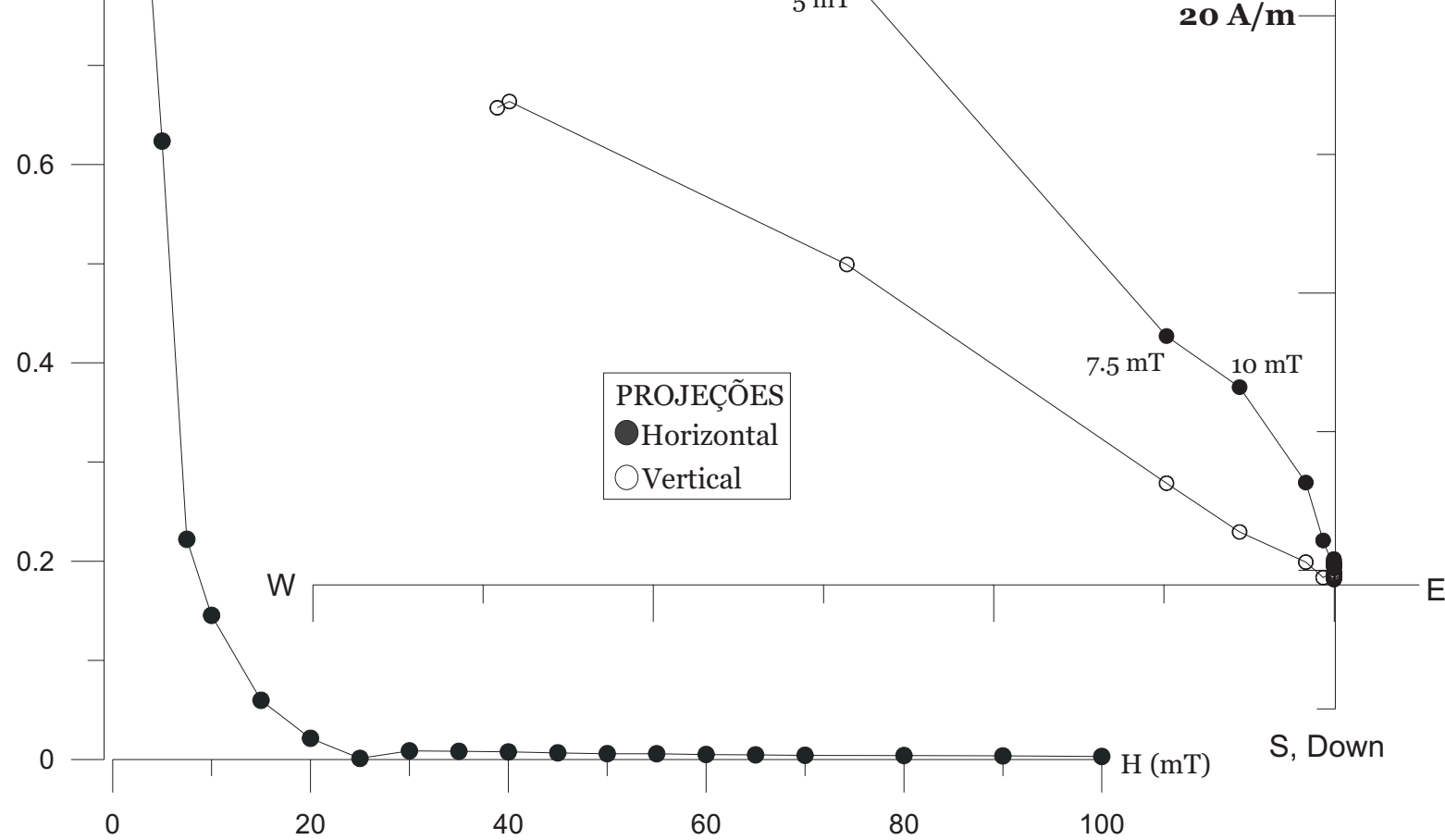

Figura 4.14: Exemplo de um espécime em que a componente A foi isolada. A figura mostra projeção estereográfica, as projeções ortogonais (diagrama de Zijderveld) e o gráfico de intensidade normalizada em função do campo alternado. 


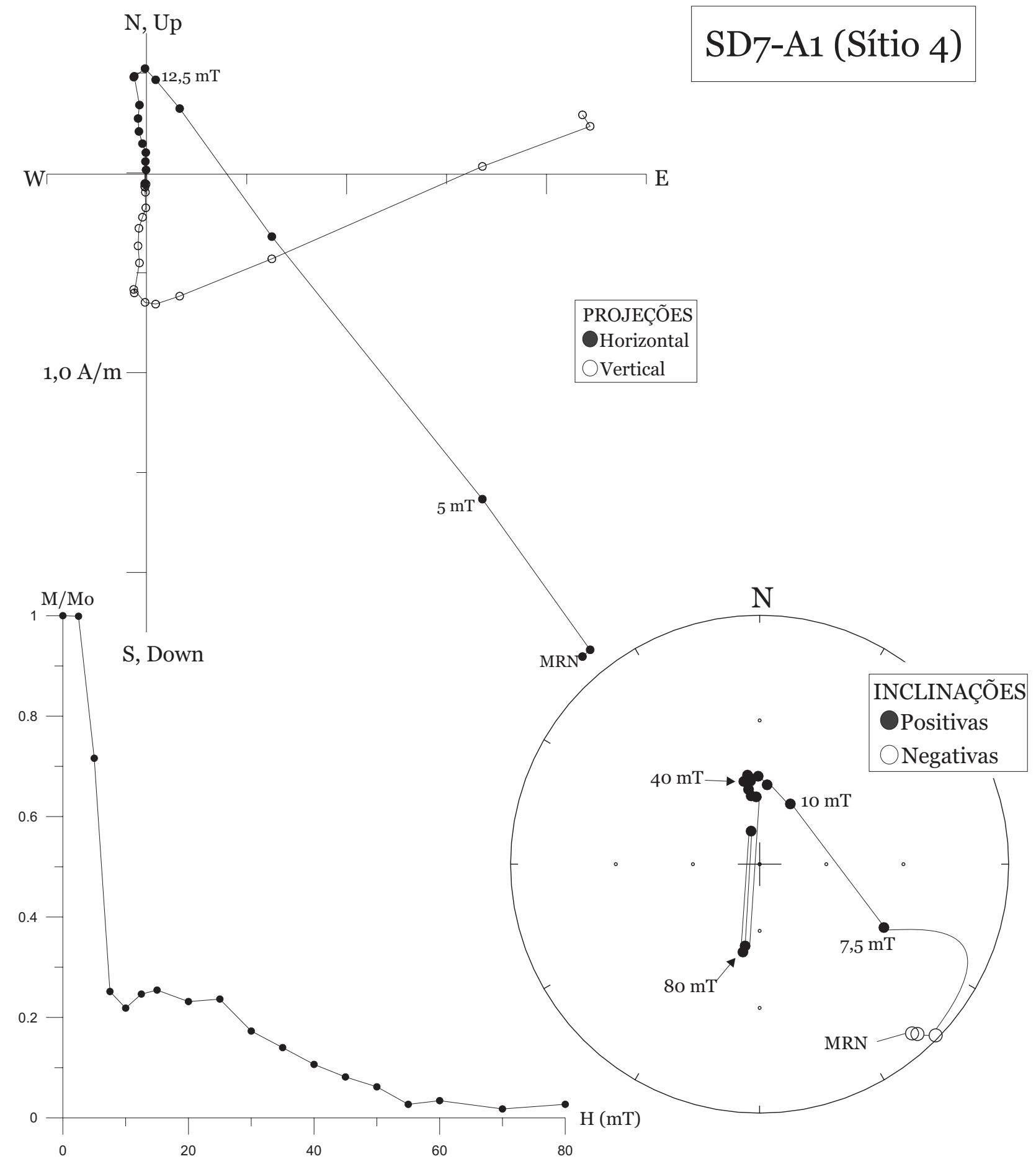

Figura 4.15: Exemplo de desmagnetização por CA de um espécime em que a componente $A$ foi isolada. A figura mostra as projeções ortogonais (diagrama de Zijderveld), a projeção estereográfica e o gráfico de intensidade normalizada em função do campo alternado. 


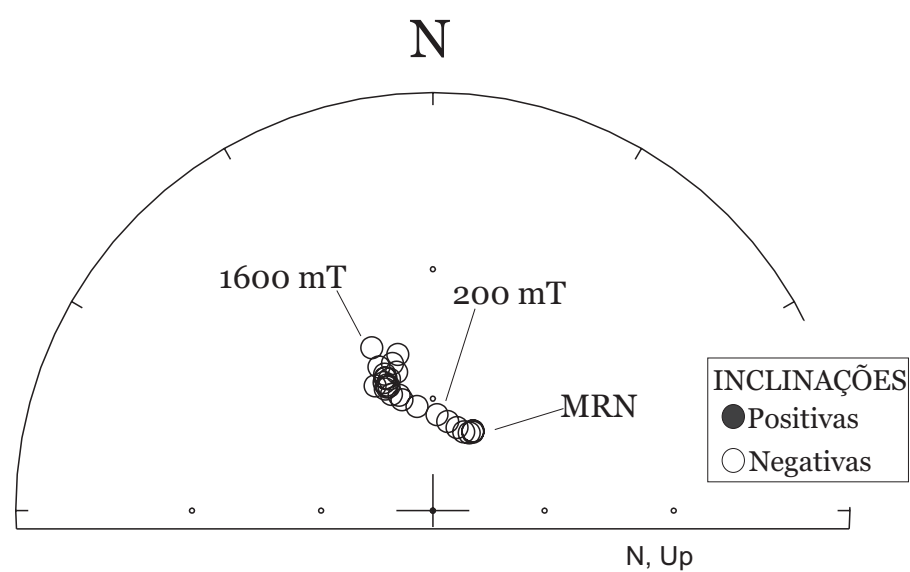

\section{SD3-A1 (Sítio 3)}

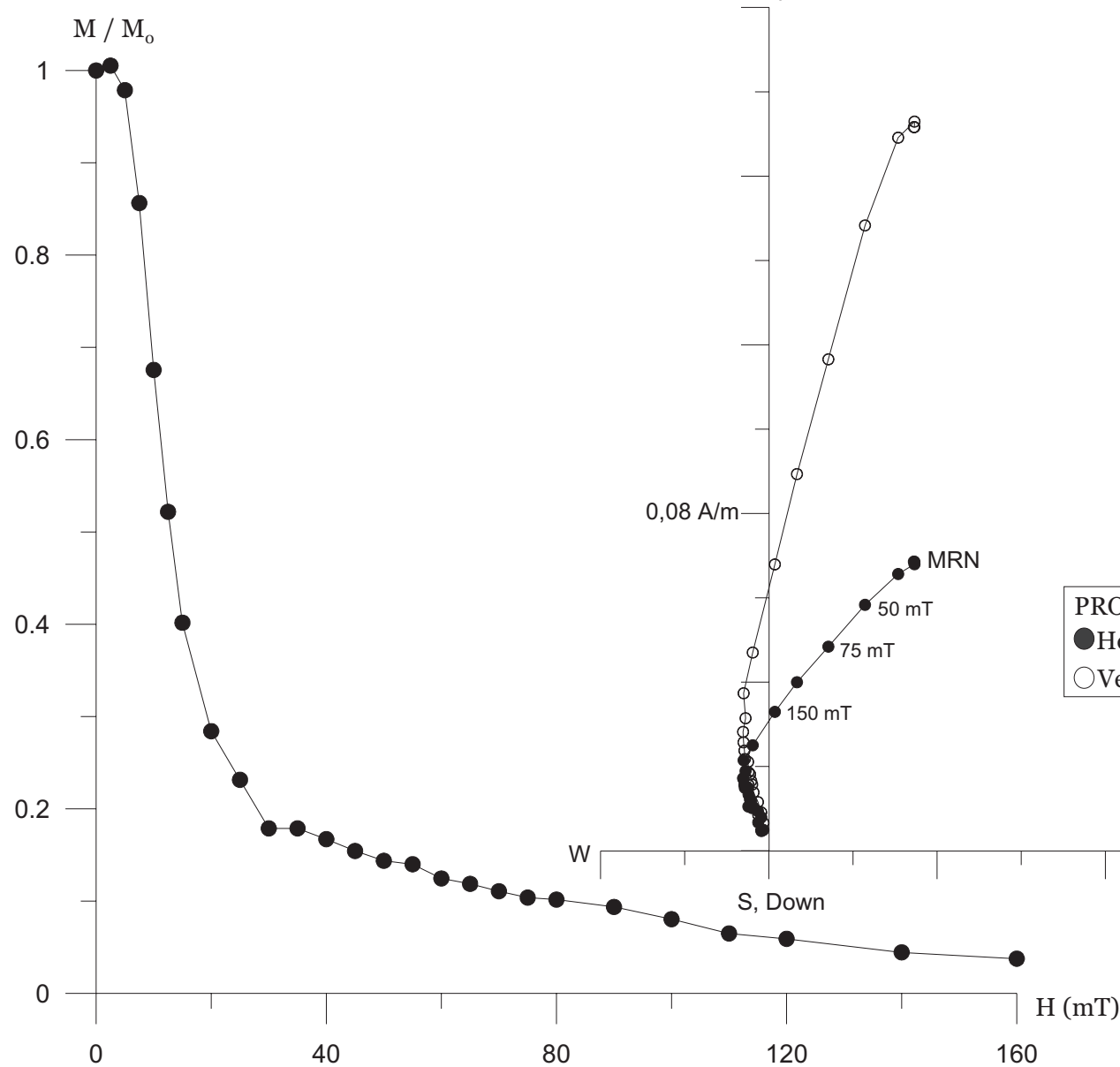

Figura 4.16: Exemplo de um espécime em que a componente B com inclinação negativa foi isolada. A figura mostra a projeção estereográfica, as projeções ortogonais (diagrama de Zijderveld) e o gráfico de intensidade normalizada em função do campo alternado. 


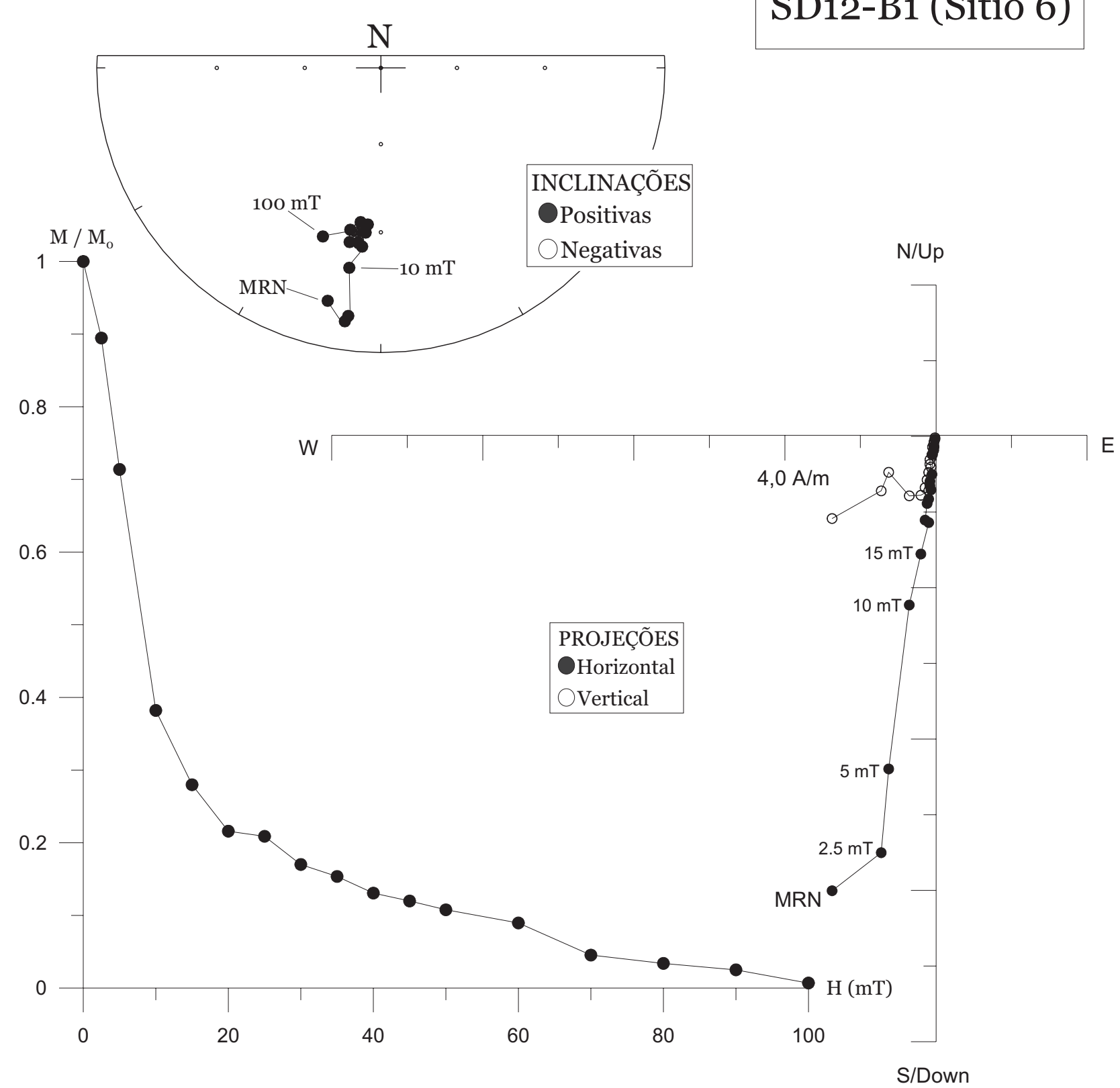

Figura 4.17: Exemplo de um espécime em que a componente B com inclinação positiva foi isolada. A figura mostra a projeção estereográfica, as projeções ortogonais (diagrama de Zijderveld) e o gráfico de intensidade normalizada em função do campo alternado. 


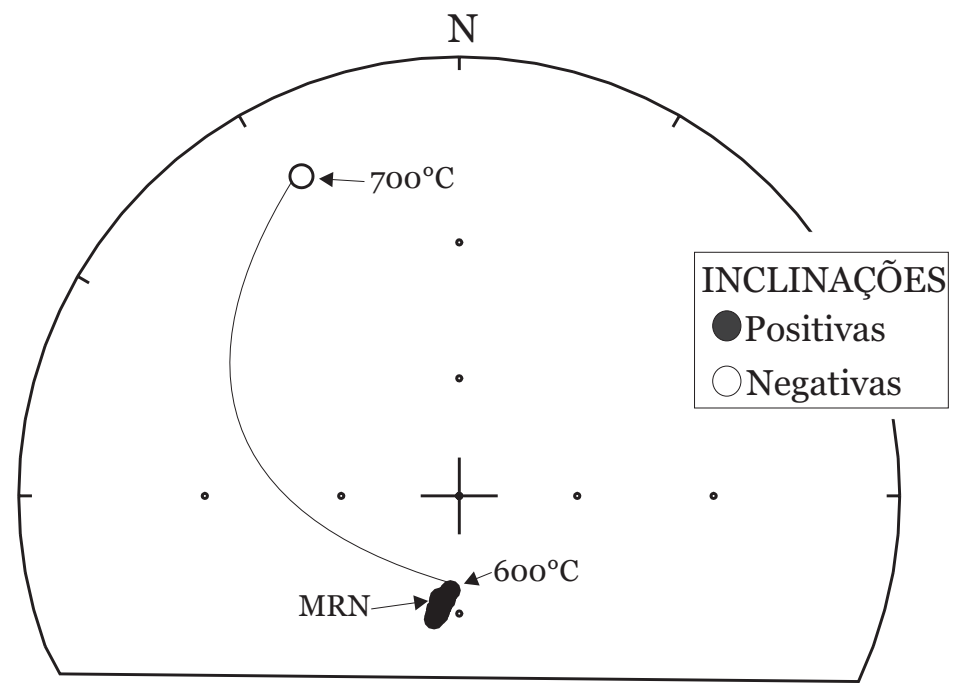

\section{SD19-B2 (Ś́tio 10)}

W

$0,01 \mathrm{~A} / \mathrm{m}$

$680^{\circ} \mathrm{C}$

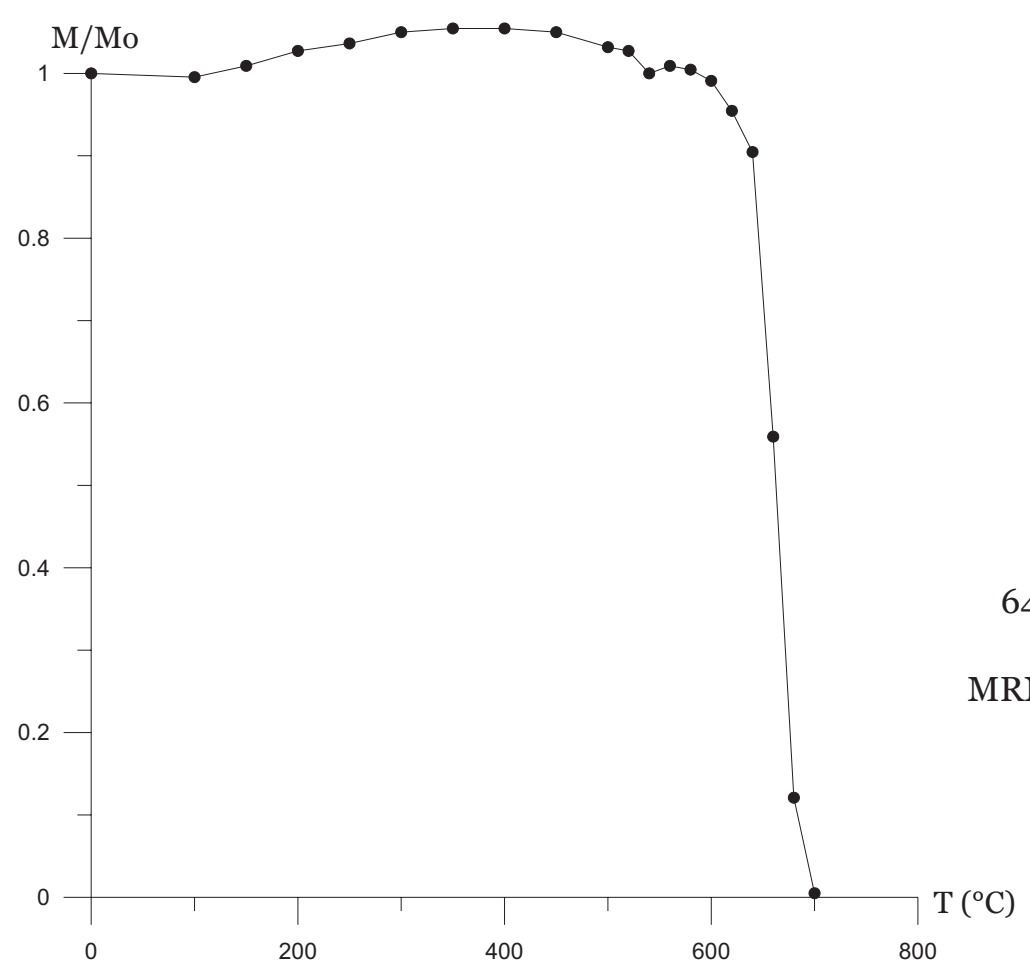

S, Down

Figura 4.18: Exemplo de um espécime em que a componente B com inclinação positiva foi isolada. A figura mostra a projeção estereográfica, as projeções ortogonais (diagrama de Zijderveld) e o gráfico de intensidade normalizada em função da temperatura. 


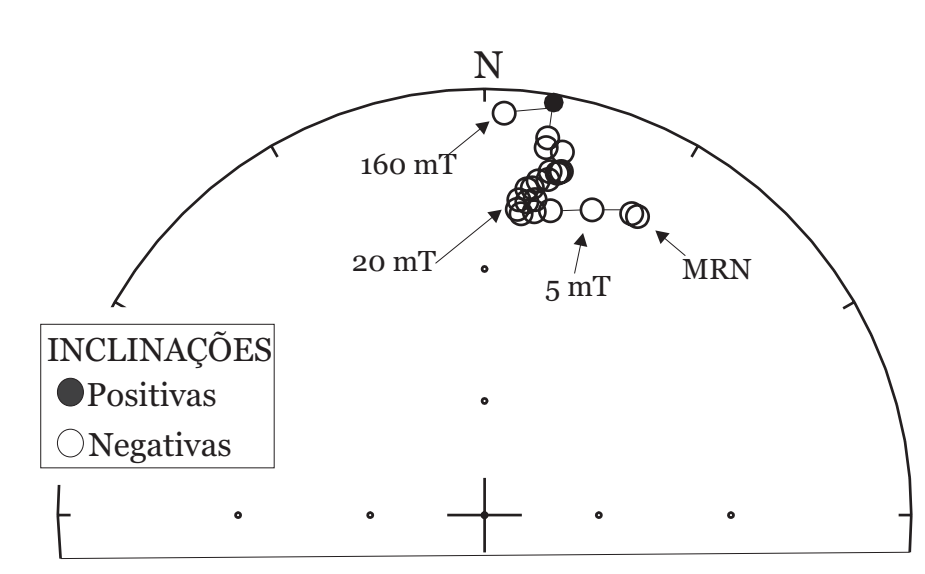

\section{SD33-c4 (Sítio 12)}

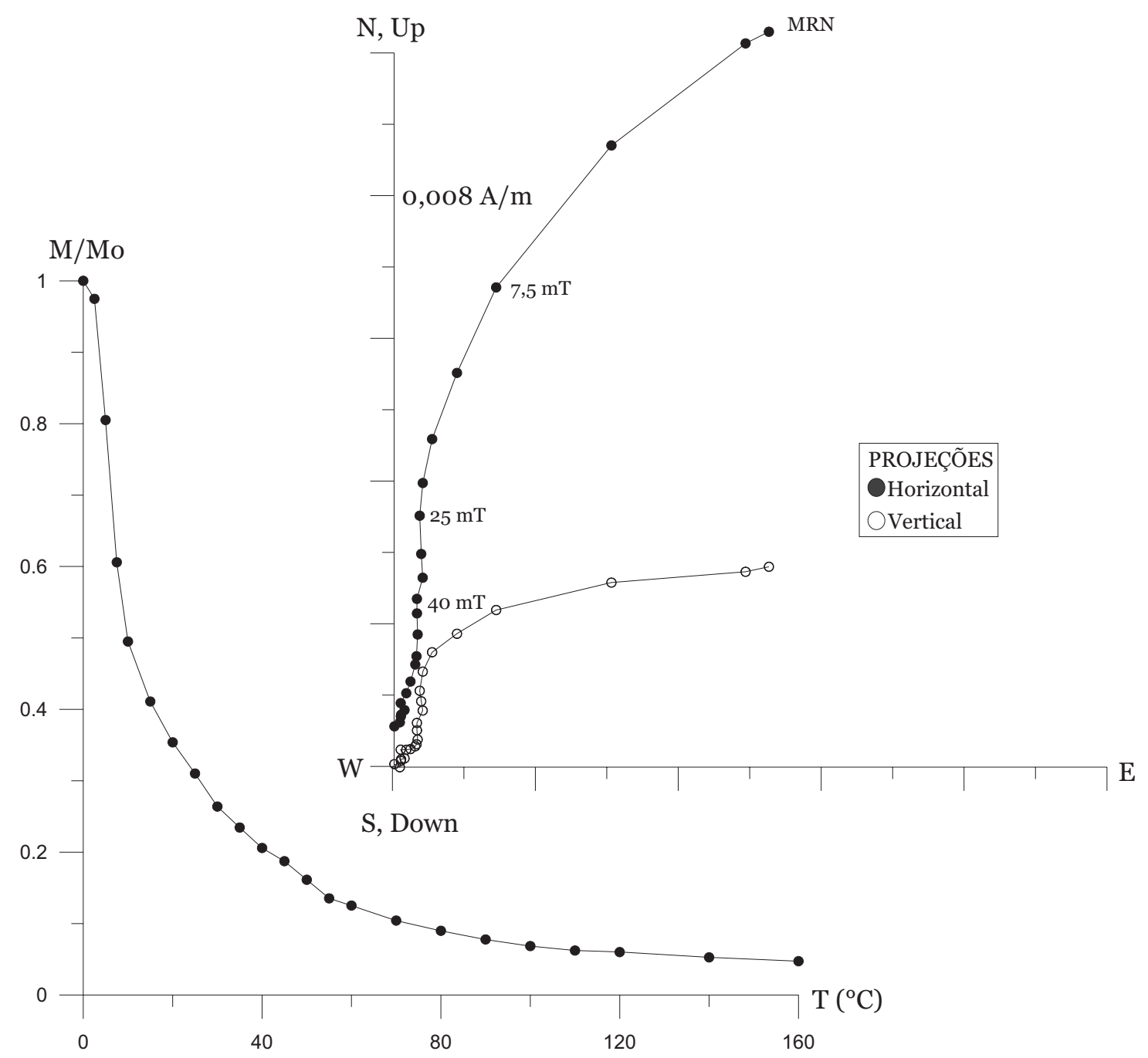

Figura 4.19: Exemplo de um espécime em que a componente $B$ com inclinações negativas foi isolada. A figura mostra a projeção estereográfica, as projeções ortogonais (diagrama de Zijderveld) e o gráfico de intensidade normalizada em função do campo alternado. 


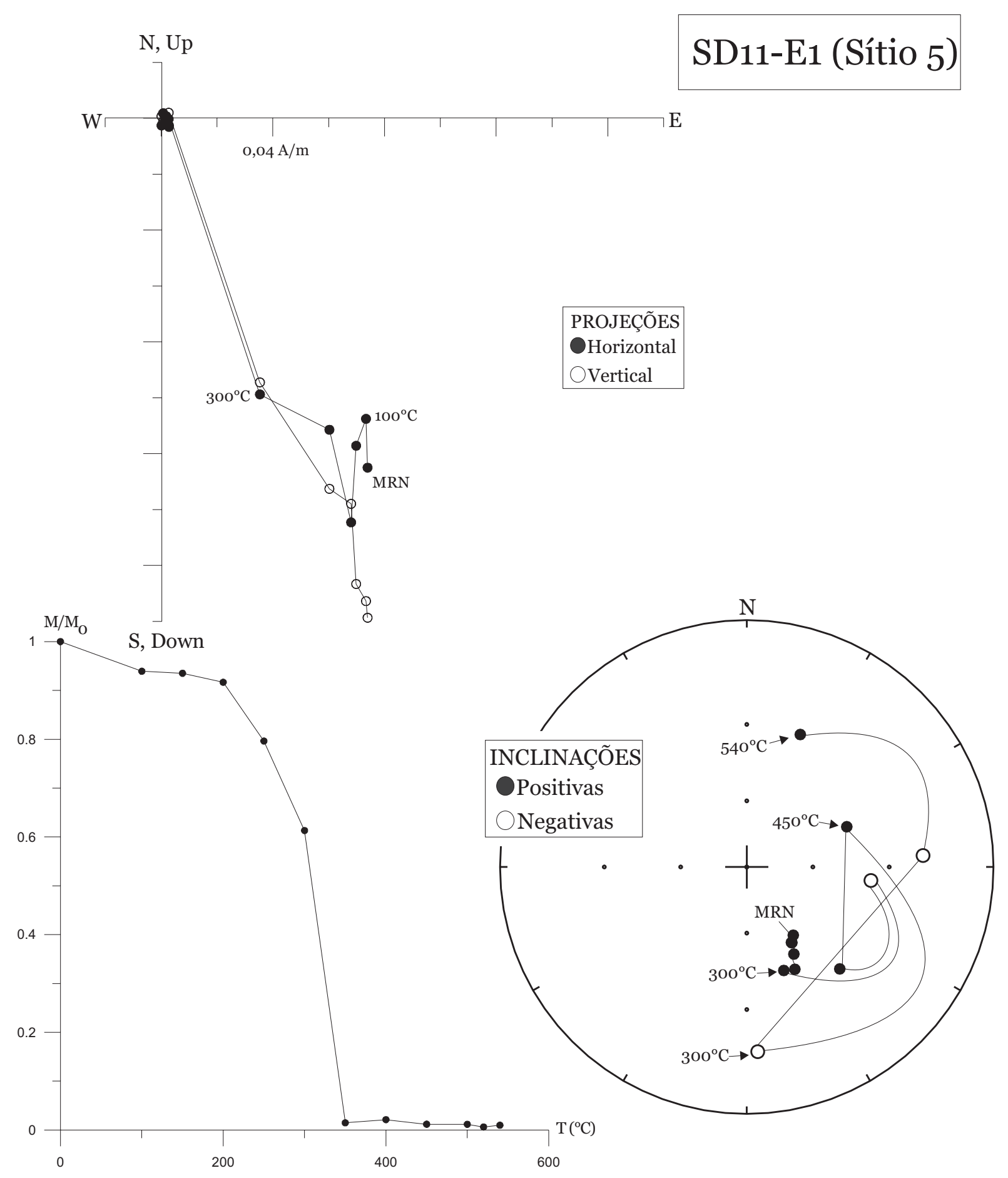

Figura 4.20: Exemplo de um espécime em que a componente B com inclinações positivas foi isolada. A figura mostra as projeções ortogonais (diagrama de Zijderveld), a projeção estereográfica e o gráfico de intensidade normalizada em função da temperatura. 


\subsection{Determinação das direções de magnetização médias e pólos paleomagnéticos}

Considerando que as amostras analisadas fazem parte de uma distribuição amostral bem espaçada ao longo do tempo, supõe-se que na média foram eliminados os efeitos da variação secular e, também, que populações de direções de magnetização (MRN) distribuídas de acordo com a função densidade de probabilidade de Fisher foram isoladas nos tratamentos por CA e térmicos no laboratório.

Para a determinação da direção de magnetização média por sítio (Fisher, 1953) foram considerados apenas os espécimes que apresentaram direções de magnetização coerentes e que tinham parâmetro estatístico aceitável $\left(\mathrm{MAD}<10^{\circ}\right)$ de acordo com a análise dos componentes principais (ACP).

Um mínimo de 4 espécimes por sítio foi utilizado no cálculo da direção média da MRC e para cada sítio também se calculou o PGV correspondente (Tabelas 4.2 e 4.3). Os sítios 1, 11, 13 e 15 não apresentaram direções de magnetização estáveis ou coerentes dentro do sítio e, por este motivo, não foram incluídos nas tabelas 4.2 e 4.3 .

A figura 4.21 mostra as direções médias por sítio; a componente A (Figura 4.21a) foi observada em três sítios, cuja direção média é $\mathrm{Dm}=356.5^{\circ}, \mathrm{Im}=47.6^{\circ}$ $\left(\alpha_{95}=15.8^{\circ}\right)$. A componente B (Figura 4.21b) foi isolada para sítios compreendendo rochas máficas e ácidas e é representada por direções normais e reversas. Após a inversão de polaridade das direções com inclinação negativa, calculou-se a seguinte direção média $\mathrm{Dm}=187.4^{\circ}, \operatorname{Im}=50.9^{\circ}\left(\alpha_{95}=11.3^{\circ}\right)$. 
Tabela 4.2: Direções médias por sítio e pólos geomagnéticos virtuais referentes a componente A.

\begin{tabular}{|c|c|c|c|c|c|c|c|}
\hline \multirow{2}{*}{$\begin{array}{c}\text { SÍTIO } \\
\text { COMPONENTE } \\
(\mathrm{A}) \\
\end{array}$} & \multicolumn{5}{|c|}{ DIREÇÃO MÉDIA POR SÍTIO } & \multicolumn{2}{|c|}{$\begin{array}{c}\text { PÓLO } \\
\text { GEOMAGNÉTICO } \\
\text { VIRTUAL }\end{array}$} \\
\hline & $\mathbf{N}$ & $\operatorname{Dec}\left({ }^{\circ}\right)$ & $\operatorname{Inc}\left(^{\circ}\right)$ & $\alpha_{95}\left(^{\circ}\right)$ & K & Plong $\left({ }^{\circ} \mathrm{E}\right)$ & $\operatorname{Plat}\left({ }^{\circ} \mathrm{N}\right)$ \\
\hline 2 & 4 & 2.4 & 38.1 & 15.6 & 35.4 & 308.2 & 58.6 \\
\hline 4 & 9 & 356.1 & 47.9 & 8.8 & 35.2 & 298.2 & 50.6 \\
\hline 16 & 5 & 348.4 & 56.5 & 17.4 & 20.1 & 292.7 & 41.5 \\
\hline Média & 3 & 356.5 & 47.6 & 15.8 & 61.9 & & \\
\hline IG & & & & 15.1 & 67.9 & 298.8 & 50.4 \\
\hline
\end{tabular}

Dec (declinação magnética), Inc (inclinação magnética), $\alpha_{95}$ (limite de confiança), N (número de espécimes utilizados no cálculo da média), K (parâmetro de precisão), Plong (longitude do Pólo) e Plat (latitude do Pólo) e IG (pólo paleomagnético para o componente A).

Tabela 4.3: Direções médias por sítio e pólos geomagnéticos virtuais referentes a componente B.

\begin{tabular}{|c|c|c|c|c|c|c|c|}
\hline \multirow[t]{2}{*}{$\begin{array}{c}\text { SÍTIO } \\
\text { COMPONENTE } \\
\text { (B) }\end{array}$} & \multicolumn{5}{|c|}{ DIREÇÃO MÉDIA POR SÍTIO } & \multicolumn{2}{|c|}{$\begin{array}{c}\text { PÓLO } \\
\text { GEOMAGNÉTICO } \\
\text { VIRTUAL }\end{array}$} \\
\hline & $\mathbf{N}$ & $\operatorname{Dec}\left(^{\circ}\right)$ & Inc $\left(^{\circ}\right)$ & $\alpha_{95}\left(^{\circ}\right)$ & $\mathbf{K}$ & Plong $\left({ }^{\circ} \mathrm{E}\right)$ & Plat $\left({ }^{\circ} \mathrm{N}\right)$ \\
\hline 3 & 10 & 344.0 & -60.8 & 3.3 & 215.3 & 144.9 & 55.1 \\
\hline 5 & 9 & 153.0 & 48.7 & 4.1 & 159.0 & 351.9 & -57.9 \\
\hline 6 & 9 & 189.9 & 31.6 & 5.1 & 101.5 & 250.9 & -78.3 \\
\hline 7 & 8 & 233.1 & 37.0 & 5.4 & 104.4 & 232.8 & -38.0 \\
\hline 8 & 6 & 225.9 & 50.8 & 8.4 & 64.6 & 248.3 & -42.6 \\
\hline 9 & 11 & 176.6 & 58.9 & 2.8 & 264.1 & 310.3 & -59.8 \\
\hline 10 & 17 & 180.6 & 68.1 & 2.5 & 197.6 & 304.5 & -48.4 \\
\hline 12 & 7 & 350.5 & -41.4 & 4.1 & 217.0 & 157.1 & 73.5 \\
\hline 14 & 11 & 161.9 & 22.4 & 4.4 & 109.8 & 28.8 & -72.2 \\
\hline 17 & 12 & 179.1 & 35.5 & 1.5 & 822.0 & 309.7 & -79.8 \\
\hline 18 & 12 & 205.8 & 45.8 & 3.6 & 142.7 & 254.7 & -59.8 \\
\hline 19 & 10 & 189.3 & 61.2 & 2.8 & 308.0 & 292.8 & -56.2 \\
\hline 20 & 7 & 198.9 & 63.7 & 2.6 & 540.0 & 284.2 & -50.6 \\
\hline
\end{tabular}




\begin{tabular}{|rrrrrrrr|}
\hline $\mathbf{2 1}$ & 10 & 325.0 & -30.6 & 6.5 & 56.3 & 199.8 & 55.2 \\
$\mathbf{2 2}$ & 11 & 196.9 & 65.3 & 2.8 & 265.7 & 287.6 & -49.4 \\
$\mathbf{2 3}$ & 10 & 237.8 & 36.0 & 8.1 & 35.7 & 231.8 & -33.7 \\
Média & 16 & 187.4 & 50.9 & 11.3 & 11.7 & & \\
SC & & & & & & & \\
\end{tabular}

Dec (declinação magnética), Inc (inclinação magnética), $\alpha_{95}$ (limite de confiança), N (número de espécimes utilizados no cálculo da média), K (parâmetro de precisão), Plong (longitude do Pólo) e Plat (latitude do Pólo) e SC (pólo paleomagnético para o componente B).

Dois pólos paleomagnéticos associados as componentes de magnetização A e $B$ foram determinados, os quais estão localizados em $298.8^{\circ} \mathrm{E}, 50.4^{\circ} \mathrm{N}(\mathrm{N}=3$, $\left.\alpha 95=15.1^{\circ}, \mathrm{K}=67.9\right)$ e $289.4^{\circ} \mathrm{E},-65.4^{\circ} \mathrm{N}\left(\mathrm{N}=16, \alpha 95=12.9^{\circ}, \mathrm{K}=9.1\right)$, respectivamente (Tabelas 4.2 e 4.3 ).

O pólo paleomagnético determinado para a componente $\mathrm{A}$, inclui a Intrusiva Máfica Guadalupe (sítio 2) e, portanto, pode representar a época de intrusão destas rochas. Por este motivo, este pólo é denominado de pólo Guadalupe (pólo IG). O pólo obtido para a componente B é caracterizado pelas rochas ácidas da Suíte Intrusiva Colíder e máficas associadas, e será referido como pólo Suíte Colíder (pólo SC). 


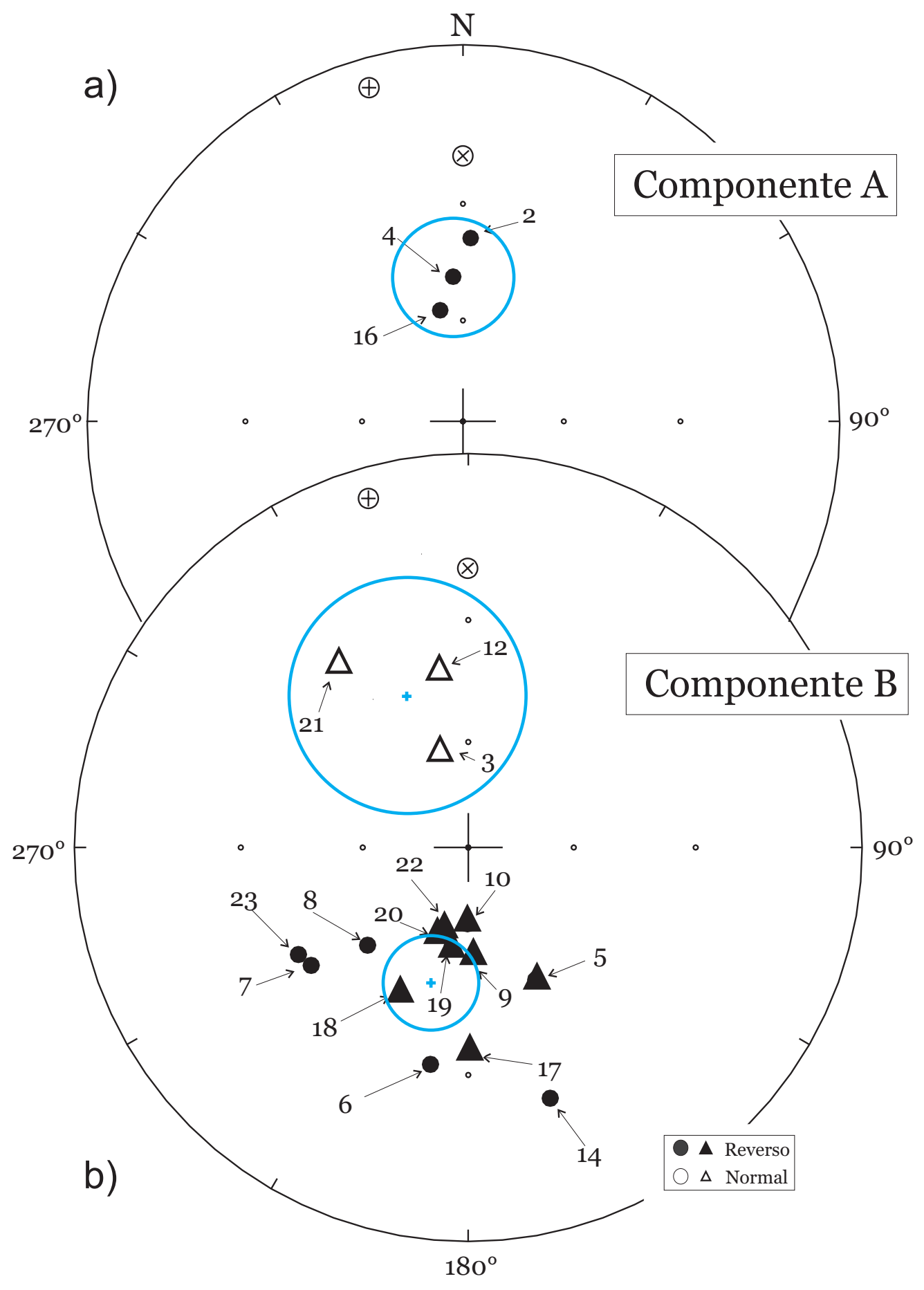

Figura 4.21: Direções médias por sítio para a Componente A (a) e a Componente B (b). Símbolos cheios (vazios) representam inclinações positivas (negativas). Os símbolos $\otimes$ e $\oplus$ representam o campo dipolar e o campo geomagnético atual, respectivamente. Os círculos representam as rochas máficas e os triângulos às rochas ácidas. O símbolo + e os círculos em azul representam as direções médias para cada grupo de direções, com seus respectivos círculos de confiança; componente A $\left(\alpha_{95}=15,8^{\circ}\right)$, componente B normal $\left(\alpha_{95}=28,5^{\circ}\right)$ e a componente B reverso $\left(\alpha_{95}=12,2^{\circ}\right)$. 


\subsection{Teste da Estabilidade da Magnetização}

\subsubsection{Teste de Contato Cozido}

Dois afloramentos mostraram-se adequados para a realização do teste do contato cozido, onde diques máficos e a rocha encaixante apresentavam-se relativamente bem expostos.

O primeiro teste de contato cozido foi realizado para o sítio 12 , onde um dique de diabásio $(\sim 2 \mathrm{~m})$ cortava rochas ácidas (ignimbritos). As amostras coletadas e suas posições relativas em relação ao dique estão representadas na figura 4.22 e na Tabela 4.4 .

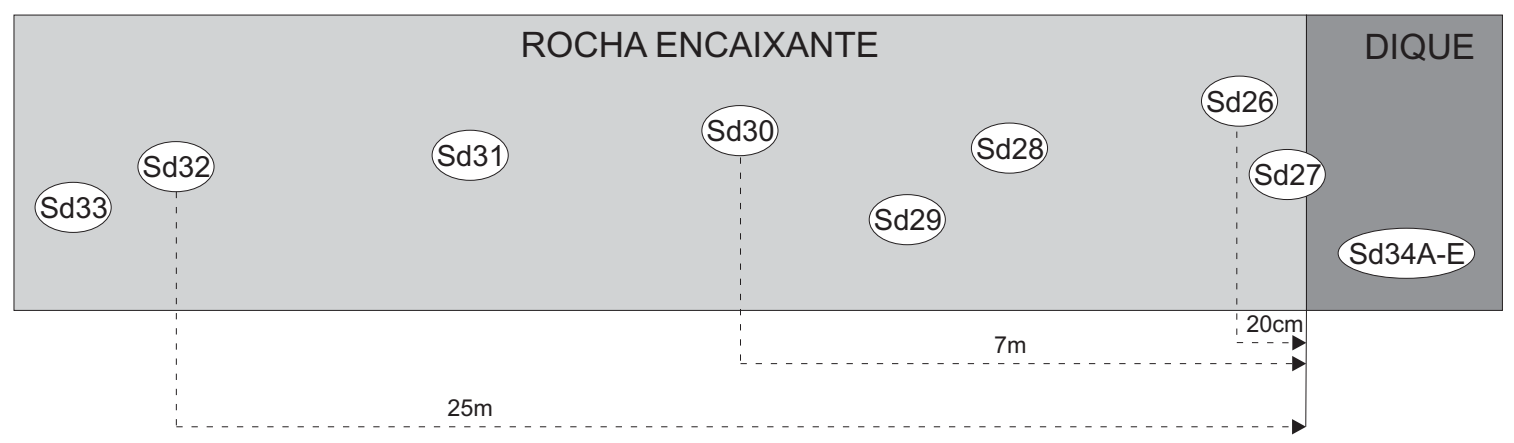

Figura 4.22: Posição relativa das amostras coletadas na rocha encaixante em relação ao dique.

As amostras deste sítio apresentaram, de modo geral, comportamento estável diante dos tratamentos por CA e térmico. A figura 4.23 apresenta os resultados obtidos para uma amostra do dique (SD34-C2) e para amostras da rocha ácida situadas, respectivamente, a 0,05 m (SD27-A1), a $7 \mathrm{~m}$ (SD30-B2) e a $25 \mathrm{~m}$ (SD32-B1) do contato. Todas elas apresentaram direção norte com inclinação negativa moderada (componente B). A figura 4.24 mostra as direções médias por amostra deste sítio. As amostras situadas mais próximo ao contato $(<11 \mathrm{~m})$ apresentam direções mais para oeste, quando comparadas às direções obtidas para 
as amostras situadas a distâncias maiores (25 - 26 m), as quais apresentam direções norte-nordeste (Figura 4.23). Apesar disto, todas estas direções não são muito diferentes da direção obtida para o dique o que pode sugerir um evento de remagnetização mais recente nestas rochas. Assim, este teste deve ser considerado negativo, visto que não atinge totalmente os requisitos do teste do contato cozido.

Tabela 4.4: Primeiro teste de contato cozido: dados das amostras coletadas, tipo de rocha e distância destas para a intrusão.

\begin{tabular}{|ccc|}
\hline AMOSTRAS & ROCHA & $\begin{array}{c}\text { DISTÂNCIA DA } \\
\text { INTRUSÃO }\end{array}$ \\
\hline SD34A a SD34E & Dique & ------ \\
SD26 & Encaixante & $0.20 \mathrm{~m}$ \\
SD27 & Encaixante & $0.05 \mathrm{~m}$ \\
SD28 & Encaixante & $4.5 \mathrm{~m}$ \\
SD29 & Encaixante & $5.5 \mathrm{~m}$ \\
SD30 & Encaixante & $7 \mathrm{~m}$ \\
SD31 & Encaixante & $11 \mathrm{~m}$ \\
SD32 & Encaixante & $25 \mathrm{~m}$ \\
SD33 & Encaixante & $26 \mathrm{~m}$ \\
\hline
\end{tabular}



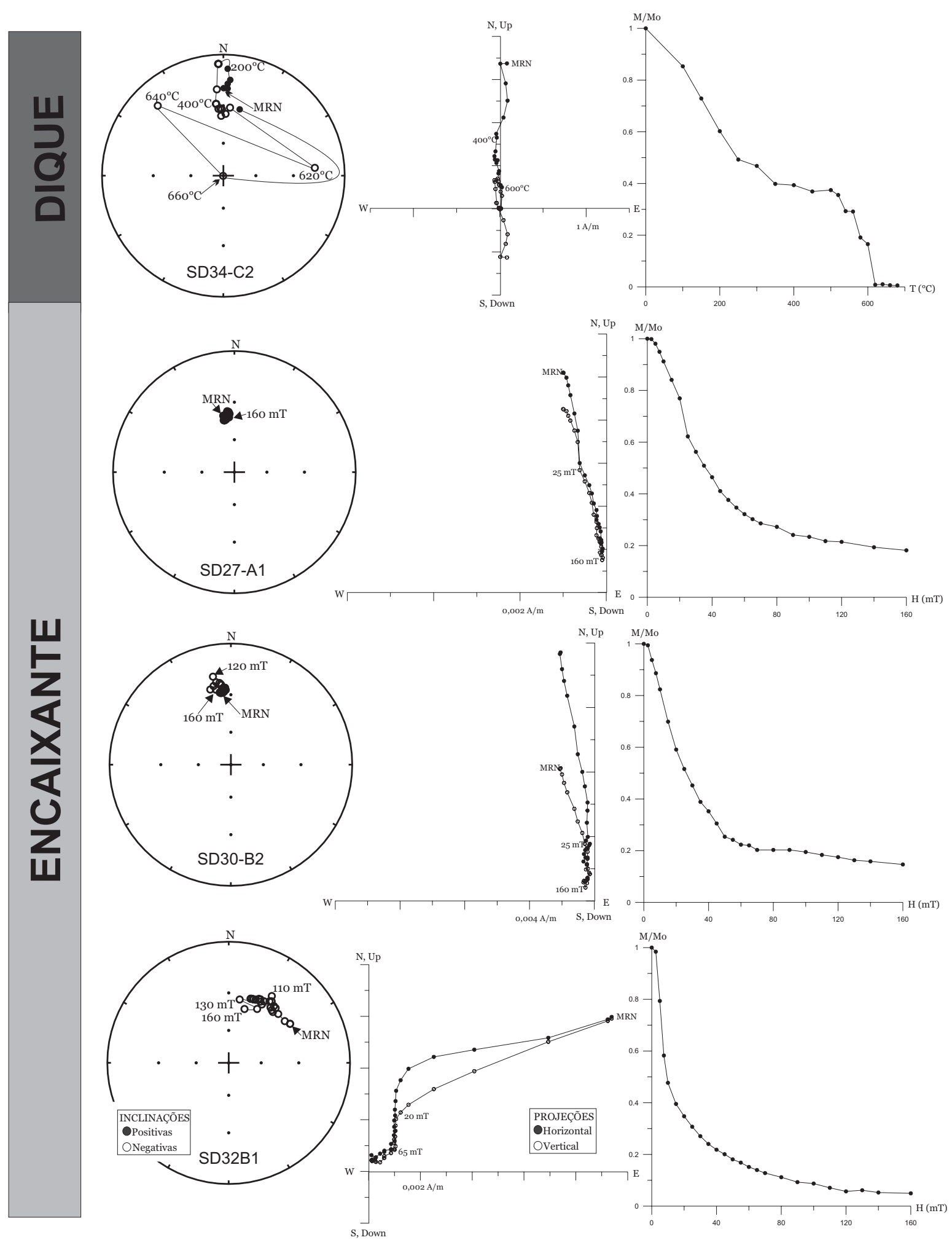

Figura 4.23: Projeção estereográfica, projeção ortogonal e curva de intensidade relativa em função do campo alternado para uma amostra do dique (SD34-C2) e para amostras de rochas ácidas coletadas a 0,05 m (SD27-A1), a $7 \mathrm{~m}$ (SD30-B2) e a $25 \mathrm{~m}$ (SD32-B1) do contato. 


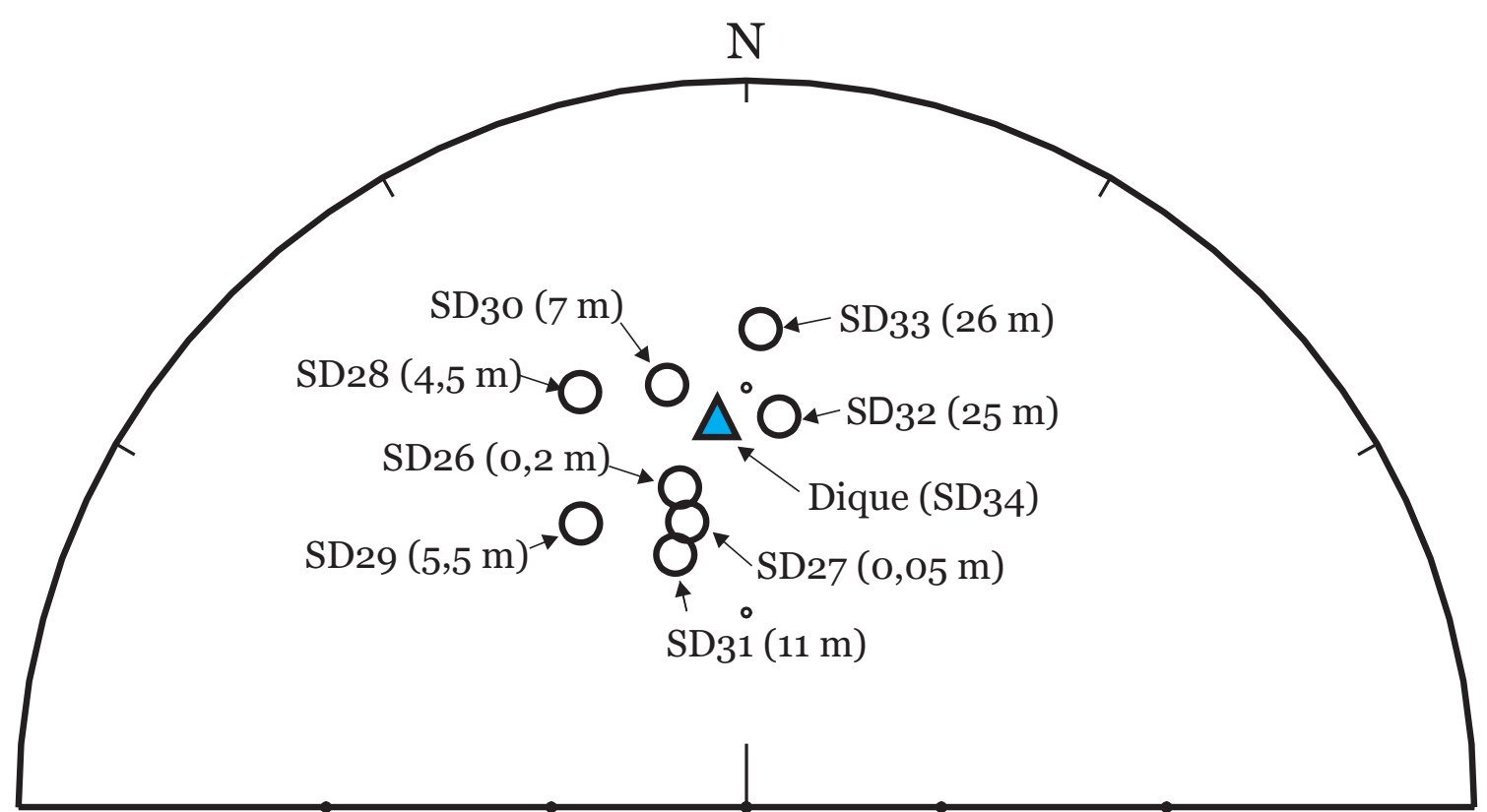

Figura 4.24: Direções médias por amostra obtidas para o teste do contato cozido efetuado para o sítio 12.

Entretanto, para várias áreas analisadas, tanto rochas ácidas como máficas apresentam a componente $B$, o que poderia também sugerir que a intrusão do dique do sítio 12 ocorreu não muito tempo depois da intrusão da rocha ácida encaixante. A obtenção de uma outra componente (A) para outras rochas da mesma área investigada (Gabro Guadalupe), totalmente diferente do campo atual, favorece esta hipótese, já que seria muito difícil supor um evento em escala regional, em tempos mais recentes, que tenha remagnetizado todas as rochas ácidas da Suíte Colider e máficas associadas, sem contudo, ter afetado as rochas que apresentam a componente A. Também, a textura ígnea preservada observada nas rochas estudadas, sem evidências de metamorfismo, assegura que nenhum evento térmico forte afetou estas rochas.

O segundo teste de contato cozido foi realizado para o sítio 23, neste caso, um dique máfico cortava um corpo granítico. Um dos contatos com a rocha encaixante não era visível, entretanto, a exposição do dique sugeria que ele tinha mais de $20 \mathrm{~m}$ de largura. A exposição do granito era pequena, aflorando até 
aproximadamente 6 metros do contato. Na tabela 4.5 e na figura 4.25 encontram-se as amostras coletadas e a posição relativa da amostragem efetuada.

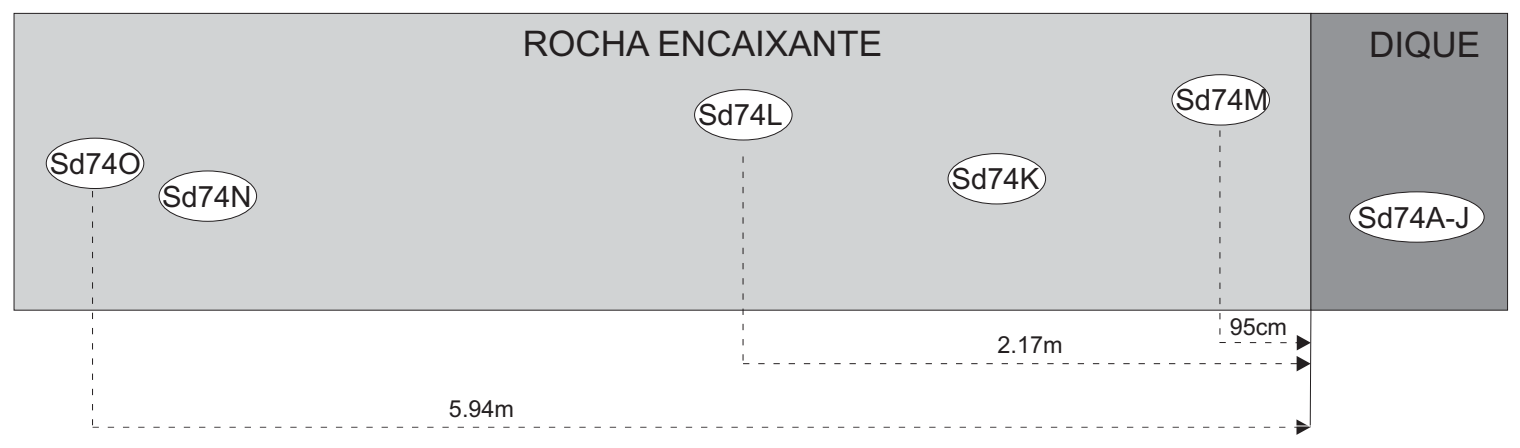

Figura 4.25: Posição relativa das amostras coletadas na rocha encaixante em relação ao dique.

Tabela 4.5: Segundo teste de contato cozido: dados das amostras coletadas, tipo de rocha e distâncias destas para a intrusão.

\begin{tabular}{|c|c|c|}
\hline AMOSTRAS & ROCHA & $\begin{array}{c}\text { DISTÂNCIA DA } \\
\text { INTRUSÃO }\end{array}$ \\
\hline SD74A a SD74J & Dique & ------ \\
\hline SD74M & Encaixante & $0.95 \mathrm{~m}$ \\
\hline SD74K & Encaixante & $1.90 \mathrm{~m}$ \\
\hline SD74L & Encaixante & $2.17 \mathrm{~m}$ \\
\hline SD74N & Encaixante & $5.67 \mathrm{~m}$ \\
\hline SD74O & Encaixante & $5.94 \mathrm{~m}$ \\
\hline
\end{tabular}

Seguindo o mesmo procedimento do teste anterior, as amostras foram submetidas aos tratamentos de laboratório, sendo obtidas direções de magnetização estáveis para a maior parte dos espécimes analisados. Entretanto, a amostra mais próxima ao dique (SD74-M) mostrou, depois dos processos de desmagnetização, um comportamento direcional instável, não sendo possível incluí-la no teste. Este comportamento instável da magnetização, provavelmente, é 


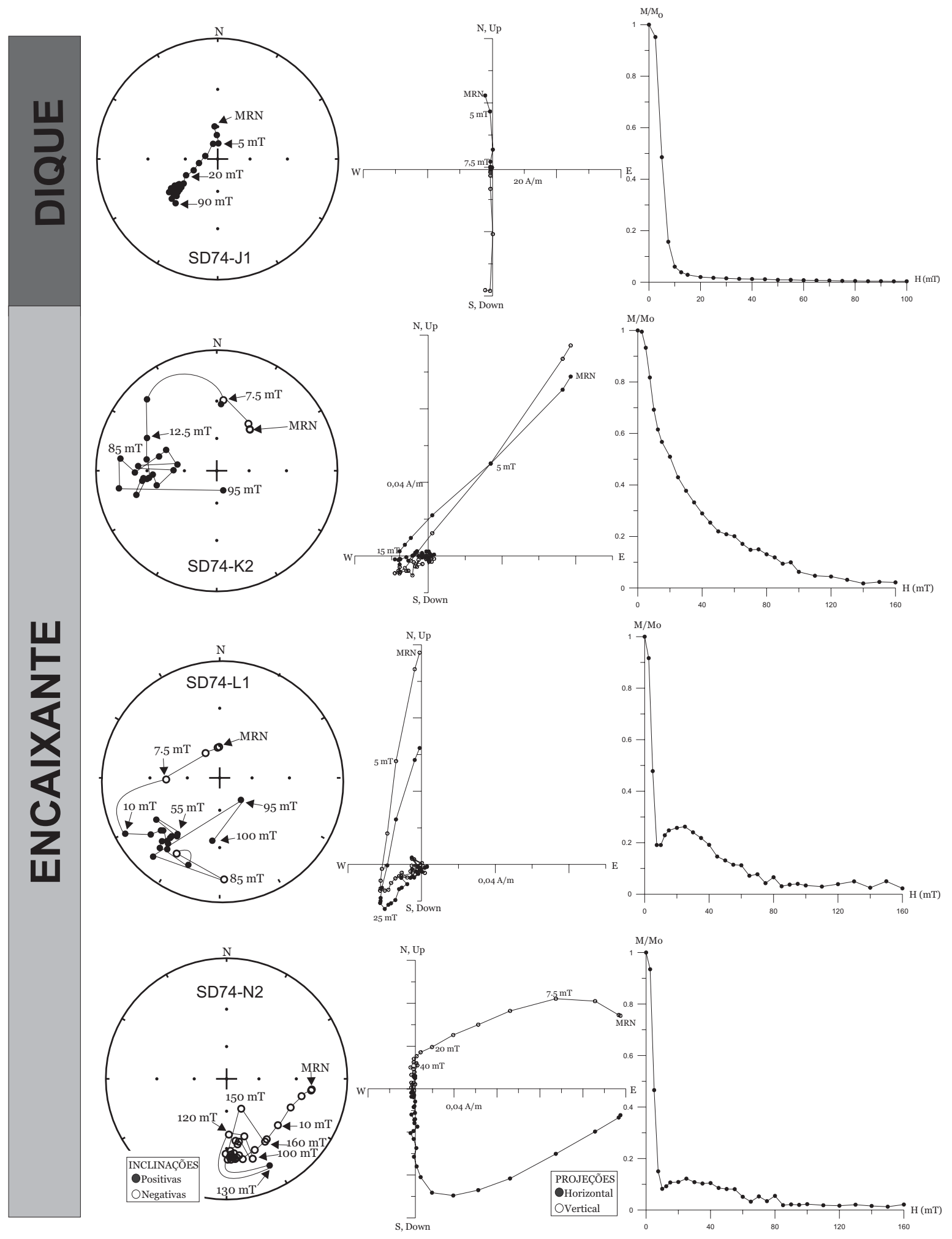

Figura 4.26: Projeção estereográfica, projeção ortogonal e curva de intensidade relativa em função do campo alternado para uma amostra do dique (SD74-J1) e para amostras de granitos coletadas à 1,90 m (SD74-K2), a 2,17 m (SD74-L1) e a 5,67 m (SD74-N2) do contato. 
devido a baixa coercividade do portador de remanescência dessa rocha.

A figura 4.26 apresenta os resultados obtidos para uma amostra do dique (SD74-J1) e para amostras do granito situadas, respectivamente, a 1,90 m (SD74K2), a 2,17 m (SD47-L1) e a $5.67 \mathrm{~m}$ (SD74-N2) do contato. A figura 4.27 mostra as direções médias por amostra deste sítio. As amostras do dique apresentaram resultados bastante coerentes os quais indicam uma direção sudoeste com inclinação positiva, correspondente a componente B citada anteriormente (Figuras 4.20 e 4.21$)$.

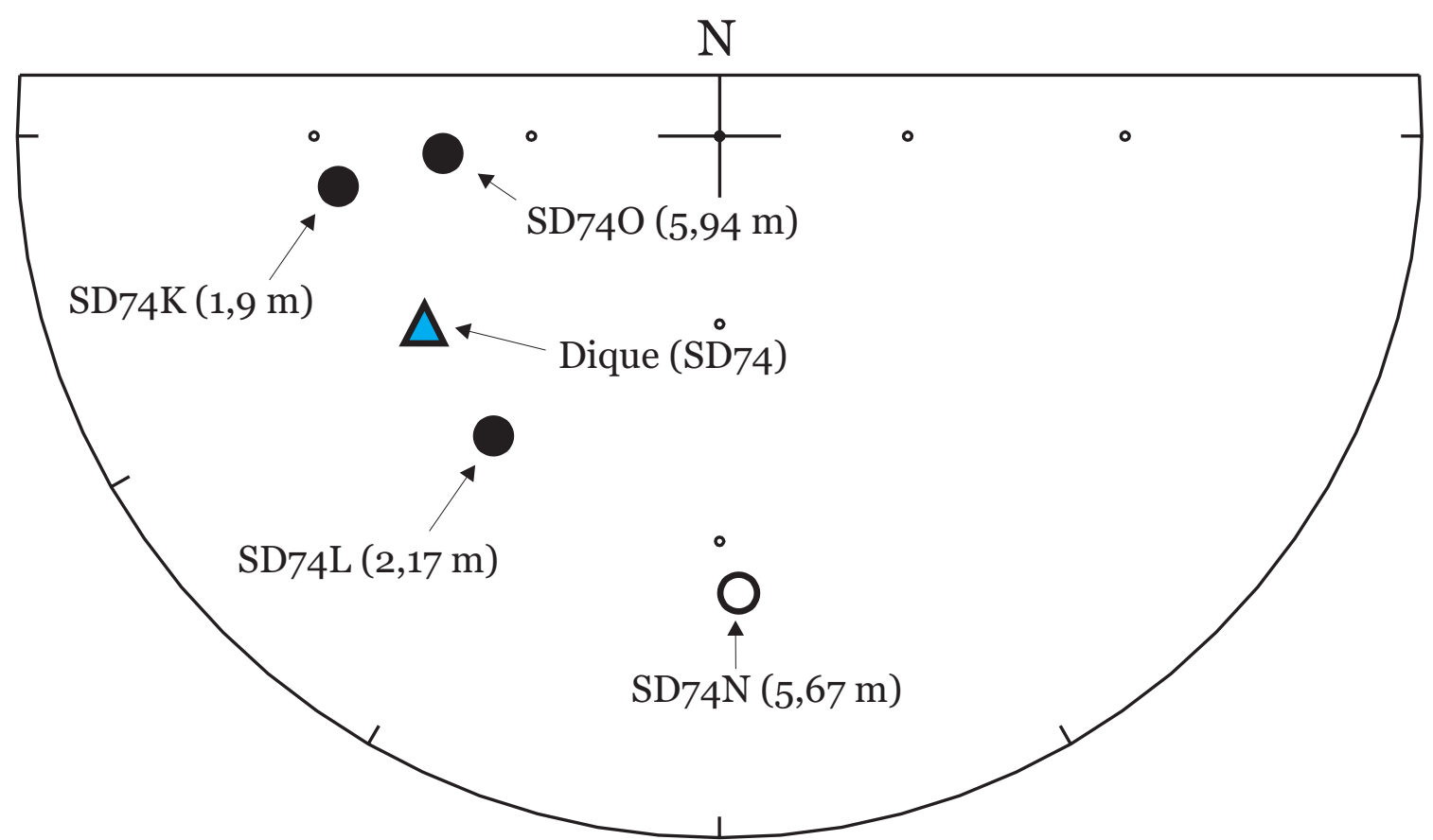

Figura 4.27: Direções médias por amostra obtidas para o teste do contato cozido efetuado para o sítio 23.

As amostras coletadas próximas ao dique (SD74K e SD74L) também apresentaram uma direção sudoeste com inclinação positiva, não muito diferente da obtida para as amostras do próprio dique (vide exemplos de desmagnetização na figura 4.26 e direções médias na figura 4.27). Por outro lado, a amostra SD74-N, uma das mais distantes do contato, apresentou uma direção totalmente diferente da apresentada pelo dique (Figuras 4.26 e 4.27), indicando um teste de contato 
cozido "positivo". Contraditoriamente, a amostra SD74-O, coletada próxima a amostra SD74-N e a mais distante do dique, apresentou uma direção oeste com inclinação positiva, não muito diferente da obtida para a amostra SD74-K e para o próprio dique, sugerindo um teste de contato cozido "negativo" (vide Figura 4.26 e 4.27). Esta incerteza da direção magnética apresentada pela rocha encaixante pode estar relacionada a litologia da rocha amostrada, visto que, o granito geralmente não apresenta direções de magnetizações coerentes. Diante deste fato classificaremos o teste de contato realizado nas amostras do sítio 23 (SD74) como inconclusivo.

\subsubsection{Teste da Reversão}

Na determinação das direções características, obteve-se direções normais e reversas para a componente B (Seção 4.3). Com isso, foi possível realizar o teste da reversão para esta componente. $\mathrm{Na}$ figura 4.28a temos a média das direções normais da componente B juntamente com o limite de confiança $\left(\alpha_{95}\right)$; da mesma forma a figura $4.28 \mathrm{~b}$ mostra a média das direções reversas da componente $\mathrm{B}$ juntamente com o limite de confiança $\left(\alpha_{95}\right)$.

A figura 4.28c mostra os círculos de confiança dos dois grupos de direções após a inversão de polaridade das direções com inclinação negativa. Existe uma intersecção entre os limites de confiança, sugerindo que existe uma relação antipodal entre ambos.

Utilizando o teste de reversão proposto por McFadden \& McElhinny (1990), essa intersecção obtida na figura $4.28 \mathrm{c}$ produziu parâmetros com $\gamma_{o}=25.2^{\circ}$ e $\gamma_{c}=$ $21.0^{\circ}$ que representam, respectivamente, o ângulo entre as duas direções médias e o ângulo crítico no qual as duas direções tornam-se significativamente diferentes em um nível de confiança de 95\%. Estes parâmetros classificam o teste de reversão 
como "indeterminado", visto que, $\gamma_{o}>\gamma_{c}$ e $\gamma_{c}>20^{\circ}$. Assim, o resultado obtido mostra que não se pode afirmar que a magnetização remanescente característica está totalmente livre de componentes secundárias. Entretanto, este resultado pode ter sido influenciado pelo pequeno número de direções normais que foram usadas no teste, produzindo uma direção média com limite de confiança elevado, fato este que, claramente, influencia na determinação dos parâmetros e na classificação do teste de reversão.

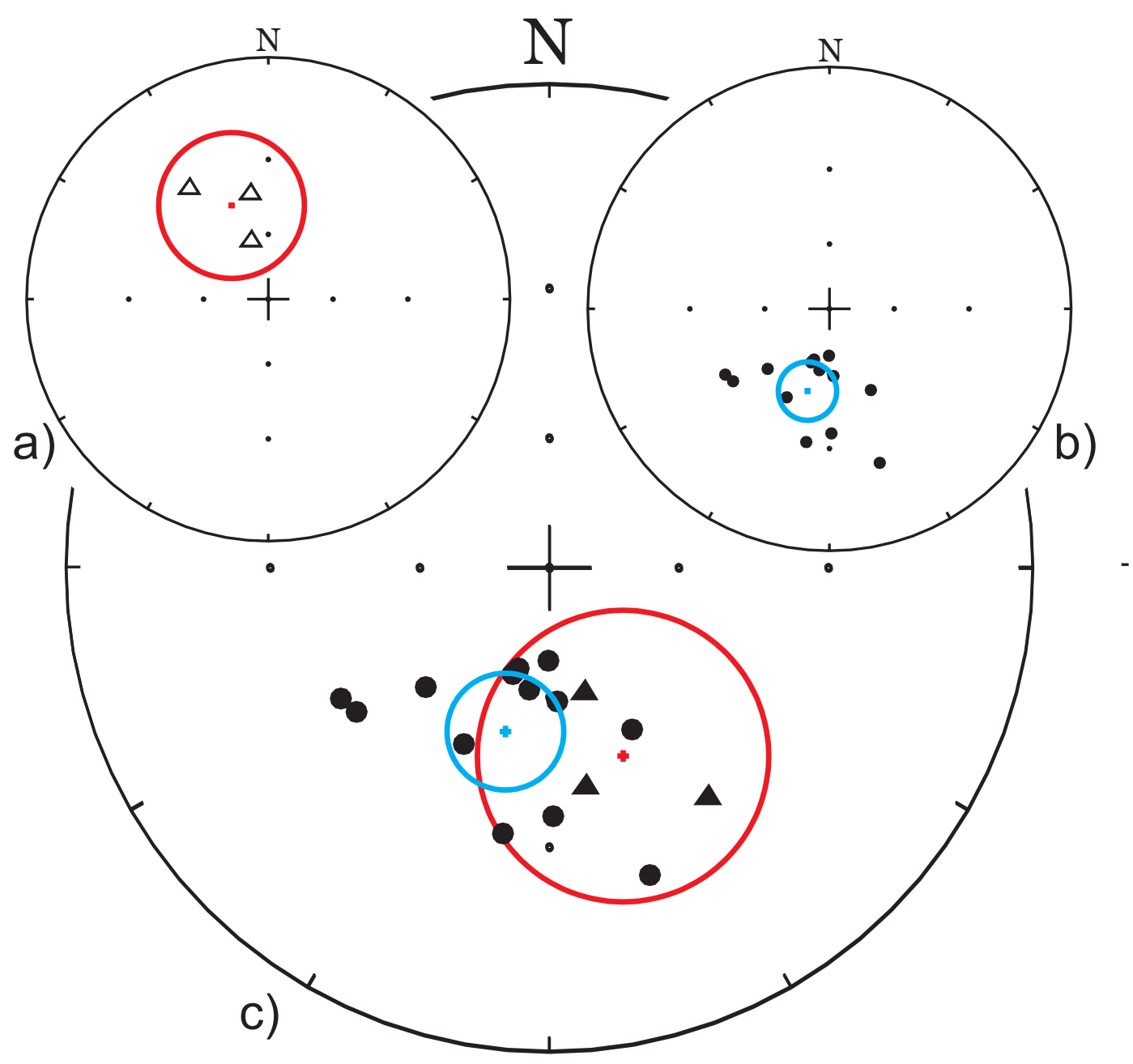

Figura 4.28: (a) Média das direções normais (componente B), (b) média das direções normais e reversas (componente B), (c) teste de reversão. Os círculos indicam o limite de confiança $\left(\alpha_{95}\right)$. O simbolo + em vermelho e em azul indicam a média das direções normais e reversas, respectivamente. Os triângulos vazios representam direções normais. 


\section{Capítulo 5}

\section{DISCUSSÃO}

\subsection{Estabilidade das direções paleomagnéticas}

Os resultados obtidos neste trabalho (Capítulo 4) mostram a presença de dois grupos de direções, representados pelas componentes de magnetização A e B, as quais estão associadas, respectivamente, ao gabro Guadalupe (incluindo dois diques máficos) e às rochas ácidas da Suíte Colíder e máficas associadas.

A componente A é representada por direções norte com inclinações positivas moderadas (sítios 2, 4 e 16), as quais foram encontradas em rochas situadas em localidades muito distantes uma da outra (Figura 2.4). Além disso, esta direção é bem diferente do campo atual e também não deve representar uma direção Mesozóica ou Cenozóica, o que exclui processos de remagnetização mais recentes nestas rochas. A análise petrográfica em amostras destes sítios mostra textura ígnea preservada, sem nenhuma (ou pouca) evidência de metamorfismo. Além disso, esta componente está associada a grãos de pseudo-domínio simples (PSD) e temperaturas de bloqueio altas, próximas da temperatura de Curie da magnetita, as quais são características de portadores de alta estabilidade magnética. Sendo assim, é muito provável que esta componente represente uma magnetização termo-remanescente (MTR), adquirida durante a intrusão e resfriamento destas rochas.

Infelizmente, não existem ainda datações da Intrusiva Guadalupe que possam estabelecer a idade deste corpo intrusivo e, por conseqüência, a idade do 
pólo determinado para a Intrusiva Guadalupe fica indeterminada. Datações K-Ar e ${ }^{40} \mathrm{Ar} /{ }^{39} \mathrm{Ar}$ estão atualmente em andamento para amostras do sítio 2. Espera-se que estas análises estabeleçam a idade deste paleopólo para que ele possa ser utilizado nas reconstruções paleogeográficas do Cráton Amazônico.

A componente B, por outro lado, é representada por direções norte (sul) com inclinações negativas (positivas), de moderada até alta, identificadas para a maior parte das amostras analisadas (rochas ácidas da Suíte Colíder e máficas associadas). Este grupo de direções é caracterizado, portanto, por polaridades reversas e normais, o que sugere que as direções de magnetização destas rochas representam o registro de um tempo suficientemente grande para ter eliminado a variação secular do campo geomagnético.

Infelizmente, os dois testes de contato cozido, efetuados para dois diques máficos, um intrusivo em rocha ácida e outro intrusivo em granito, mostraram-se inconclusivos, pois não foi possível isolar uma direção da rocha encaixante, que seja diferente da representada pelos diques (Seção 4.5.1). Entretanto, algumas evidências sugerem que a direção de magnetização característica (MRC) obtida para estas rochas pode representar uma magnetização primária adquirida durante a formação das rochas.

1) As rochas máficas que apresentam esta direção têm como portadores magnéticos, grãos de magnetita na estrutura de pseudo-domínio simples e temperaturas de bloqueio altas, próximas da temperatura de Curie da magnetita, os quais são considerados como portadores eficientes de MTR (Dunlop \& Özdemir, 1997).

2) As rochas ácidas contêm hematita como principal portador magnético que apresenta alta coercividade e temperaturas de bloqueio elevadas, próximas da sua temperatura de Curie $\left(680^{\circ} \mathrm{C}\right)$. Este mineral, de alta estabilidade magnética, pode ser formado em altas temperaturas $\left(585-880^{\circ} \mathrm{C}\right)$ através de processos de oxidação 
(metassomatismo) quando ocorre uma alta fugacidade de oxigênio (Mann et al., 2006; Ade Hall et al., 1971), o que pode ter sido o caso das rochas analisadas neste trabalho.

3) A análise petrográfica dessas rochas mostra textura ígnea preservada, sem nenhuma (ou pouca) evidência de metamorfismo.

4) A componente B, apesar de não coincidir com o campo geomagnético atual, pode representar uma remagnetização em tempos mais recentes, já que o pólo SC se assemelha a pólos do Mesozóico (Marzoli et al., 1999). Entretanto, a componente B foi encontrada para rochas máficas e ácidas coletadas em uma área relativamente grande. Além disso, outras rochas máficas situadas na mesma região apresentaram uma MRC diferente (componente B), a qual deve, muito provavelmente, ter sido adquirida durante o Pré-cambriano. Diante destes fatos, fica difícil imaginar um evento de remagnetização regional que afetasse toda a área estudada e preservasse direções mais antigas somente em algumas rochas.

Vale ainda discutir o resultado apresentado pelas amostras do sítio 5. Estas amostras representam um dique de granodiorito que também apresentou a componente B. Entretanto, os dados de mineralogia magnética mostram que o seu principal portador magnético é a maghemita, que se forma pela oxidação da magnetita em baixas temperaturas, sugerindo uma origem secundária para a magnetização destas rochas, adquirida em tempos mais recentes. Entretanto, estudos mostram que a oxidação de grãos de domínio simples de magnetita e titanomagnetita (portadores de MTR), produzindo maghemita ou titanomaghemita, geram uma magnetização remanescente química (MRQ) que permanece paralela a MTR inicial, portada pelo mineral de origem, não importando a direção do campo magnético que atua durante a oxidação (Heider \& Dunlop, 1987; Özdemir \& Dunlop, 1985; Johnson \& Merrill, 1974; Heider et al., 1992). Segundo Johnson \& Heider (1974), este paralelismo entre a MRQ e a MTR 
pode estar relacionado à anisotropia de forma que domina o crescimento da MRQ ou ainda a interações de troca positivas que ocorrem entre a magnetita e a maghemita durante a oxidação. É interessante notar que os dados de histerese obtidos para as amostras do sítio 5 (SD8-A e SD10-C), mostram estruturas de pseudo-domínio simples no diagrama de Day e são as que mais se aproximam do campo de domínio simples (Tabela 4.1 e Figura 4.7).

Ainda, a análise petrográfica destas rochas indica textura ígnea preservada, sem evidências de metamorfismo ou alterações intempéricas, tanto que, entre todas as amostras analisadas que apresentaram a componente B, foi a que se mostrou mais adequada para datação.

\subsection{Pólos Paleomagnéticos Obtidos}

Neste trabalho, determinou-se dois pólos paleomagnéticos para o Cráton Amazônico associados as componentes A (pólo IG, Intrusiva Guadalupe) e B (pólo SC, Suíte Colíder), os quais estão localizados em $298.8^{\circ} \mathrm{E}, 50.4^{\circ} \mathrm{N}\left(\alpha_{95}=15.1^{\circ}\right)$ e $289.4^{\circ} \mathrm{E}, 65.4^{\circ} \mathrm{S}\left(\alpha_{95}=12.9^{\circ}\right)$, respectivamente. A representação desses dois pólos em relação a posição atual do Cráton Amazônico está na figura 5.1. 


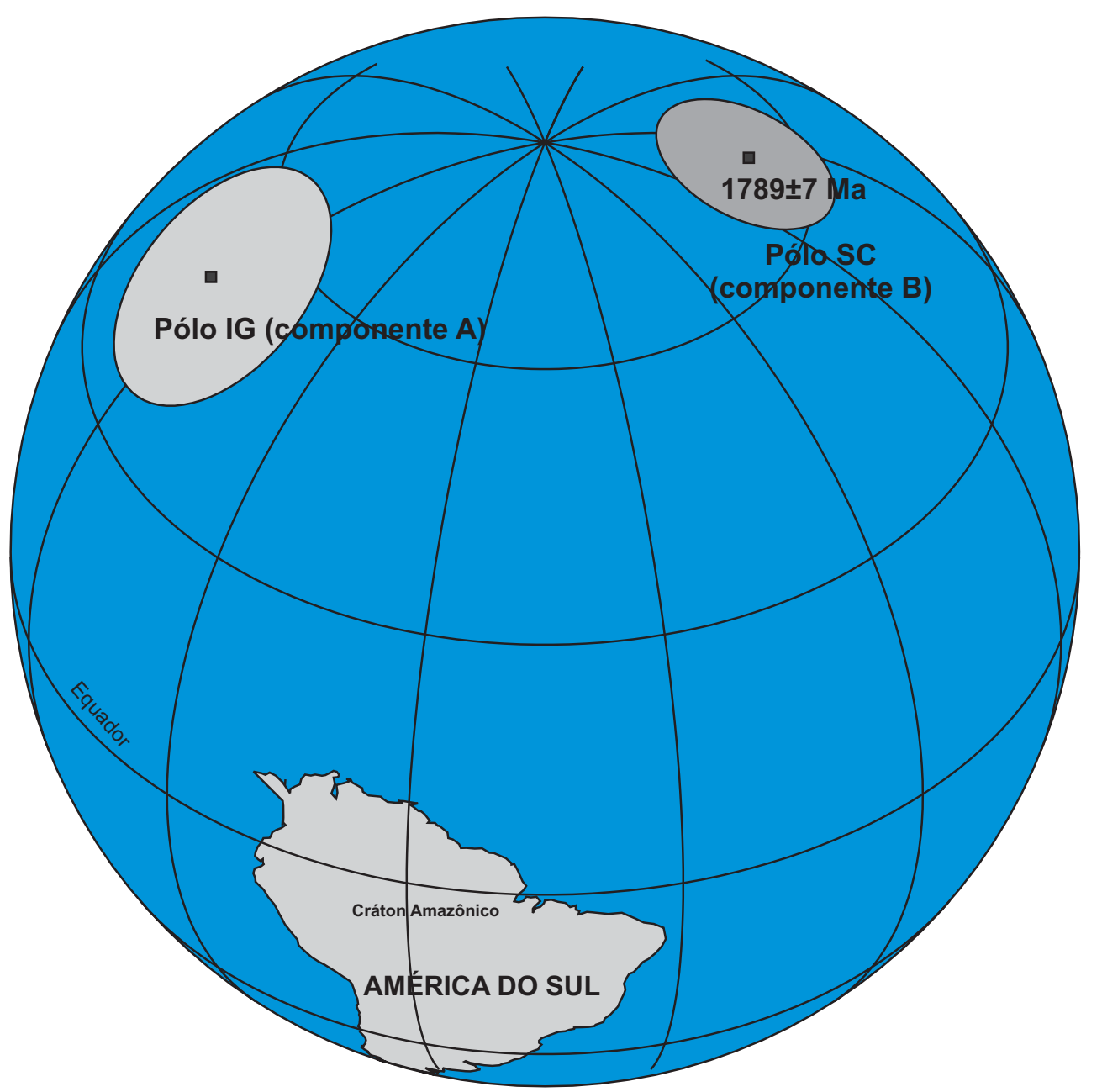

Figura 5.1: Representação dos dois pólos paleomagnéticos obtidos neste trabalho em relação a posição atual do Cráton Amazônico.

Para a determinação do pólo paleomagnético SC utilizou-se 16 sítios da amostragem. Os tratamentos de laboratório forneceram direções magnéticas estáveis e coerentes em aproximadamente 73\% dos espécimes analisados, além de parâmetros estatísticos adequados, fatores que destacam a boa qualidade deste paleopólo.

Já para a determinação do pólo paleomagnético IG foram utilizados apenas 3 sítios. Embora esta direção esteja bem caracterizada em $72 \%$ dos espécimes analisados, três sítios é considerado um número pequeno de pontos amostrados para eliminar o efeito da variação secular do campo geomagnético. 


\subsection{Confiabilidade dos Pólos Paleomagnéticos}

\subsubsection{Componente B}

Segundo os critérios de confiabilidade (Seção 3.8) de Van der Voo (1990) que qualificam pólos paleomagnéticos, podemos associar a componente $B$, um fator de confiabilidade $\mathrm{Q}=5$, já que este cumpri 5 dos 7 critérios:

1) A idade das rochas da Suíte Colíder pode ser considerada bem determinada: segundo as datações U-Pb descritas na seção 2.4.4 (Pimentel et al., 2001; Pinho et al., 2003; Lacerda-Filho et al., 2004), elas possuem idade U-Pb média de $1789 \pm 7$ Ma. Esta idade apresenta um erro menor que $4 \%$ da idade da rocha.

2) Para a determinação do pólo paleomagnético foram utilizados um número adequado de amostras ( $\mathrm{N}=160,16$ sítios); também encontrou-se parâmetros estatísticos adequados $\left(\alpha_{95}=11.3^{\circ}\right.$ e $\left.\mathrm{K}=11.7\right)$ na determinação da direção média.

3) As amostras foram submetidas a desmagnetizações por CA e térmica detalhadas para isolar as componentes de magnetização, as quais foram obtidas vetorialmente (detalhes da desmagnetização na seção 3.2).

4) Controle estrutural e tectônico: os sítios paleomagnéticos amostrados no Cráton Amazônico não apresentam evidências de que esta região sofreu movimentos tectônicos posteriores. A área em que essas rochas foram originadas é considerada geologicamente estável em relação ao desenvolvimento da Província Rio NegroJuruena (Seção 2.3). Além disso, as amostras foram coletadas em uma ampla região (Figura 2.4) e obteve-se direções coerentes entre os vários sítios, o que mostra que, pelo menos, não houve movimentos tectônicos intra-sítios, após a aquisição da magnetização. 
5) Presença de reversões nas direções magnéticas obtidas (Figura 4.16b), sugerindo que a variação secular do campo geomagnético foi eliminada na média.

6) Para testar a estabilidade da magnetização, dois testes de contato cozido foram realizados para os sítios 12 e 23 (Seção 4.4.1), porém, ambos mostraram-se inconclusivos.

7) As direções paleomagnéticas obtidas são semelhantes às encontradas para os sedimentos do Grupo Aguapeí (1.22-1.15 Ga) e sills que cortam essas rochas (D'Agrella-Filho et al., 2003).

Desta forma, apenas dois dos critérios estabelecidos por Van der Voo (1990) não foram satisfeitos, o critério 6 (testes de contato cozido mostraram-se inconcluivos) e o critério 7 (paleopólo SC assemelha-se a paleopólo de idade mais jovem). Todavia, estudos petrográficos e de mineralogia magnética sugerem uma origem primária para a magnetização isolada nestas rochas (Seção 5.1).

\subsubsection{Componente $A$}

Podemos associar ao pólo paleomagnético obtido para a componente $\mathrm{A}$, um fator de confiabilidade $Q=3$, já que este cumpri 3 dos 7 critérios, de acordo com os critérios de confiabilidade estabelecidos por Van der Voo (1990):

1) As rochas da Intrusiva Máfica Guadalupe não possuem ainda idade determinada por métodos radiométricos (Seção 2.4.2), não sendo possível estabelecer a idade deste pólo com incerteza menor ou igual a $4 \%$ da idade da rocha;

2) Embora, o cálculo da direção média tenha fornecido parâmetros estatísticos adequados $\left(\alpha_{95}=15.8^{\circ}, \mathrm{K}=61.9\right)$, o número de espécimes $(\mathrm{N}=18)$ e sítios (3) utilizados no cálculo do pólo, é considerado insuficiente para eliminar a variação secular do campo geomagnético; 
3) As amostras foram submetidas a desmagnetizações por CA e térmica detalhadas para isolar as componentes de magnetização, as quais foram obtidas vetorialmente (detalhes da desmagnetização na seção 3.2).

4) Controle estrutural e tectônico: os sítios paleomagnéticos amostrados no Cráton Amazônico não apresentam evidências de que esta região sofreu movimentos tectônicos posteriores. A área em que essas rochas foram originadas é considerada geologicamente estável em relação ao desenvolvimento da Província Rio NegroJuruena (Seção 2.3). Além disso, os sítios foram coletados a grandes distâncias entre si (Figura 2.4), e em regiões onde também foram coletados sítios que fornecem o componente B. Esta evidência reforça o argumento de que não houve movimentos tectônicos intra-sítios.

5) Não há presença de reversões das direções magnéticas para os sítios da componente A (Figura 4.16a)

6) Não foi realizado um teste de estabilidade magnética, pois, durante a amostragem não se encontrou afloramentos em que este teste pudesse ser realizado.

7) Embora não saibamos a idade desta componente, não há relatos de componentes semelhantes para rochas do Cráton Amazônico. O pólo paleomagnético (pólo FP; $326.9^{\circ} \mathrm{E}, 33.6^{\circ} \mathrm{N}$ ) obtido para os Carbonatos da Formação Puga (Trindade et al., 2003) de idade Neoproterozóica é o que mais se aproxima do pólo obtido para a componente A $\left(298.8^{\circ} \mathrm{E}, 50.4^{\circ} \mathrm{N}\right)$. A componente de magnetização que originou o pólo FP é interpretado como decorrente de um processo de remagnetização dos

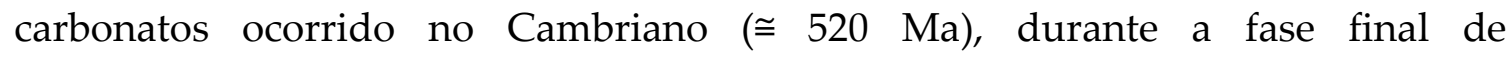
amalgamação do Gondwana (Trindade et al., 2003). Entretanto, nenhum evento desta idade parece ter afetado a área em estudo. 


\subsection{Pólos Paleomagnéticos Paleoproterozóicos disponíveis para o Cráton Amazônico}

A tabela 5.1 apresenta os dados paleomagnéticos obtidos para o Cráton Amazônico para o intervalo de tempo entre 1.6 e $2.1 \mathrm{Ga}$, incluindo os paleopólos (SC) e (IG) obtidos neste trabalho para a Suíte Colíder e para Intrusiva Guadalupe. O apêndice A apresenta uma breve discussão de cada pólo, compreendendo litologia estudada, componentes de magnetização isolados, natureza primária ou secundária destes componentes e as idades associadas.

Tabela 5.1: Lista de pólos paleomagnéticos para o Cráton Amazônico entre 2.1-1.6 Ga.

\begin{tabular}{|c|c|c|c|c|c|c|c|}
\hline Formação & Sigla & $\operatorname{Plat}\left({ }^{\circ} \mathrm{N}\right)$ & Plong $\left({ }^{\circ} \mathrm{E}\right)$ & $\alpha_{95}\left(^{\circ}\right)$ & Age(Ma) & Q & Referência \\
\hline $\begin{array}{c}\text { Tonalito e } \\
\text { MetaUltrabásicas } \\
\text { Oyapok }\end{array}$ & OYA & -28.0 & 346.0 & 13.8 & $2036 \pm 14$ & 5 & $\begin{array}{l}\text { Nomade et } \\
\text { al., } 2001\end{array}$ \\
\hline $\begin{array}{l}\text { Granitos e } \\
\text { amfibolitos }\end{array}$ & GUI1 & -62.0 & 61.0 & 10.0 & $2014 \pm 27$ & 5 & $\begin{array}{l}\text { Nomade et } \\
\text { al., } 2003\end{array}$ \\
\hline $\begin{array}{l}\text { Complexo } \\
\text { Imataca }\end{array}$ & IM1 & -49.0 & 18.0 & 9.0 & $\begin{array}{l}2000- \\
2055\end{array}$ & 3 & $\begin{array}{c}\text { Onstott \& } \\
\text { Hargraves, } \\
1981\end{array}$ \\
\hline $\begin{array}{l}\text { Complexo } \\
\text { Imataca }\end{array}$ & IM2 & -29.0 & 21.0 & 13.0 & $\begin{array}{l}2000- \\
2055\end{array}$ & 2 & $\begin{array}{c}\text { Onstott \& } \\
\text { Hargraves, } \\
1981\end{array}$ \\
\hline $\begin{array}{c}\text { Granitos e } \\
\text { metasedimentos }\end{array}$ & GU12 & -5.0 & 50.0 & 18.0 & $1993 \pm 25$ & 5 & $\begin{array}{l}\text { Nomade et } \\
\text { al., } 2003\end{array}$ \\
\hline $\begin{array}{c}\text { Pluton } \\
\text { Encrucijada }\end{array}$ & EN1 & 53 & 202 & 4 & $\begin{array}{l}1900- \\
2000\end{array}$ & 3 & $\begin{array}{l}\text { Onstott et } \\
\text { al., 1984a }\end{array}$ \\
\hline Pluton & EN2 & -38 & 37 & 15 & $1900-$ & 2 & Onstott et \\
\hline
\end{tabular}




\begin{tabular}{|c|c|c|c|c|c|c|c|}
\hline Encrucijada & & & & & 2000 & & al., $1984 a$ \\
\hline $\begin{array}{l}\text { Cuchivero- } \\
\text { Caicara }\end{array}$ & $\mathrm{CC}$ & -69.0 & 70.0 & 22.0 & $\begin{array}{l}1960- \\
1940\end{array}$ & 2 & $\begin{array}{c}\text { Onstott \& } \\
\text { Hargraves, } \\
1981\end{array}$ \\
\hline $\begin{array}{c}\text { Dikes Rio Aro e } \\
\text { Guaniamo }\end{array}$ & DDII & -42.0 & 0.0 & 6.0 & $1820 \pm 20$ & 5 & $\begin{array}{l}\text { Onstott et } \\
\text { al., 1984b }\end{array}$ \\
\hline Suíte Colíder & SC & -65.4 & 289.4 & 12.9 & $1789 \pm 7$ & 5 & $\begin{array}{c}\text { Este } \\
\text { trabalho }\end{array}$ \\
\hline Teles Pires ${ }^{*}$ & $\mathrm{TP}$ & -68.8 & 292.4 & 8.7 & 1700 & & $\begin{array}{c}\text { Pacca \& } \\
\text { Cordani, } \\
1979\end{array}$ \\
\hline $\begin{array}{c}\text { Dikes Rio Aro e } \\
\text { Guaniamo }\end{array}$ & DDI & 59.0 & 222.0 & 7.0 & $1640 \pm 3$ & 4 & $\begin{array}{l}\text { Onstott et } \\
\text { al., 1984b }\end{array}$ \\
\hline $\begin{array}{l}\text { Doleritos } \\
\text { Suriname }\end{array}$ & SD2 & -44.0 & 30.0 & 2.0 & $\begin{array}{l}1750- \\
1600\end{array}$ & 1 & $\begin{array}{l}\text { Veldkamp } \\
\text { et al., } 1971\end{array}$ \\
\hline $\begin{array}{l}\text { Doleritos } \\
\text { Suriname }\end{array}$ & SD1 & -8.0 & 53.0 & 6.0 & $\begin{array}{l}1750- \\
1600\end{array}$ & 1 & $\begin{array}{l}\text { Veldkamp } \\
\text { et al., } 1971\end{array}$ \\
\hline Formação Uairen & U1n & 72 & 204 & 7 & $\begin{array}{l}1580- \\
1960\end{array}$ & 3 & $\begin{array}{c}\text { Castillo \& } \\
\text { Costanzo- } \\
\text { Alvarez } \\
(1993)\end{array}$ \\
\hline Formação Uairen & U1r & -63 & 8 & 12 & $\begin{array}{l}1580- \\
1960\end{array}$ & 3 & $\begin{array}{c}\text { Castillo \& } \\
\text { Costanzo- } \\
\text { Alvarez } \\
(1993)\end{array}$ \\
\hline Formação Uairen & $\mathrm{U} 2$ & 67 & 189 & 18 & $\begin{array}{l}1580- \\
1960\end{array}$ & 2 & $\begin{array}{c}\text { Castillo \& } \\
\text { Costanzo- } \\
\text { Alvarez } \\
(1993)\end{array}$ \\
\hline $\begin{array}{c}\text { Grupo } \\
\text { Beneficente }\end{array}$ & GB & 75.2 & 211.2 & 5.4 & $1430 \pm 70$ & & $\begin{array}{c}\text { Pacca \& } \\
\text { Cordani, } \\
1979\end{array}$ \\
\hline
\end{tabular}




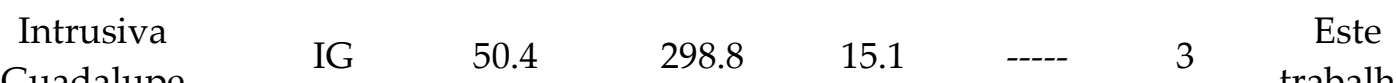

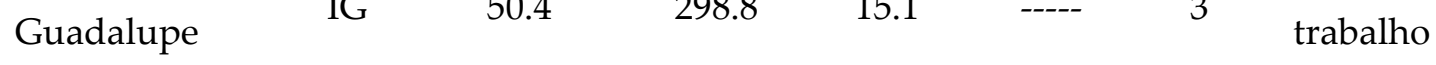

Q (fator de confiabilidade), * (incluído no pólo SC)

Os trabalhos paleomagnéticos até agora realizados para o Cráton Amazônico demonstram a escassez de paleopólos de boa qualidade para este período. D'Agrella-Filho (1999) apresentou uma compilação de dados paleomagnéticos proterozóicos para o Cráton Amazônico. A maioria dos 16 paleopólos apresentados é de má qualidade. Apenas 37,5\% destes pólos apresentam fator $\mathrm{Q}>3$, sendo que poucos apresentam idades bem determinadas.

Trabalhos mais recentes (Nomade et al., 2001, 2003) apresentam novos dados paleomagnéticos obtidos para a Guiana Francesa para o intervalo de tempo entre 2,04 e 1,97 Ga. Com base nestes dados e os disponíveis na literatura para a Venezuela (Onstott \& Hargraves; 1981; Onstott et al., 1984), Nomade et al. (2003) propuseram uma curva de deriva polar aparente para o Escudo da Guiana entre 2040 e 1990 Ma (Figura 5.2).

Para idades mais recentes, somente o pólo obtido para os diques da Venezuela (Doleritos Roraima, Rio Aro e Rio Guianiamo), pólo DDII (Tabela 5.1, Apêndice A) com idade $1820 \pm 20 \mathrm{Ma}\left({ }^{40} \mathrm{Ar} /{ }^{39} \mathrm{Ar}\right.$, biotita) e o pólo determinado neste trabalho para a Suíte Colíder (pólo SC) com idade $1789 \pm 7$ Ma (U-Pb), mostram-se mais confiáveis. Estes pólos são cerca de 170 Ma mais jovens que o pólo GUI2 (1993 $\pm 25 \mathrm{Ma}$ ) obtido para a Guiana Francesa (Nomade et al., 2003) o que dificulta a construção da CDPA para o próton-Cráton Amazônico para idades mais recentes, devido a indefinição na polaridade dos pólos DDII e SC.

A figura 5.1 mostra duas possíveis CDPAs, uma utilizando o pólo DDII e SC e a outra seus antipólos. 

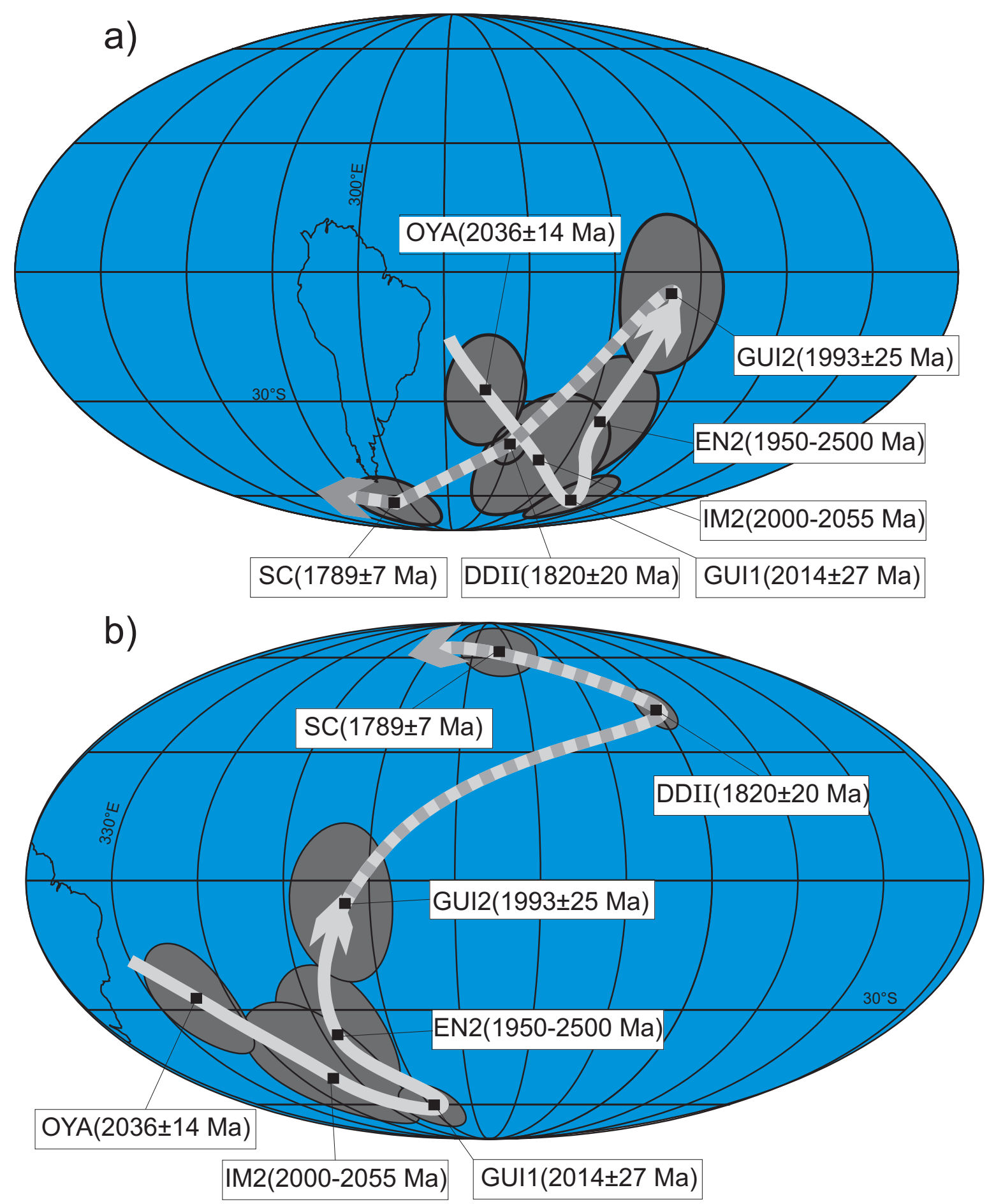

Figura 5.2: Representação da curva de deriva polar aparente (CDPA) para o Cráton Amazônico para o intervalo entre 2040-1790 Ma. A parte contínua é a proposta por Momade et al. (2003) e a parte tracejada é proposta por este trabalho utilizando os pólos DDII e SC (a) e seus respectivos anti-pólos (b). A parte tracejada é ainda indefinida devido a falta de pólos paleomagnéticos de referência para o intervalo de idades entre 1990 e 1820 Ma Os círculos indicam o limite de confiança $\left(\alpha_{95}\right)$ para cada paleopólo. 
Diante da impossibilidade de se construir uma curva de deriva polar aparente confiável para o Cráton Amazônico, entre 1990 Ma e 1780 Ma, optou-se por utilizar pólos de referência para investigar a paleogeografia continental na época da evolução do cinturão Rio Negro-Juruena $(\sim 1,8 \mathrm{Ga})$ e a possibilidade da existência de um supercontinente paleoproterozóico (Buchan et al., 2000, Pesonen et al., 2003).

O Cráton Amazônico é caracterizado por uma evolução geológica PaleoMesoproterozóica singular na América do Sul, com a formação de arcos magmáticos que foram acrescidos ao proto-cráton Amazônico. Trabalhos sobre a Laurentia e a Báltica mostram que estas unidades tiveram uma evolução geológica semelhante, o que sugere que estes três proto-crátons podem ter sido partes de uma mesma crosta continental por boa parte do Paleo-Mesoproterozóico (Park et al., 1973; Buchan et al., 2000; Geraldes et al., 2001; Karlstrom et al., 2001; Pesonen et al., 2003). Discutiremos a seguir a possibilidade da existência desta grande massa continental, com base em dados paleomagnéticos de referência.

\subsection{Recontruções Paleogeográficas}

A tabela 5.2 apresenta pólos paleomagnéticos selecionados para a Laurentia, a Báltica e o Cráton Amazônico para o intervalo de tempo entre 1,84 e 1,77 Ga, o qual abrange a idade do pólo paleomagnético obtido para a Suíte Colíder (1,78 1,80 Ga). Incluiu-se também nesta tabela, um pólo obtido para um enxame de diques do Norte da China, de excelente qualidade ( $Q=6)$ (Halls et al., 2000). A idade de um destes diques, datado em zircão primário pelo método U-Pb, é de 1769,1 \pm 2,5 Ma. 
Tabela 5.2: Pólos paleomagnéticos selecionados para a Laurentia, a Báltica, o Norte da China e o Cráton Amazônico entre 1,83-1,70 Ga.

\begin{tabular}{|c|c|c|c|c|c|c|}
\hline Continente & Formação & $\operatorname{Plat}\left({ }^{\circ} \mathrm{N}\right)$ & Plong $\left({ }^{\circ} \mathrm{E}\right)$ & $\alpha_{95}\left(^{\circ}\right)$ & Idade(Ma) & Referência \\
\hline Laurentia & $\begin{array}{l}\text { Pluton Boot- } \\
\text { Phantom }\end{array}$ & 62.0 & 279.0 & 8.0 & $1838 \pm 1$ & $\begin{array}{c}\text { Symons \& } \\
\text { Mackay, } \\
1999\end{array}$ \\
\hline Laurentia & $\begin{array}{l}\text { Diques } \\
\text { Sparrow } \\
(\text { caso } A)\end{array}$ & 12.0 & 291.0 & 8.0 & $1827 \pm 4$ & $\begin{array}{c}\text { McGlynn et } \\
\text { al., } 1974\end{array}$ \\
\hline Laurentia & $\begin{array}{l}\text { Formação } \\
\text { Deschambault }\end{array}$ & 77.0 & 258.0 & 6.0 & $1796 \pm 15$ & $\begin{array}{c}\text { Symons et } \\
\text { al., } 2000\end{array}$ \\
\hline Laurentia & $\begin{array}{l}\text { Grupo } \\
\text { Dubawnt }\end{array}$ & 7.0 & 277.0 & 8.0 & $1785 \pm 4$ & $\begin{array}{c}\text { Park et al., } \\
1973\end{array}$ \\
\hline Laurentia & $\begin{array}{l}\text { Peninsular } \\
\text { Sill }\end{array}$ & -22.0 & 263.0 & 7.0 & 1760 & $\begin{array}{c}\text { Irving \& } \\
\text { McGlynn, } \\
1979\end{array}$ \\
\hline Laurentia & $\begin{array}{l}\text { Diques } \\
\text { Molson } \\
(\text { comp. A) }\end{array}$ & -16.0 & 277.0 & 4.0 & 1750 & $\begin{array}{c}\text { Zhail et al., } \\
1994\end{array}$ \\
\hline Báltica & $\begin{array}{l}\text { Diques } \\
\text { Haukivesi }\end{array}$ & 48.0 & 225.0 & 3.0 & 1840 & $\begin{array}{l}\text { Neuvonen } \\
\text { et al., } 1981\end{array}$ \\
\hline Báltica & $\begin{array}{l}\text { Formação } \\
\text { Shosksha }\end{array}$ & 42.0 & 221.2 & 7.0 & $1790-1770$ & $\begin{array}{l}\text { Pisarevsky } \\
\text { et al., } 2001\end{array}$ \\
\hline Báltica & $\begin{array}{l}\text { Sills } \\
\text { Ropruchey }\end{array}$ & 40.5 & 229.8 & 8.1 & $1770 \pm 12$ & $\begin{array}{c}\text { Fedotova et } \\
\text { al., } 1999\end{array}$ \\
\hline $\begin{array}{l}\text { Norte da } \\
\text { China }\end{array}$ & $\begin{array}{l}\text { Diques Norte } \\
\text { da China }\end{array}$ & 36.0 & 247.0 & 3.0 & $1769.1 \pm 2.5$ & $\begin{array}{l}\text { Halls et al., } \\
\quad 2000\end{array}$ \\
\hline $\begin{array}{c}\text { Cráton } \\
\text { Amazônico }\end{array}$ & $\begin{array}{l}\text { Diques } \\
\text { Rio Aro e } \\
\text { Guaniamo }\end{array}$ & -42.0 & 0.0 & 16 & 1843 & $\begin{array}{l}\text { Onstott et } \\
\text { al., 1984b }\end{array}$ \\
\hline $\begin{array}{c}\text { Cráton } \\
\text { Amazônico }\end{array}$ & Suíte Colíder & -65.4 & 289.4 & 12.9 & $1789 \pm 7$ & $\begin{array}{c}\text { Este } \\
\text { trabalho }\end{array}$ \\
\hline
\end{tabular}




\subsubsection{Reconstrução em $1,83 \mathrm{Ga}$}

Pesonen et al. (2003), utilizando pólos de referência para os vários blocos continentais, propuseram reconstruções paleogeográficas para vários períodos do Proterozóico. A reconstrução proposta para 1,83 Ga é reproduzida na figura 5.3. Para esta reconstrução, Pesonen e colaboradores escolheram o pólo de referência obtido para os Diques Sparrow (excelente idade U-Pb de 1.827 \pm 4 Ma, Tabela 5.2) para representar a Laurentia (Caso A da Figura 7a no trabalho deles), o qual a coloca em latitudes intermediárias, entre $20^{\circ}$ e $60^{\circ}$. Outros pólos de mesma idade obtidos somente para a província Orogênica Trans-Hudsoniana (OTH) colocam a Laurentia em altas latitudes nesta época (Caso C da Figura $7 \mathrm{~b}$ no trabalho de Pesonen et al., 2003). Algumas interpretações para estes resultados são possíveis, inclusive a existência de um grande Oceano entre a OTH e o resto da Laurentia (Symons \& MacKay, 1999). Outra interpretação possível é a de que estes pólos representam magnetizações secundárias e, portanto, não podem ser utilizados para definir a posição da Laurentia nesta época (Pesonen et al., 2003).

Estes autores apresentam três razões para a escolha de pólos que colocam a Laurentia em latitudes intermediárias em detrimento de uma região mais polar, indicada pelos pólos da OTH: (I) não existem testes de campo rigorosos que comprovem a origem primária da magnetização encontrada para as unidades da OTH, (II) não existem evidências paleoclimatológicas para se colocar a Laurentia em latitudes polares, em 1,83 Ga atrás e (III) a posição da Báltica, estabelecida pelo pólo (1840 Ma, U-Pb) bem definido para os Lamprófiros Haukivesi da Finlândia (Tabela 5.2), é lateralmente contígua a Laurentia (Figura 5.3), coerente com a idéia de que cinturões coevos presentes na Laurentia e na Báltica foram acrescidos em um processo de subducção tipo-Andino (acresção de arcos magmáticos) em uma margem convergente no lado Oeste. 


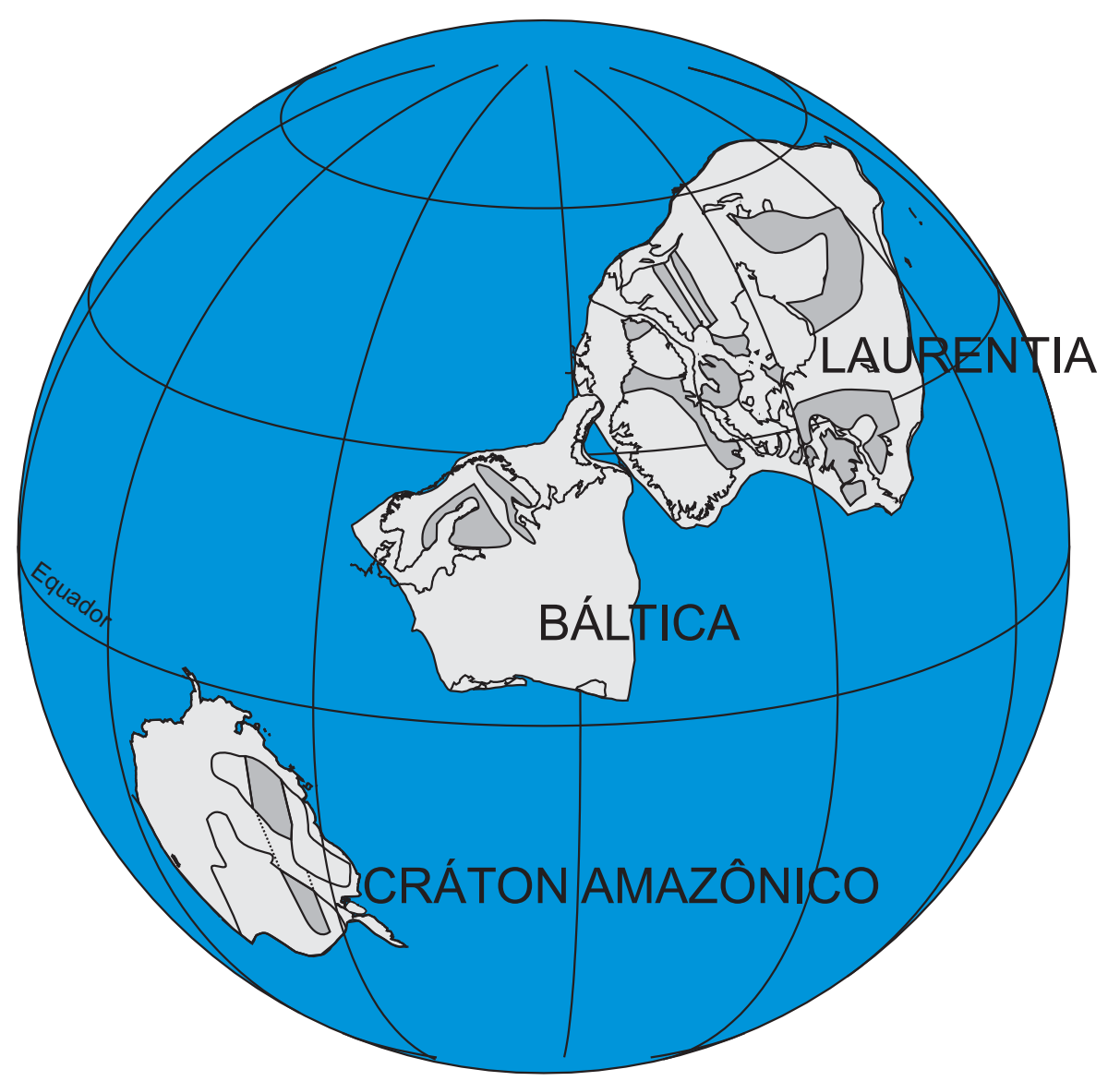

Figura 5.3: Reconstrução paleogeográfica proposta por Pesonen et al. (2003) para 1.83 Ga.

A posição do Cráton Amazônico é definida pelo pólo médio obtido para os diques Rio Aro, Rio Guaniamo e pelos doleritos Roraima (pólo DDII, Tabela 5.2) com idade ${ }^{40} \mathrm{Ar} /{ }^{39} \mathrm{Ar}$ (em biotita) de $1820 \pm 20 \mathrm{Ma}$. Apesar da ambigüidade na escolha de pólo ou anti-pólo, Pesonen et al. (2003) preferem a posição apresentada na figura 5.3, pois o Cráton Amazônico, que apresenta evolução geológica PaleoMesoproterozóica similar à da Báltica e à da Laurentia, pode representar a continuidade lateral no hemisfério sul de uma grande massa continental que existiu há 1,83 Ga atrás, a qual Pesonen e colaboradores chamam de "Hudsonland". 
Se esta interpretação estiver correta, a lacuna existente entre a Báltica e o Cráton Amazônico deve ser ocupada por uma massa continental. Outros candidatos para compor este supercontinente são a Austrália, a Sibéria e o Norte da China, entretanto, não existem pólos de referência desta idade para estas unidades tectônicas.

\subsubsection{Reconstrução em $1,78 \mathrm{Ga}$}

A figura 5.4 mostra a reconstrução paleogeográfica proposta para 1,78 Ga. Nesta reconstrução a posição do Cráton Amazônico está representada pelo pólo obtido para a Suíte Colíder (pólo SC, componente B). A Báltica representa a unidade com a melhor qualidade de dados paleomagnéticos para esta época. Existem dois pólos de referência para este continente: um deles foi obtido para gabros e doleritos do sill Ropruchey (Tabela 5.2), com idade U-Pb bem estabelecida de $1770 \pm 12$ Ma e cuja magnetização é tida como primária (Fedotova et al., 1999). O outro pólo foi obtido para arenitos da parte superior da Formação Shosksha. Estes sedimentos são posteriores a granitos com idades de $1794 \pm 24$ Ma e $1778 \pm 16$ Ma (datação pelo método U-Pb em zircões) e são intrudidos pelo sill Ropruchey de idade $1770 \mathrm{Ma}$, a qual indica a idade mínima da Formação Shosksha. Assim, podese atribuir uma idade entre 1790 e 1770 Ma para a época de sedimentação desta formação. A análise paleomagnética revela uma remanescência estável portada por hematita de domínio simples (SD), tida como diagenética, formada logo após a formação da rocha. Os pólos obtidos para estas duas unidades são muito parecidos (Tabela 5.1), tendo sido utilizada uma média para o posicionamento da Báltica na figura 5.4 .

Um dos problemas encontrado nesta reconstrução deve-se aos dados paleomagnéticos disponíveis para a Laurentia, os quais são considerados menos 
confiáveis em razão da maior incerteza na idade destes pólos. Novamente, alguns pólos obtidos para a Província Orogênica Trans-Hudsoniana (OTH) indicam paleolatitudes altas para a Laurentia e, do mesmo modo que na reconstrução anterior (Figura 5.1), foi dado preferência para os dados paleomagnéticos obtidos para as outras províncias, os quais são discutidas a seguir.

Zhail et al. (1994) apresentaram dados paleomagnéticos para o enxame de diques Molson (Cráton Superior, Tabela 5.2), onde três componentes de magnetização (A, B e C) foram encontradas. Estes autores interpretaram a componente A como sendo de origem primária e atribuíram a idade de 1,83 Ga para este componente, com base na datação de um dique deste enxame através do método U-Pb. Entretanto, Halls \& Heaman (2000) mostram que a componente A é, na realidade, de origem secundária, tendo sido adquirida entre 1700 e $1800 \mathrm{Ma}$, em decorrência da orogênese Trans-Hudsoniana. Para estes autores, as componentes B e C são consideradas mais antigos que 1,88 Ga e estão associados a magnetizações primárias. 


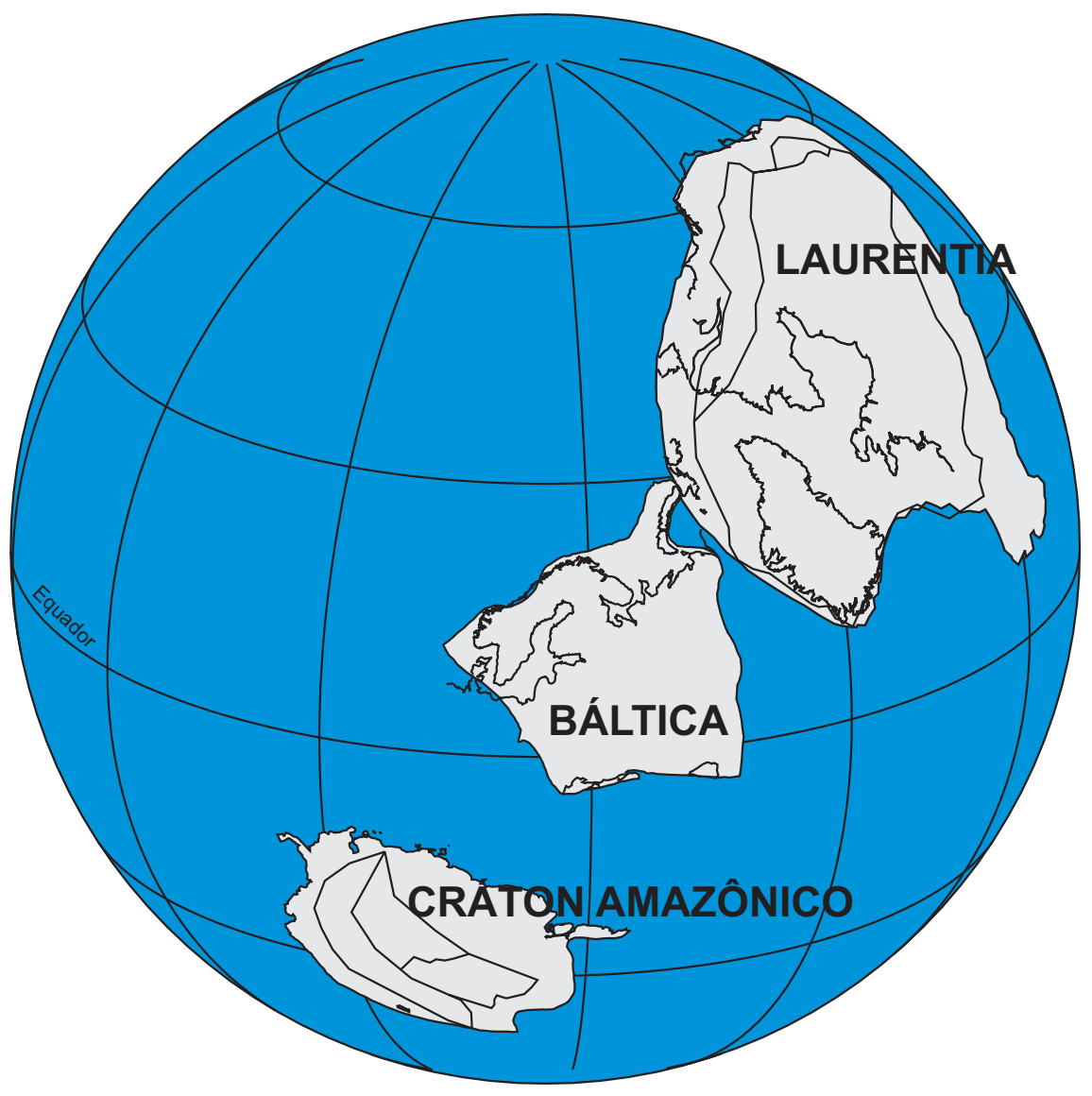

Figura 5.4: Reconstrução paleogeográfica para 1,8- 1,78 Ga feita utilizando o pólo da componente B (pólo SC) para o Cráton Amazônico e os pólos obtidos para a Laurentia (Park et al., 1973) e a Báltica (Pisarevky \& Sokolov, 2001).

Irving \& McGlynn (1979) apresentam dados paleomagnéticos obtidos para o sill Pininsular da Província Coronation caracterizado por direções bem agrupadas após os tratamentos de laboratório. O pólo correspondente a estas direções (Tabela 5.2) foi utilizado na reconstrução de 1,77 Ga proposta por Pesonen et al. (2003), entretanto, o teste de contato cozido efetuado por Irving \& McGlynn (1979) mostrou-se inconclusivo, além do que a idade deste pólo é ainda mal determinada, através do método $\mathrm{Rb}-\mathrm{Sr}$, o qual forneceu idade de aproximadamente $1800 \mathrm{Ma}$ (Irving \& McGlynn, 1979).

Park et al. (1973) apresenta dados paleomagnéticos obtidos para rochas sedimentares (red beds da Formação Kazan) e rochas vulcânicas da Formação 
Christopher Island (Grupo Dubawnt-Província Churchill, Tabela 5.2), além de dois grandes diques considerados como alimentadores dos fluxos de lavas da Formação Christopher Island e que foram utilizados para realizar testes de contato cozido. Os autores encontraram consistência entre os resultados obtidos para as rochas sedimentares e ígneas, a presença de reversões e os testes de contato cozido indicaram que a magnetização nestas rochas foi adquirida logo após a formação destas rochas. Park et al. (1973) apresenta uma idade média de 1716 Ma com base em datações K-Ar em biotita e flogopita das rochas ígneas, corroboradas por uma isócrona $\mathrm{Rb}-\mathrm{Sr}$ que forneceu a idade de $1725 \pm 4$ Ma. Entretanto, Rainbird \& Hadlari, 2000 atribuem idades mais antigas para as formações que constituem o Grupo Dubawnt, entre 1,83 e 1,76 Ga.

Embora a idade do pólo obtido para o Grupo Dubawnt não seja ainda determinada com precisão adequada, optou-se por utilizá-lo na reconstrução paleogeográfica da Figura 5.4, pois ele corresponde a direções que são consideradas de origem primária. Um fato interessante nesta reconstrução é que a Báltica e o Cráton Amazônico continuam a representar uma continuidade lateral da Laurentia, similar a que existiu há 1,83 Ga atrás, como sugerido por Pesonen et al. (2003). Por outro lado, continua a existir uma lacuna entre o Cráton Amazônico e a Báltica $\left(\sim 20^{\circ}\right)$, sugerindo que uma outra massa continental deve ter ocupado este espaço.

O Norte da China pode ter sido a unidade que ocupou este espaço. Quando utilizamos o pólo de referência obtido para o enxame de diques do Norte da China, com idade de 1769,1 \pm 2,5 Ma (Halls et al., 2000), obtemos a reconstrução da figura 5.5. Esta grande massa continental é caracterizada pelo alinhamento de faixas orogênicas Paleo-Mesoproterozóicas ao longo das quatro unidades que compunham este supercontinente: faixas Yavapai-Mazatzal-Labradoriana $(1,8-1,4$ Ga) na Laurentia, as faixas Trans-escandinava-Kongsbergiana (1,8-1,7 Ga) na 
Báltica, a faixa Trans-Norte da China $(1,85-1,8 \mathrm{Ga})$ e a faixa Rio Negro-Juruena (1,85-1,55 Ga) no Cráton Amazônico.

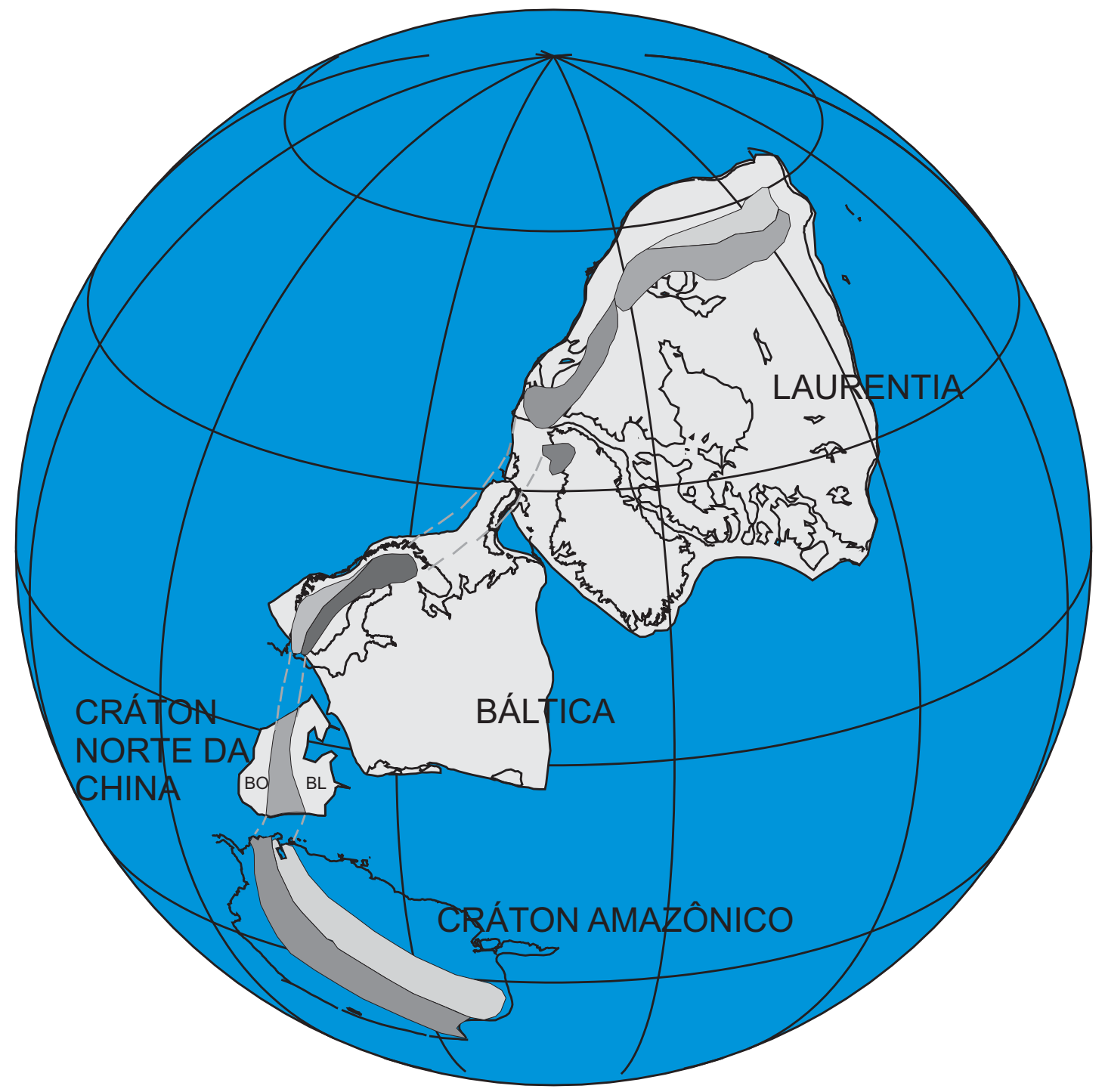

Figura 5.5: Reconstrução paleogeográfica para 1,8-1,78 Ga utilizando o pólo SC para o Cráton Amazônico e pólos obtidos para a Laurentia (Park et al., 1973), para a Báltica (Pisarevky \& Sokolov, 2001; Fedotova et al., 1999) e para o Norte da China (Halls et al., 2000). As faixas em cinza evidenciam a continuidade das províncias geológicas paleoproterozóicas ao longo das quatro massas continentais. BL (Bloco Leste), BO (Bloco Oeste).

Correlações geológicas, tectônicas e paleomagnéticas entre Laurentia e Báltica estão bem estabelecidas em trabalhos dos últimos anos (Buchan et al., 2000, Karlstrom et al., 2001, Zhao et al., 2002, 2003, Pesonen et al., 2003). 
A união entre o Cráton do Norte da China e a Báltica já foi proposta por Qian (1997). O principal evento de formação de crosta arqueana da Báltica ocorreu um pouco antes de 2.60 Ga (Rosen et al., 1994). Da mesma forma, o Bloco Leste do Cráton do Norte da China (Figura 5.5) experimentou o maior evento de formação de crosta arquena entre 2.6 e 2.5 G (Krönen et al., 1998).

Por outro lado, dados geoquímicos e geocronológicos sugerem que o Bloco Leste do Norte da China tinha uma margem continental ativa em seu lado oeste, em que arcos magmáticos continentais e bacias intra-arco estavam se desenvolvendo, enquanto que o Bloco Oeste tinha uma margem continental passiva do seu lado leste. O final do fechamento do oceano que separava estes dois blocos levou a formação do cinturão Trans-Norte da China, em torno de 1,8 Ga, com a amalgamação final do cráton Norte da China (Zhao et al., 2003). É interessante notar que os outros blocos cratônicos (Báltica, Amazônia e Laurentia) também formaram-se pela amalgamação de pequenos blocos cratônicos entre 2,1 e 1,8 Ga, resultando na formação do Supercontinente Columbia. Vale também salientar que, durante a fase de amalgamação do Norte da China, um processo de subducção se desenvolvia no pro-cráton Amazônico com a formação de arcos magmáticos ligados à evolução do cinturão Verntuari Tapajós (1,95-1,80 Ga, Tassinari \& Macambira, 1999, 2004).

Existem algumas semelhanças geológicas que reforçam a hipótese de que o Norte da China foi a massa continental que existia entre a Báltica e o Cráton Amazônico. Zhao et al. $(2002,2003)$ destacam que o efeito de um supercontinente deve ser refletido em um registro magmático e sedimentar de escala global. Zhao e colaboradores mostram algumas evidencias geológicas deste acontecimento:

a) A Laurentia, a Báltica, o Norte da China e o Cráton Amazônico são caracterizados por cinturões magmáticos relacionados a processos de subducção tipo-Andino que se desenvolveram entre 1,8-1,3 Ga; os cinturões Yavapai- 
Mazatzal-Labradoriano (Laurentia), os cinturões Trans-escandinavoKongsbergiano (Báltica), o cinturão Xiong'er (Norte da China) e os cintuõres Rio Negro-Juruena e Rondoniano-San Ignácio (Craton Amazônico).

b) Durante o intervalo de tempo entre 1,6-1,2 Ga, a América do Norte, a Groelândia, a Báltica, o Cráton Amazônico e o Norte da China eram caracterizados por um amplo magmatismo anorogênico que inclui erupções de riolitos e uma associação de anortositos-mangeritos-charnoquitos-granitos (AMCG), além de granitos rapakivi, carbonatitos e intrusivas alcalinas. Esses granitos Mesoproterozóicos são expostos em um enorme cinturão que tende a atravessar a América do Norte e a parte sul da Groelândia, a Báltica e também aparecem no Norte da China e no Cráton Amazônico. Acredita-se que esse magmatismo anorogênico está provavelmente relacionado a um extenso 'underplating', que aconteceu antes da dispersão do supercontinente;

c) O período entre 1.4-1.2 Ga é caracterizado por enxames de diques que ocorrem extensamente na América do Norte, Groelandia, Báltica e no Norte da China.

Segundo Park (1992) os enxames de diques de 1,4-1,2 Ga constituem um episódio extensional. Eles podem marcar os pontos de correlação entre os diferentes continentes que formaram o supercontinente Columbia. 


\section{Capítulo 6}

\section{CONCLUSÕES}

Este trabalho apresenta o estudo paleomagnético realizado em rochas ácidas e intermediárias da Suíte Colíder e máficas associadas pertencentes à Suíte Flor da Serra e à Intrusiva Guadalupe, situadas no norte do Estado do Mato Grosso (Cráton Amazônico). Datações U-Pb em rochas ácidas da Suíte Colíder indicam idades de $1801 \pm 11 \mathrm{Ma}, 1786 \pm 17 \mathrm{Ma} 1.781 \pm 8$ Ma para esta unidade.

O estudo da mineralogia magnética mostra que as rochas máficas são caracterizadas pela presença de grãos de titanomagnetita pobre em titânio, com estrutura PSD e temperaturas de bloqueio altas, próximas da temperatura de Curie da magnetita. Estas características, associadas a observações petrográficas que indicam textura ígnea preservada e ausência (ou pouca ação) de metamorfismo, sugerem que a magnetização associada às rochas máficas representa uma MTR, adquirida durante o resfriamento da rocha. Por outro lado, a maioria das rochas ácidas é caracterizada pela presença de minerais magnéticos com altas coercividades e temperaturas de bloqueio próximas da temperatura de Curie da hematita. Este mineral, de alta estabilidade magnética, foi interpretado como sendo produto de oxidação a altas temperaturas, durante a formação da rocha.

Os tratamentos por campos magnéticos alternados e térmicos revelaram dois grupos de direções de magnetização característica. O primeiro é representado por direções norte com inclinações positivas moderadas (componente A $\left.\mathrm{Dm}=356.5^{\circ}, \mathrm{Im}=47.6^{\circ}, \mathrm{N}=3, \alpha 95=15.1^{\circ}, \mathrm{K}=61.9\right)$, as quais foram isoladas para o gabro Guadalupe e dois diques máficos. O segundo grupo é representado por direções 
norte (sul) com inclinações negativas (positivas) de moderada a alta (componente B - $\left.\mathrm{Dm}=187.4^{\circ}, \mathrm{Im}=50.9^{\circ}, \mathrm{N}=16, \alpha 95=11.3^{\circ}, \mathrm{K}=11.7\right)$, que foram isoladas para a maior parte das rochas ácidas e intermediárias da Suíte Colíder e máficas associadas.

Dois pólos paleomagnéticos foram determinados para estas duas componentes de magnetização característica: (I) o pólo IG (Intrusiva Guadalupe) representado pela componente $A$, está localizado em $298.8^{\circ} \mathrm{E}, 50.4^{\circ} \mathrm{N}(\mathrm{N}=3$, $\left.\alpha 95=15.1^{\circ}, \mathrm{K}=67.9\right)$. Datações $\mathrm{K}-\mathrm{Ar}$ e ${ }^{40} \mathrm{Ar} /{ }^{39} \mathrm{Ar}$ estão em andamento para determinar a idade deste pólo paleomagnético; (II) o pólo SC (Suíte Colider), representado pela componente $\mathrm{B}$, está localizado em $289.4^{\circ} \mathrm{E}, 65.4^{\circ} \mathrm{S}\left(\mathrm{N}=16, \alpha 95=12.9^{\circ}, \mathrm{K}=9.1\right)$, ao qual foi associado uma idade de $1789 \pm 7$ Ma (média das três idades U-Pb disponíveis para a Suíte Colider). De acordo com os critérios de confiabilidade de Van der Voo (1990), o pólo SC apresenta fator de confiabilidade $Q=5$, sendo considerado um pólo paleomagnético de referência para o Cráton Amazônico.

A curva de deriva polar aparente (CDPA) traçada por Nomade et al. (2003) para o Cráton Amazônico, para o intervalo de tempo entre 2040 Ma e 1990 Ma, não pôde ser definida para idades mais recentes. Somente dois pólos paleomagnéticos podem ser considerados como pólos de referência para o Cráton Amazônico; o pólo DDII obtido para diques da Guiana Francesa e da Venezuela (Onstott et al., 1984b), que apresenta idade ${ }^{40} \mathrm{Ar} /{ }^{39} \mathrm{Ar}$ (em biotita) de $1820 \pm 20$ Ma e o pólo SC determinado neste trabalho para a Suíte Colíder com idade U-Pb de $1789 \pm 7$ Ma. A diferença de idade entre estes pólos e os apresentados por Nomade e colaboradores (2003) é de mais de $150 \mathrm{Ma}$, o que tornam indefinidas as polaridades dos pólos DDII e SC. Portanto, novos pólos de referência são necessários para este intervalo de idades para que uma curva de deriva polar aparente confiável possa ser construída para o Cráton Amazônico.

Duas reconstruções paleogeográficas são apresentadas neste trabalho, para as épocas de 1,83 Ga (Figura 5.3) e 1,78 Ga (Figuras 5.4 e 5.5), com base em pólos de 
referência atualmente existentes para os blocos Laurentia, Báltica e Cráton Amazônico. Nestas duas reconstruções, estes blocos continentais estão situados de forma contígua, indicando que eles formavam uma grande massa continental nesta época. Esta paleogeografia continental está de acordo com evidências geológicas que mostram evoluções similares para estes três continentes durante boa parte do Paleoproterozóico e Mesoproterozóico (subducção tipo-Andino, com a acresção de arcos magmáticos). Entretanto, existe uma lacuna de aproximadamente $20^{\circ}$ entre a Báltica e o Cráton Amazônico nas duas reconstruções, sugerindo que uma outra massa continental, com evolução geológica similar, preenchia este espaço. Sugerese neste trabalho que este bloco continental pode ser o Cráton do Norte da China (Figura 5.5), o qual apresenta evolução geológica Paleo-Mesoproterozóica similar a dos outros blocos continentais (Zhao et al. 2001, 2003). Este modelo é apoiado pelo pólo paleomagnético de referência obtido para rochas do enxame de diques Fuping no Cráton do Norte da China de idade U-Pb (zircões) de $1769 \pm 2.5 \mathrm{Ma}$ (Halls et al., 2000).

Desta forma, as evidências geológicas e paleomagnéticas indicam que a Laurentia, a Báltica, o Norte da China e o Cráton Amazônico estavam unidos de forma contígua há 1,83-1,78 Ga atrás, formando uma grande massa continental, a qual sugere a existência de um Supercontinente Paleoproterozóico.

Outros blocos continentais (Austrália, Leste da Antárica, Sibéria, Índia e outros) podem ter participado deste supercontinente que se formou durante o Paleoproterozóico e que é conhecido como Columbia (Park, 1992; Buchan et al., 2000, Karlstrom et al., 2001; Meert, 2002; Zhao et al., 2002, 2003, Pesonen et al., 2003). 


\section{Referências Bibliográficas}

Ade-Hall, J.M., Palmer, H.C.\& Hubbard, T.P., 1971. The magnetic and opaque petrological response of basalts hydrothermal alteration. Geophys. J.R. astr. Soc., 24: 137-174.

Alkimim, F. F., 2004. O que faz de um cráton um cráton? O cráton do São Francisco e as revelações almedianas ao delimitá-lo. In: Mantesso-Neto, V., Bartorelli, A., Carneiro, C. D. R., Brito-Neves, B. B., 2004. Geologia do Continente Sul-Americano: Evolução da obra de Fernando Flávio Marques de Almeida. Beca Produções Culturais Ltda, São Paulo.

Almeida, F.F.M., 1977. O Cráton São Francisco. Revista Brasileira de Geociências, v. 7, p. 349-364.

Amaral, G., 1974. Geologia Pré-Cambriana da Região Amazônica. Tese de Livre Docência, Instituto de Geociências, Universidade de São Paulo, 212p.

Bahia, R. B. C., Quadros, M. L. E. S. (Orgs). 2000. Programa Levantamentos Geológicos Básicos Do Brasil Projeto Especial Província Mineral do Tapajós. PROMIN Tapajós. Geologia e recursos minerais da Folha Caracol (SB.21-X-C). Estado do Pará. Escala 1:250.000. Brasília, CPRM.

Basei, M. A. S., 1977. Idade do vulcanismo ácido a intermediário na região amazônica. Dissertação de Mestrado, Instituto de Geociências, Universidade de São Paulo, 133p.

Brito Neves, B.B., 1995. Crátons e Faixas Móveis. Boletim IG-USP, Série Didática, n. 7. 187p.

Buchan, K. L., Mertanen, S., Park, R. G. Pesonen, L. J., Elming, S. A., Abrahamsen, N., Bylund, G., 2000. Comparing the drift of Laurentia and Baltica in the Proterozoic: the importance of key palaeomagnetic poles. Tectonophysics, vol. 319, n. 3, pg. 167-198.

Butler, F. R., 1992. Paleomagnetism: Magnetic Domains to Geologic Terranes. Blackwell Scientific Publications, United States of América.

Carvallo, C., Özdemir, Ö. Dunlop, D., 2004. Palaeointensity determinations, palaeodirections and magnetic properties of basalts from the Emperor seamounts. Geophysical Journal International, v. 156, (1), p. 29-38.

Castillo, J. H., Costanzo-Alvarez, V., 1993. Paleomagnetism of the Uairen Formation, Roraima Group, southeastern Venezuela: evidence for one of the oldest (Middle Proterozoic) depositional remanent magnetizations. Can. J. Earth Sci., v. 30, 2380-2388.

Condie, K. C., 2002. Breakup of a Paleoproterozoic Supercontinent. Gondwana Research, 5, n. 1, pp. 41-43. 
Cordani, U. G., Tassinari, C. C. G., Teixeira, W., Basei, M. A. S., Kawashita, K., 1979. Evolução Tectônica da Amazônia com base nos dados geocronológicos. In: Congr. Geol. Chileno, 2, Arica , Chile, Actas, pp. 137-48.

Cordani, U. G., Teixeira, W., 2006. Proterozoic accretionary belts in the Amazonian Craton. Submetido a Gological Society of America (GSA).

Cox, A., Doell, R. R., 1960. Review of Paleomagnetism. Bulletin of the Geological Society of America. Vol. 71, june, pg. 645-768.

D’Agrella-Filho, M. S., 1984. Estudo Paleomagnético dos Grupos Itajaí, Castro, Camaquã e Bom Jardim. Dissertação de Mestrado, Departamento de Geofísica, Instituto de Astronomia, Geofísica e Ciências Atmosféricas, Universidade de São Paulo.

D'Agrella-Filho, M. S., 1992. Paleomagnetismo de Enxames de Diques Máficos Proterozoícos e Rochas do Embasamento do Cráton do São Francisco. Tese de Doutorado, Departamento de Geofísica, Instituto de Astronomia, Geofísica e Ciências Atmosféricas, Universidade de São Paulo.

D’Agrella-Filho, M. S., Elming, S.-A., Pacca, I. G., Trindade, R. I. F., Geraldes, M. C., Teixeira, W. Paleomagnetic Study of the Mesoproterozoic Aguapei Group, Western Mato Grosso State, Amazonian Craton., 2003. Geophysical Research Abstracts, European Geophysical Society, v. 5, 05541,

Dalziel, I. W. D., 1997. Neoproterozoic-Paleozoic geography and tectonics: review, hypothesis, environmental speculation. Geol. Soc. Am. Bull. 108, pp. 16-42.

Day, R., Fuller, M., Schmidt, V. A., 1977. Hysteresis properties of titanomagnetites: Grain-size and compositional dependence. Physics of the Earth and Planetary Interiors, 13, 260-267.

Dunlop, D. J., Özdemir, Ö., 1997. Rock Magnetism: Fundamentals and frontiers. Cambrigde University Press.

Dunlop, D. J., 2002a. Theory and application of the Day plot (Mrs/Ms versus Hcr/Hc) 1. Theorical curves and tests using titanomagnetita data. Journal of Geophysical Research, v. 107, n. B3, 10.1029/2001JB000486.

Dunlop, D. J., 2002b. Theory and application of the Day plot (Mrs/Ms versus Hcr/Hc) 2. Application to data for rocks, sediments, and soils. Journal of Geophysical Research, v. 107, n. B3, 10.1029/2001JB000487.

Fedotova, M. A., Khramov, N. A., Pisakin, B. N., Priyatkin, A. A., 1999. Early Proterozoic palaeomagnetism: new results from the intrusives and related rocks of the Karelian, Belomorian and Kola provinces, eastern Fennoscandian Shield. Geophys. J. Int. 137, pp. 691-712.

Fisher, R. A., 1953. Dispersion on a Sphere. Proc. Roy. Soc. London. 217, pg. 295-305. 
Geraldes, M. C., Van Schmus, W. R., Condie, K. C., Bell, S., Teixeira, W., Babinski, M., 2001. Proterozoic geologic evolution of the SW part of the Amazonian Craton in Mato Grosso state, Brazil. Precambrian Research, 111, pp. 91-128.

Halls, H. C., Li, J., Davis, D. Hou, G., Zhang, B., Qian, X., 2000. A precisely dated Proterozoic palaeomagnetic pole from the North China craton, and its relevance to palaeocontinental reconstruction. Geophys. J. Int., 143, 185-203.

Halls, H. C., Heaman, L. M., 2000. The paleomagnetic significance of new U-Pb age data the Molson dyke swarm, Cauchon Lake area, Manitoba. Can. J. Earth Sci. 37, 957-966.

Hartmann, L. A., Delgado, I. M., 2001. Cratons and orogenic belts of the Brazilian Shield and their contained gold deposits. Mineralium Deposita. Publisher: Springer Berlin-Heidelberg, v. 36, n. 3-4, July, pg. 207-217.

Heider, F. \& Dunlop, D.J., 1987. Two types of chemical remanent magnetization during the oxidation of magnetite. Physics Earth Planet. Int., 46: 24-45.

Heider, F., Geiss, C., Dunlop, D.J. \& Inokuchi, H., 1992. Rock-magnetic investigation of basalts from the southern Kerguelen Plateau (LEG 120). Wise, S.W., Jr., Schlich, R, et al., 1992. Proccedings of the Ocean Drilling Program, Scientific Results, Vol. 120: 79-87.

Irving, E., McGlynn, J. C., 1979. Palaeomagnetism in the Coronation Geosyncline and arrangement of continents in the middle Proterozoic. Geophys. J. R. astr. Soc. 58, 309-336.

Johnson, H.P. \& Merrill, R.T., 1974. Low-temperature oxidation of a single-domain magnetite. J. Geophys. Res., 79 (35): 5533-5534.

Kirschvink, J. L., 1980. The least-squares line and plane and the analysis of palaeomagnetic data. Geophysics Journal Research Astronomics Societs, 62, pg. 699-718.

Karlstrom, K. E., Ahall, Karl-Inge, Harlan, S. S., Williams, M. L., McLelland, J., Geissman, J. W., 2001. Long-lived (1.8-1.0 Ga) convergent orogen in southern Laurentia, its extensions to Australia and Baltica, and implications for refining Rodinia. Precambrian Research, 111, p. 5-30.

Köber, L., 1921. Der Bau der Erde. Borntraeger, ed. Berlim. 324p.

Kröner, A., Cui, W.Y., Wang, S.Q., Wang C.Q., Nemchin, A.A., 1998. Single zircon ages from highgrade rocks of the Jianping Complex, Liaoning Province, NE China. J. Asian Earth Sci., 16, pp. 519532.

Kusky, T. M., Li, J., 2003. Paleoproterozoic tectonic evolution of the North China Craton. Journal of Asian Earth Science, 22, 383-397.

Lacerda-Filho, J. V., Souza, J. O., Oliveira, C. C., Ribeiro, P. S. E., Boas, P. F. V., Albuquerque, M. C., Frasca, A. A. S., Borges, F. R., Moreton, L. C., Martins, E. G., Camargo, M. A., Valente, C. R., Pimentel, M. M., Botelho, N. F., 2001 Geologia e evolução tectônica da região norte do Mato Grosso (Projeto Promin-Alta Floresta). In: SBG, Simp. Geol. Amazônia, 7, Belém, Sessão Temática VII. 
Lacerda-Filho, J. V., Abreu Filho, W., Valente, C. R., Oliveira, C. C., Albuquerque, M. C., 2004. Geologia e Recursos Minerais do Estado do Mato Grosso. Texto explicativo dos mapas geológico e de recursos minerais do Estado do Mato Grosso, Escala 1:1.000.000, Convênio CPRM e SICME-MT, 235p.

Lowrie, W., 1997. Fundamentals of Geoghysics, Geomagnetism and Paleomagnetism, Cap. 5, pg. 229-306, Cambridge University Press, Cambrigde.

Mann, U., Marks, M. \& Markl, G., 2006. Influence of oxygen fugacity on mineral compositions in peralkaline melts: the Katzenbuckel volcano, southwest Germany. Lithos, 91: 262-285.

Marzoli, A., Renne, P. R., Piccirillo, E. M., Ernesto, M., Bellieni, G., Min, A., 1999. Extensive 200Million-Year-Old Continental Flood Basalts of the Central Atlantic Magmatic Province. Science, v. 284, pp. 616-618.

McElhinny, M. W., 1973. Palaeomagnetism and Plate Tectonics, Cambridge University Press.

McFadden, P. L., McElhinny, M. W., 1990. Classification of the reversal test in palaeomagnetism. Geophys. J. Int., 103, 725-729.

McElhinny, M. W., McFadden, P. L., 2000. Paleomagnetism: Continents and Oceans. International Geophysics Series, v. 73, Academic Press.

Meert, J. G., 2002. Paleomagnetic Evidence for a Paleo-Mesoproterozoic Supercontinent Columbia. Gondwana Research, v. 5, n. 1, pp. 207-215.

Nomade, S., Chen, Y., Féraud, G., Pouclet, A., Théveniaut, H., 2001. First paleomagnetic and ${ }^{40} \mathrm{Ar} /{ }^{39} \mathrm{Ar}$ study of Paleoproterozoic rocks from the French Guyana (Camopi and Oyapok rivers), northeastern Guyana Shield. Precambrian Research. 109, 239-256.

Nomade, S., Chen, Y., Pouclet, A., Féraud, G., Théveniaut, H., Daouda, B. Y. Vidal, M., Rigolet, C., 2003. The Guiana and West African Shield Palaeoproterozoic grouping: new palaeomagnetic data for French Guiana and Ivory Coast. Geophy. J. Int., 154, 677-694.

Oliveira, C. C. O., Albuquerque, M. C., 2004. Programa Levantamentos Geológicos Básicos do Brasil. Projeto Província de Alta Floresta (PROMIN ALTA FLORESTA). Geologia e recursos minerais da Folha Alta Floresta (SC.21-Z-X-C). Brasília, CPRM.

Oliveira, A. L., Leonardos, O. H., 1940. Geologia do Brasil. Rio de Janeiro, comissão brasileira dos centenários Portugal, 472p.

Onstott, T. C., Hargraves, R. B., 1981. Proterozoic transcurrent tectonics: palaeomagnetic evidence from Venezuela and Africa. Nature, 289, 131-136, January.

Onstott, T. C., Hargraves, R. B., York, D., Hall, C., 1984a. Constraints on the motions of South American and African Shields during the Proterozoic: ${ }^{40} \mathrm{Ar} /{ }^{39} \mathrm{Ar}$ and paleomagnetic correlations between Venezuela and Liberia. Gological Society of America Bulletin, v. 95, 1045-1054, September. 
Onstott, T. C., Hargraves, R. B., York, D., 1984b. Dating of Precambrian diabase dikes of Venezuela using Paleomagnetic and ${ }^{40} \mathrm{Ar} /{ }^{39} \mathrm{Ar}$ methods. Anais II do Simpósio Amazônico, Manaus, Brasil, DNPM, 2:513-518.

Özdemir, Ö \& Dunlop, D.J., 1985. An experimental study of chemical remanent magnetizations of synthetic monodomian titanomaghemites with initial thermoremanent magnetizations. J. Geophys. Res., 90: 11.513-11.523.

Pacca, I. G., Cordani, U. G., 1979. Contribution for the South American Precambrian Apparent Polar Wandering Path. International Association of Geomagnetism and Aeronomy Bulletin, n. 43, pg. 181.

Pacca, I. G., 1981. Contribuições ao paleomagnetismo. Tese de Livre-Docência, Instituto Astronômico e Geofísico da Universidade de São Paulo. 83 p.

Park, J. K., Inving, E., Donaldson, J. A., 1973. Paleomagnetism of the Precambrian Dubawnt Group. Geol. Soc. Amer. Bull. 103, 522-537.

Park, R.G., 1992. Plate kinematic history of Baltic during the Middle to Late Proterozoic: a model. Geology, 20, pp. 725-728.

Park, R.G., Jaroszewski, W., 1994. Craton tectonics, stress and sismicity. In: P. L. Hancork (ed.). Continental deformation. Oxford, Pergamon Press, p. 200-222.

Pesonen, L.J., Elming, S-A., Mertanen, S., Pisarevsky, S., D'Agrella-Filho, M.S., Meert, J. G., Schmidt, P.W. Abrahamsen, N., Bylund, G., 2003. Palaeomagnetic configuration of continents during the Proterozoic. Tectonophysics, 375, 289-324.

Pimentel, M., 2001. Resultados geocronológicos do Projeto Promin Alta Floresta. Relatório Interno, Brasília, UnB.

Pinho, M.A.S.B., Lima, E.F., Fetter, A., Van Schmus, W.R., Chemale-Jr, F. 2001. Caracterização petrográfica e dados geocronológicos preliminares das rochas vulcânicas da Formação Iriri - porção Centro-Sul do Cráton Amazônico, Aripuanã, Mato Grosso. Rev. Bras. Geoc., 31:1-5.

Pinho, M.A.S.B., 2002. Proposta de Nova Terminologia Estratigráfica para Rochas VulcanoPlutônicas Paleoproterozóicas do Norte do Estado de Mato Grosso, Porção Ocidental Sul do Cráton Amazônico. Revista Brasileira de Geociências. 32 (1), 153-156.

Pinho, M. A. S. B., Chemale-Jr, F., Van Schmus, W. R., Pinho, F. E. C., 2003. U-Pb and Sm-Nd evidence for 1.76-1.77 Ga magmatism in the Moriru region, Mato Grosso, Brazil: implications for province boundaries in the SW Amazon Craton. Precambrian Research, 126, 1-25.

Pisarevsky, S. A; Sokolov, S. J. 2001 The magnetostratigraphy and a 1780 Ma paleomagnetic pole from the red sandstones of the Vazhinka River section, Karelia, Russia. Geophys. J. Inter., 146, 531538. 
Qian, X.L., 1997. Tectonic correlations of the Precambrian Evolution of the North China Craton with the Baltic Shield. In: X.L. Qian, Z.D. You and H.C. Halls, Editors, Precambrian Geology and Metamorphic Petrology, Utrcht, the Netherlands, pp. 43-58.

Rainbird, R. H., Hadlari, T., 2000. Revised stratigraphy and sedimentology of the Paleoproterozoic Dubawnt Supergroup at the northern margin of Baker Lake Basin, Nunavut. Geological Survey of Canada. 2000-C8, p. 1-9.

Robertson, D. J., France, D. E., 1994. Discrimination of remanence-carrying minerals in mixtures, using isothermal remanent magnetisation acquisition curves. Physics of the Earth and Planetary Interiors, 82, p. 223-234.

Roberts, A. P., Cui, Y., Verosub, K. L., 1995. Wasp-waisted hysteresis loops: Mineral magnetic characteristics and discrimination of components in mixed magnetic systems. Journal of Geophysical Research, v. 110, n. B9, p. 17,909-17,924, September.

Rogers, J. J. W., 1996. A history of the continents in the past three billion years, J. Geology, 104: 91107.

Rogers, J. J., Santosh, M., 2003. Supercontinents in Earth History. Gondwana Research, v. 6, n. 3, pp. 357-368.

Rosen, O.M., Condie, K.C., Natapov, L.M. Nozhkin, A. D., 1994. Archean and Early Proterozoic evolution of the Siberian craton: a preliminary assessment. In: K.C. Condie, Editor, Archean Crustal Evolution, Elsevier, Amsterdam, pp. 411-459.

Ruiz, A. S., Geraldes, M. C., Matos, J. B., Teixeira, W., Van Schmus, W. R., Schmitt, R. S., 2004. The 1590-1520 Ma Cachoeirinha magmatic arc and its tectonic implications for the Mesoproterozoic SW Amazonic Craton crustal evolution. Anais da Academia Brasileira de Ciências, n. 76, v. 4, pg. 807824.

Sadowski, G. R., Bettencourt, J. S., 1996. Mesoproterozoic tectonic correlations between eastern Laurentia and western border of the Amazon Craton. Precambrian Research, n. 76, pg. 213-227.

Santos, J. O. S., Hartmann, L. A., Gaudette, H. E., Groves, D. I., McNaugthon, N.J., Fletcher, I. R., 2000. A new understanding of the Provinces of Amazon Craton based on integration of field mapping and U-Pb and Sm-Nd geochronology. Gondwana. Research., 3, pp. 453-488.

Santos, F. B., D’Agrella-Filho, M. S., Elming, S. Å., Pacca, I. G., Pinho, M. A .S. B., Pinho, F., 2006. Paleomagnetismo da Suíte Colider e Máficas Associadas, SW do Cráton Amazônico. Anais do XLIII Congresso Brasileiro de Geologia, Aracaju, Sessão Temática IV, p.298.

Schobbenhaus, C., Campos, D. A., Derze, G. R., Asmus, H. E., 1984. Geologia do Brasil: Texto explicativo do mapa geológico e da área oceânica adjacente incluindo depósitos minerais. Escala 1: 2500 000. Departamento Nacional da Produção Mineral (DNPM) Brasília, 501p. 
Schobbenhaus, C., Brito-Neves, B. B., 2003. A geologia do Brasil no Contexto da Plataforma SulAmericana. In: Bizzi, L. A., Schobbenhaus, C., Vidotti, R. M., Gonçalves, J. H., Geologia, tectônica e recursos minerais do Brasil: texto, mapas \& SIG, Brasília, CPRM - Serviço Geológico do Brasil, 692 p.

Silva, G. H., Leal, J. W. L., Montalvão, R. M. G., Bezerra, P. E. L., Pimenta, O. N. S., Tassinari, C. C. G., Fernandes, C. A. C., 1974. Folha SC-21 Juruena. In: SBG, Congr. Bras. Geol., 28, Porto Alegre, Anais, pp. 309-320.

Sollas, H.B.C., 1904. Authorized English translation of Suess, Eduard. the face of the Earth. Oxford, Clarendon Press, v.1, 604p.

Stille, H., 1936. Tektonische Beziehungen zwischen Nordamerika und Europa. XXVI Int. Geol. Congr., Washington, pp. 829-838.

Tarling, D. H., 1983. Paleomagnetism: Principles and Applications in Geology, geophysics and Arquaeology. Chapman and Hall Ltd, New York.

Tassinari, C. C. G., 1996. O mapa geocronológico do Cráton Amazônico: revisão dos dados isotópicos. Tese de Livre Docência, Instituto de Geociências, Universidade de São Paulo, 139 p.

Tassinari, C. C. G., Cordani, U. G., Nutman, A. P., Van Schumus, W. R., Bettencourt, J. S., Taylor, P. N., 1996. Geochronological systematics on basement rocks from the Rio Negro-Juruena Province (Amazonian Craton) and tectonic implications. Int. Geol. Rev. 38 (2), 161-175.

Tassinari, C. C. G., Macambira, M. J. B., 1999. Geochronological provinces of the Amazonic Craton. Episodes, vol. 22, n.3, September.

Tassinari, C. C. G., Macambira, M. J. B., 2004. A evolução do Cráton Amazônico. In: Mantesso-Neto, V., Bartorelli, A., Carneiro, C. D. R., Brito-Neves, B. B., Geologia do Continente Sul-Americano: Evolução da obra de Fernando Flávio Marques de Almeida. Beca Produções Culturais Ltda, São Paulo.

Tauxe, L., 2002. Paleomagnetic Principles and Practice, Kluwer Academic Publishers.

Teixeira, W., Tassinari, C. C. G., Cordani, U. G., Kawashita, K., 1989. A review of the geochronology of the Amazonian Craton: tectonic implications. Precambrian Research. 42, 213-227.

Tohver, E., Van der Pluijm, B. A., Van der Voo, R., Rizzotto, G., Scandolara, J. E., 2002. Paleogeography of the Amazon craton at $1.2 \mathrm{Ga}$ : early Grenvillian collision with the Llano segment of Laurentia. Earth and Planetary Science Letters, 199, p. 185-200.

Trindade, R. I. F., Font, E., D’Agrella-Filho, M. S., Nogueira, A. C. R., Riccomini, C., 2003. Lowlatitude and multiple geomagnetic reversals in the Noeproterozoic Puga cap carbonate, Amazon Craton.Terra Nova, v.00, n.0, 1-6 (DOI: 10.1046/j.1365-3121.2003.00510.x).

Van der Voo, R., 1990. The reliability of paleomagnetic data. Tectonophysics, 184, pg. 1-9, Elsevier Science Publishers B. V. Amesterdam. 
Vasquez, M. L., Klein, E. L.(Orgs.). 2000. Programa Levantamentos Geológicos Básicos do Brasil: Projeto Especial Província Mineral do Tapajós. PROMIN Tapajós. Geologia e recursos minerais da Folha Rio Novo (SB.21-Z-C). Estado do Pará. Escala 1:250.000. Brasília: CPRM.

Veldkamp, J., Mulder, F. G., Zijderveld, D. A., 1971. Paleomagnetism of Surimane dolerites. Phys. Earth Planet. Interiors, 4, 370-380, Amsterdam.

Zhao, G., Wilde, S. A., Cawood, P. A., Sun, M., 2001. Archean blocks and their boundaries in the North China Craton: lithological, geochemical, structural and P-T path constraints and tectonic evolution. Precambrian Research. 107, p. 45-73.

Zhao, G., Cawood, P. A., Wilde, S. A., Sun, M., 2002. Review of global 2.1-1.8 Ga orogens: implications for a pre-Rodinia supercontinent, Earth Sci. Rev. 59, pp. 125-162.

Zhao, G., Sun, M., Wilde, S. A., Li, S., 2003. Assembly, Accretion and Breakup of the PaleoMesoproterozoic Columbia Supercontinent: Records in the North China Craton. Gondwana Research, v. 6, n. 3, pp. 417-434.

Zijderveld, J. D. A., 1967. A. C. Demagnetization of Rocks: Analysis of Results. In: Methods in Paleomagnetism; Collinson, D. W.; Creer, K. M. \& Runcorn, S. K., pg. 254-286. 


\section{Apêndice A}

\section{Análise dos paleopólos obtidos para o Cráton Amazônico}

Os paleopólos selecionados na tabela 5.1 são aqui discutidos, com a intenção de evidenciar o caráter de confiabilidade dos dados paleomagnéticos obtidos para o Cráton Amazônico.

Pólos GUI2 e GUI1 - Estes pólos paleomagnéticos foram obtidos por Nomade et al. (2003), através de granitos, metassedimentos e anfibolitos da Guiana Francesa. Duas componentes magnéticas foram encontradas com idades ${ }^{40} \mathrm{Ar} /{ }^{39} \mathrm{Ar}$ de $2036 \pm$ 14 Ma e $2014 \pm 27$ Ma que produziram os pólos GUI2 e GUI1, respectivamente. A análise da mineralogia magnética mostra a presença de magnetita sem evidências de deformação e alteração como principal portador magnético, o que sugere uma magnetização remanescente de origem primária, formada durante $\mathrm{o}$ Paleoproterozóico. As duas direções magnéticas remanescentes que foram isoladas possuem altas temperaturas de bloqueio. Um teste de reversão realizado foi classificado como indeterminado.

Pólo OYA - Este pólo foi determinado por Nomade et al. (2001) em tonalitos, anfibolitos, metassedimentos e meta-ultrabasaltos do Escudo da Guiana Francesa. Segundo os autores, a magnetização que originou este pólo é de origem primária, tendo sido adquirida entre 2022 Ma e 2050 Ma. 
Pólos DDI e DDII - Estes pólos representam as médias de direções comuns encontradas em diques e doleritos dos rios Aro e Guaniamo (Sul do Escudo da Guiana) além de doleritos Roraima (Venezuela). (Onstott et al., 1984b). Um dos diques pertencentes ao grupo de direções que originou o pólo DDII foi datado pelo método ${ }^{40} \mathrm{Ar} /{ }^{39} \mathrm{Ar}$ em biotita, o qual forneceu a idade de $1820 \pm 20 \mathrm{Ma}$ (pólo DDII). A única idade disponível para o pólo DDI é de $1640 \pm 3 \mathrm{Ma}$, determinada pelo método Rb-Sr. Amostras dos dois conjuntos de diques forneceram magnetizações estáveis dominadas por magnetitas pseudo-domínio simples (PSD) e de domínio simples (SD).

Pólos EN1 e EN2 - Estes pólos foram determinados para os granitos plutônicos La Encricijada, que ocorrem na Venezuela, ao norte do Escudo da Guiana (Onstott et al., 1984a). Duas direções de magnetização estáveis (A1 e A2), com altas temperaturas de bloqueio, originaram os pólos EN1 e EN2, respectivamente. Datações Rb-Sr em biotita revelaram idade de $1958 \pm 45$ Ma e datações ${ }^{40} \mathrm{Ar} /{ }^{39} \mathrm{Ar}$ em horneblenda e biotita forneceram idades entre 1969Ma e 1972 Ma. Grãos de magnetita com textura de exsolução são considerados como os principais portadores magnéticos dos componentes A1 e A2.

Pólos SD1 e SD2 - Estes pólos foram determinados para doleritos do Rio Suriname no Escudo da Guiana (Veldkamp et al., 1971). Duas direções características muito estáveis, portadas por magnetita, foram isoladas para estas amostras, as quais originaram os pólos SD1 e SD2. Os autores atribuem idades entre 1,75 e 1,60 Ga para estes pólos com base em determinações K-Ar.

Pólos U1n, U1r e U2 - Estes três pólos foram determinados para a Formação Uairen do Grupo Roraima, situada no Escudo da Guiana Francesa (Castillo \& 
Costanzo-Alvarez, 1993). Os tratamentos de laboratório revelaram a presença de três componentes magnéticas: U1n, U1r e U2. As duas primeiras são portadas por grãos finos de magnetita e hematita, com altas coercividades e temperaturas de bloqueio. O Componente U2 é portado por grãos grosseiros de magnetita com baixas coercividades e baixas temperaturas de bloqueio. Os pólos paleomagnéticos não possuem idades definidas (1580-1960 Ma), entretanto, sugere-se que as magnetizações que os originaram possuem caráter primário.

Pólos TL e GB - Estes pólos paleomagnéticos preliminares foram obtidos para rochas ácidas da seqüência vulcânica Teles Pires (pólo TL) e para sedimentos do Grupo Beneficente (pólo GB), ambos na fronteira do Mato Grosso com o Pará (Pacca \& Cordani, 1979). As rochas ácidas vulcânicas revelaram idade Rb-Sr entre $1561 \pm 38$ Ma e os sedimentos idade de $1430 \pm 70$ Ma. Atualmente, Pinho et al. (2001) revelam que as rochas ácidas dessa formação são mais antigas (>1700 Ma).

Pólos IM1, IM2 e CC - Estes pólos foram determinados para o Complexo Imataca (pólo IM1 e IM2) de idade 2000-2050Ma (Rb-Sr), para as vulcânicas ácidas de Cichivero-Caicara (pólo CC) de idade 1960-1640 Ma (Rb-Sr) (Onstott \& Hargraves, 1981). Segundo os autores, todos os pólos possuem, provavelmente, magnetizações remanescentes primárias com exceção da encontrada para as ácidas de CichiveroCaicara que apresentam direções de magnetização não muito bem definidas, porém, a consistência nas direções de magnetização para sítios separados por mais de 400 km, sugerem uma relativa confiabilidade nesta magnetização. 